NATIONAL LABORATORY

MANAGED BY UT-BATTELLE

FOR THE DEPARTMENT OF ENERGY

\title{
Hydropower Baseline Cost Modeling
}

January 2015

Prepared by

Patrick W. O'Connor

Qin Fen (Katherine) Zhang

Scott T. DeNeale

Dol Raj Chalise

Emma Centurion

Approved for public release;

distribution is unlimited.

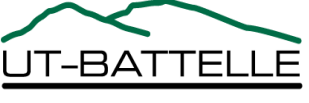




\title{
DOCUMENT AVAILABILITY
}

Reports produced after January 1, 1996, are generally available free via the U.S. Department of Energy (DOE) Information Bridge.

Web site http://www.osti.gov/bridge

Reports produced before January 1, 1996, may be purchased by members of the public from the following source.

\author{
National Technical Information Service \\ 5285 Port Royal Road \\ Springfield, VA 22161 \\ Telephone 703-605-6000 (1-800-553-6847) \\ TDD 703-487-4639 \\ Fax 703-605-6900 \\ E-mail info@ntis.gov \\ Web site http://www.ntis.gov/support/ordernowabout.htm
}

Reports are available to DOE employees, DOE contractors, Energy Technology Data Exchange (ETDE) representatives, and International Nuclear Information System (INIS) representatives from the following source.

Office of Scientific and Technical Information

P.O. Box 62

Oak Ridge, TN 37831

Telephone 865-576-8401

Fax 865-576-5728

E-mail reports@osti.gov

Web site http://www.osti.gov/contact.html

This report was prepared as an account of work sponsored by an
agency of the United States Government. Neither the United States
Government nor any agency thereof, nor any of their employees,
makes any warranty, express or implied, or assumes any legal
liability or responsibility for the accuracy, completeness, or
usefulness of any information, apparatus, product, or process
disclosed, or represents that its use would not infringe privately
owned rights. Reference herein to any specific commercial product,
process, or service by trade name, trademark, manufacturer, or
otherwise, does not necessarily constitute or imply its endorsement,
recommendation, or favoring by the United States Government or
any agency thereof. The views and opinions of authors expressed
herein do not necessarily state or reflect those of the United States
Government or any agency thereof.


ORNL/TM-

\title{
Hydropower Baseline Cost Modeling
}

Date Published: January 2015

\author{
Prepared by \\ OAK RIDGE NATIONAL LABORATORY \\ Oak Ridge, Tennessee 37831-6283 \\ managed by \\ UT-BATTELLE, LLC \\ for the \\ U.S. DEPARTMENT OF ENERGY \\ under contract DE-AC05-00OR22725
}


(THIS PAGE LEFT BLANK INTENTIONALLY) 


\section{Table of Contents}

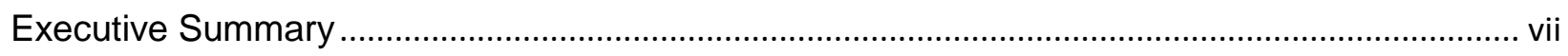

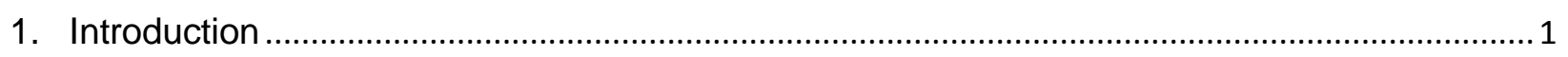

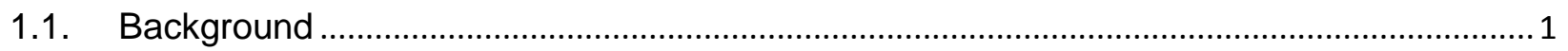

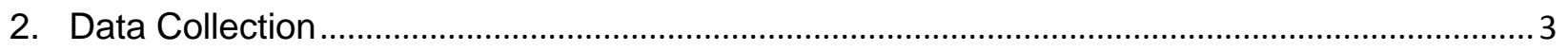

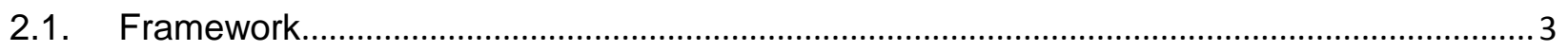

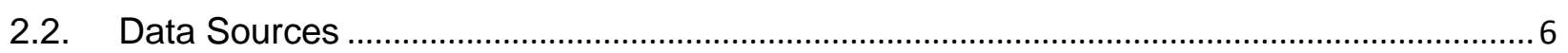

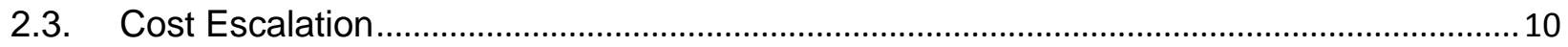

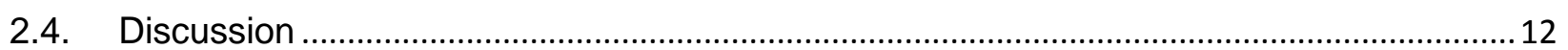

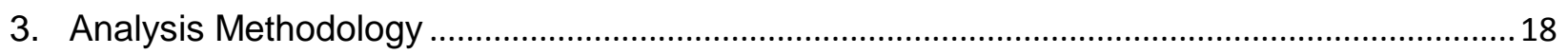

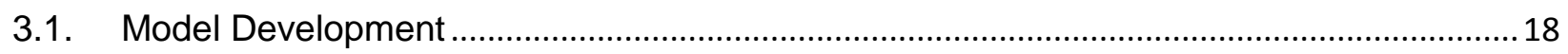

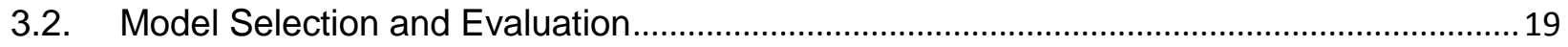

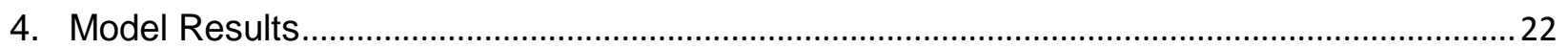

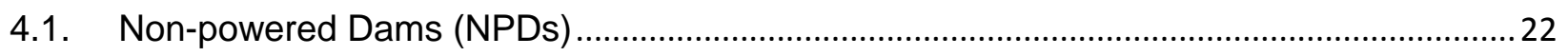

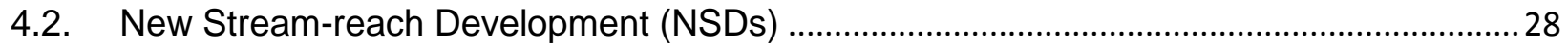

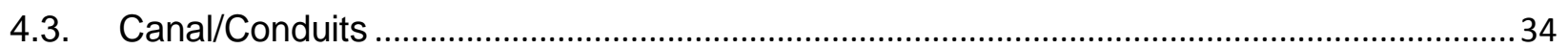

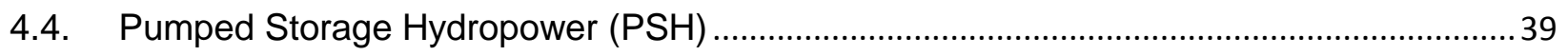

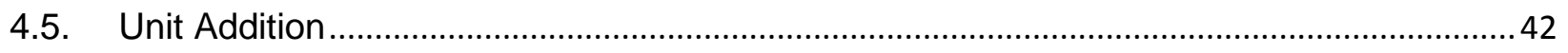

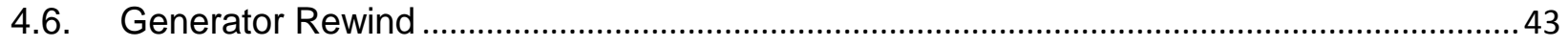

4.7. Results Summary, Discussion, and Application ............................................................... 44

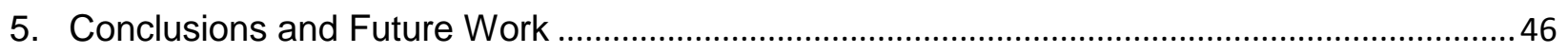

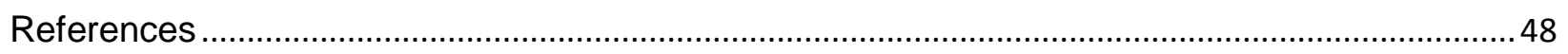

Appendix A - Alternative Models, Detailed Comparison, and Validation ................................... A-1 


\section{List of Figures}

Figure 1. Hydropower Cost Breakdown Structure 4

Figure 2. Project activity diagram for IIR database (Cotchen, 2014) ......................................... 6

Figure 3. Cost indexes comparison.......................................................................................... 12

Figure 4. Finalized BCM data project count by data source, project development stage, and

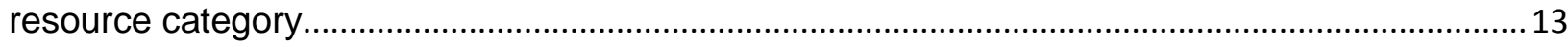

Figure 5 - Capital costs of recently developed hydropower facilities ........................................... 15

Figure 6 - Levelized Cost of Energy (LCOE) of recently developed new hydropower resources 16

Figure 7. NPD data distribution histograms .................................................................................24

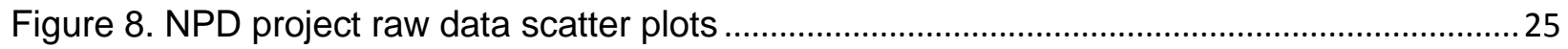

Figure 9. Comparison of ORNL and INL model-estimated costs with actual NPD costs ...27

Figure 10. Breakdown cost distribution for NPD projects (EC dataset) ....................................... 28

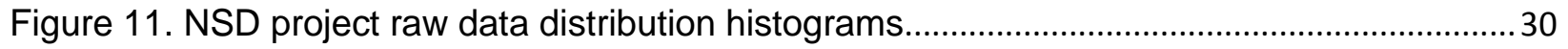

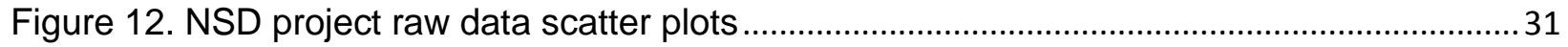

Figure 13. Comparison of ORNL and INL model-estimated costs with actual NSD costs ........... 33

Figure 14. Breakdown cost distribution for NSD projects (EC dataset) ........................................ 34

Figure 15. Canal/Conduit project raw data distribution histograms............................................... 36

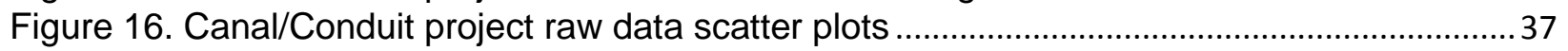

Figure 17. Breakdown cost distribution for Canal/Conduit projects (EC dataset) ........................ 38

Figure 18. PSH project raw data distribution histograms .......................................................... 40

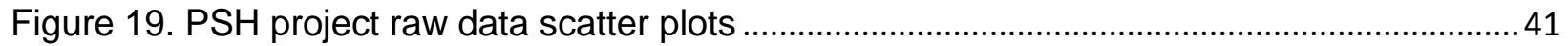

Figure 20. Breakdown cost distribution for PSH projects (PE dataset) ......................................... 42

Figure 21 - Application of NSD and NPD BCMs to U.S. undeveloped resources > 1 MW.......... 45

Figure 22. Raw data statistics ................................................................................................. A

Figure 23. Regional classification of the United States ........................................................... A-4

Figure 24. Regional distribution of Non Powered Dams (NPDs) cost data............................... A-7

Figure 25. NPD in-sample model validation.......................................................................... A-9

Figure 26. NPD breakdown cost distributions by Capacity range ........................................... A-10

Figure 27. NPD breakdown cost distributions by Head range ................................................ A-11

Figure 28. Regional distribution of New Stream-reach Development (NSDs) cost data .......... A-14

Figure 29. NSD in-sample model validation..................................................................... A-16

Figure 30. NSD breakdown cost distributions by Capacity range ......................................... A-17

Figure 31. NSD breakdown cost distributions by Head range ................................................. A-18

Figure 32. Regional distribution of Canal/Conduit cost data ................................................... A-20

Figure 33. Canal/Conduit in-sample model validation.......................................................... A-22

Figure 34. Canal/Conduit breakdown cost distributions by Capacity range ............................ A-23

Figure 35. Canal/Conduit breakdown cost distributions by Head range ................................. A-24

Figure 36. Regional distribution of PSH cost data .............................................................. A-26

Figure 37. PSH in-sample model validation ............................................................................. A-28

Figure 38. PSH breakdown cost distributions by Capacity range ............................................. A-29

Figure 39. PSH breakdown cost distributions by Head range .................................................. A-29

Figure 40. Regional distribution of Unit Addition cost data .................................................... A-31

Figure 41. Regional distribution of Generator Rewind cost data ............................................ A-32

Figure 42. Unit Addition and Generator Rewind in-sample model validation ........................... A-34

Figure 43. Unit Addition and Generator Rewind in-sample model validation ........................... A-34 


\section{List of Tables}

Table 1. Summary of projects collected from FERC .....................................................................

Table 2. Summary of projects collected from the DOE-EPRI small-hydropower development

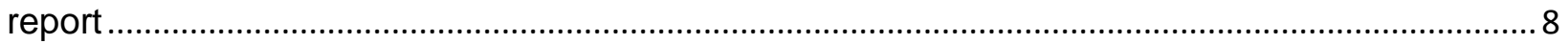

Table 3. Summary of projects collected from the IIR database .....................................................

Table 4. Summary of Other data sources .................................................................................10

Table 5. Summary of projects collected from Other sources .........................................................10

Table 6 - Summary of projects with actual costs (C-stage) …………………………...................13

Table 7. Comparison between planning, engineering, and construction stage cost for DOE-EPRI

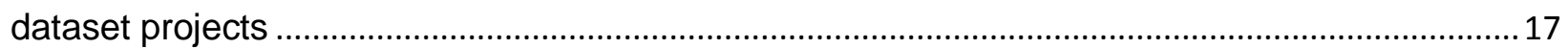

Table 8. Comparison between actual project cost, engineering stage, and feasibility stage cost

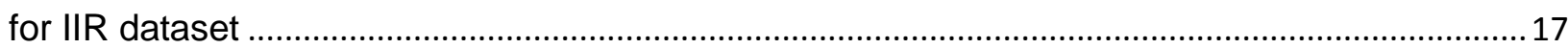

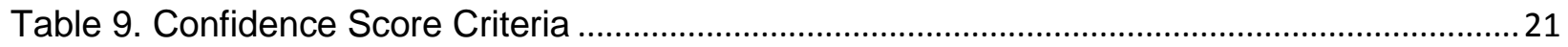

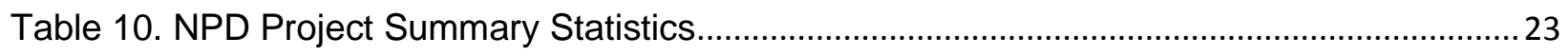

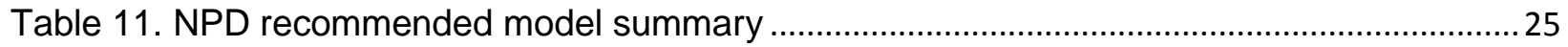

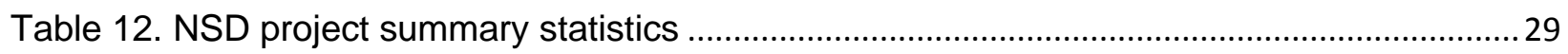

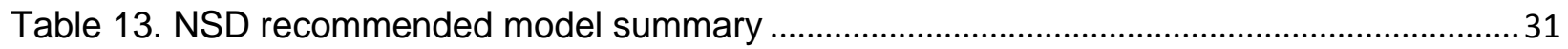

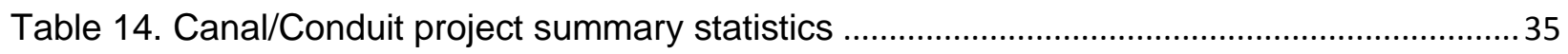

Table 15. Canal/Conduit recommended model summary ..............................................................3

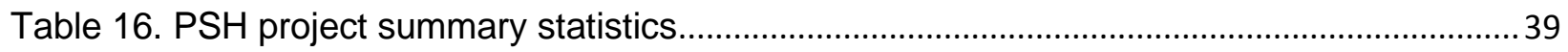

Table 17. PSH recommended model summary …………............................................................... 41

Table 18. Unit Addition recommended model summary .................................................................. 43

Table 19. Generator Rewind recommended model summary .........................................................4

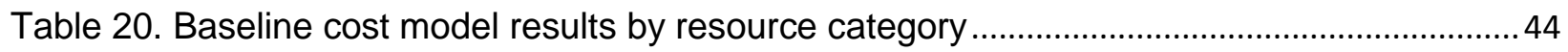

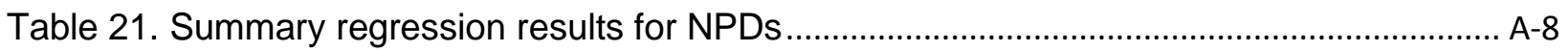

Table 22. Summary regression results for NSDs ............................................................... A-15

Table 23. Summary regression results for Canal/Conduit ..................................................... A-21

Table 24. Summary regression results for PSH ................................................................. A-27

Table 25. Summary regression results for Unit Addition and Generator Rewind ..................... A-33 


\section{Executive Summary}

Recent resource assessments conducted by the United States Department of Energy have identified significant opportunities for expanding hydropower generation through the addition of power to non-powered dams and on undeveloped stream-reaches. Additional interest exists in the powering of existing water resource infrastructure such as conduits and canals, upgrading and expanding existing hydropower facilities, and the construction new pumped storage hydropower. Understanding the potential future role of these hydropower resources in the nation's energy system requires an assessment of the environmental and techno-economic issues associated with expanding hydropower generation. To facilitate these assessments, this report seeks to fill the current gaps in publically available hydropower cost-estimating tools that can support the national-scale evaluation of hydropower resources.

The report presents the background, framework, methodology, and results of the collection of contemporary cost data and the development of a series of parametric models to predict the initial capital cost (ICC) of hydropower projects. Recent cost data helps provide the economic context for recent hydropower development; the parametric "baseline cost models" are used to generate cost estimates for hydropower projects in various resource categories and are intended to produce generalized, representative estimates suitable for the national or regionalscale evaluation of hydropower economic competitiveness. More sophisticated, bottom-up (as opposed to top-down, parametric) techniques are necessary for the development of individual site costs; however, the parametric approaches described in the report are a necessary simplification to systematically evaluate hydropower potential across the U.S.

Nearly 600 unique cost estimates were gathered from 16 different sources, including reports, market intelligence databases, and private communications with owners, developers and consultants. The scope and extent of each cost estimate varied with many projects lacking data for the costs and risks associated with the licensing, permitting, and development of hydropower projects. Future iterations of this report will tackle the contemporary costs of the licensing and project development processes, but in this initial iteration, references to historical estimates of the cost of licensing hydropower projects are provided within the report.

Based on the United States-only subset of the collected data, the cost of constructing a hydropower plant on existing conduits, on non-powered dams, or along new, undeveloped stream reaches has ranged from $\$ 1000$ to $\$ 9000$ per kilowatt, with the average canal project averaging $\$ 4100$ per kilowatt, the average non-powered dam project costing approximately $\$ 3800$ per kilowatt and development along new stream reaches costing approximately $\$ 4900$ per kilowatt. In all three cases costs were most noticeably driven by economies of scale (i.e. lower costs) from higher hydraulic head, while only canal projects exhibited meaningful economies of scale from higher installed capacity. Across the timespan of the collected data (roughly 1980 to present), construction costs for hydropower plants have not grown on a real, inflation adjusted basis. On a lifecycle basis, for those plants for which generation estimates were available, the unsubsidized levelized cost of energy (LCOE) of constructing recent hydropower plants has ranged from $\$ 30$ to $\$ 180$ per megawatt-hour, with the median project 
costing approximately $\$ 110$ per megawatt-hour (excluding licensing) for powering conduits, nonpowered dams, and new stream reaches.

In addition to the construction of power generating facilities on previously unpowered infrastructure or stream reaches, costs estimates were also collected for the installation of additional units in existing powerhouses and the rewinding of existing generators; the average addition of a new unit to an existing powerhouse has cost $\$ 1930$ per kilowatt, and the average generator rewind has cost $\$ 114$ per kilowatt, but both are subject to strong economies of scale based on the size of the units involved.

Statistical analysis of this cost data has produced a series of cost models that can be used to estimate the cost of constructing a hydropower plant at a reconnaissance level based on key design parameters of capacity $(P)$ and hydraulic head $(H)$. The results of this analysis-the models recommended for use in the evaluation of national-scale hydropower economics-are presented in the table below.

\begin{tabular}{|l|l|}
\hline \multicolumn{1}{|c|}{ Resource Category } & \multicolumn{1}{c|}{$\begin{array}{c}\text { Cost Model Equation } \\
(I C C \text { in } 2012 \$ ; P \text { in MW; } H \text { in } \mathrm{ft})\end{array}$} \\
\hline Non-powered Dams & $I C C=12,038,038 P^{0.980} H^{-0.265}$ \\
\hline New Site Development projects & $I C C=8,717,830 P^{0.975} H^{-0.120}$ \\
\hline Canal/Conduit projects & $I C C=11,277,566 P^{0.819} H^{-0.177}$ \\
\hline Pumped Storage Hydropower projects & $I C C=2,442,817 P^{0.959}$ \\
\hline Unit Addition projects & $I C C=3,030,671 P^{0.811}$ \\
\hline Generator Rewind projects & $I C C=299,461 P^{0.753}$ \\
\hline
\end{tabular}

These modeled costs represent averaged capital costs to construct/modify generating facilities, impoundment structures, and supporting water conveyance infrastructure, and do not necessarily include the additional costs of licensing or environmental mitigation. Substantial discussion is devoted to the classification and evaluation of data quality to provide the reader with a transparent evaluation of the strengths, limitations, and appropriate uses for each of the models. The data quality framework discussed in this document will be used for the continual collection of data and reevaluation of the models, ultimately producing future iterations of the report to document data and methodological improvements, as well as the modeling of additional cost centers, such as operations and maintenance. 


\section{Introduction}

\subsection{Background}

Recently, the United States (U.S.) Department of Energy (DOE) completed major assessments to identify hydropower resource development potential nationwide. In 2012, researchers from Idaho National Laboratory (INL) and Oak Ridge National Laboratory (ORNL) completed the Non-Powered Dam (NPD) Resource Assessment (Hadjerioua et al., 2012) which indicated the potential to expand hydropower by up to $12.1 \mathrm{GW}$ at NPDs across the U.S. In a similar fashion, in 2014, researchers at ORNL completed the New Stream-reach Development (NSD) Resource Assessment (Kao et al., 2014) and identified over $65 \mathrm{GW}$ of additional undeveloped hydropower potential. Compared with the current U.S. hydropower fleet totaling approximately $80 \mathrm{GW}$, these reports demonstrate significant expansion potential exists. Additionally, substantial interest also exists in the powering of other existing water resource infrastructure such as canals and conduits, and the use of Pumped Storage Hydropower to balance an increasingly renewable grid. While the resource potential for new hydropower is clear, improved costing tools are necessary to evaluate the economic feasibility of these resources.

Comprehensive engineering design and cost evaluations would provide the most accurate sitespecific cost estimates, however data limitations and the breadth of hydropower sites across the U.S. makes the systematic use of such costing methods infeasible for evaluating national-scale economic competitiveness and resource potential. Statistical and parametric cost estimation provides a simpler alternative method for evaluating the cost dynamics of hydropower resources at a national scale. While previous studies have been conducted to evaluate U.S. hydropower development costing, the existing models suffer from several issues including that:

- the most recent DOE-sponsored comprehensive cost study was conducted over 10 years ago (INL, 2003);

- many existing cost models are largely outdated or bas on non-U.S. data;

- key resource classes, particularly NPDs and canal/conduit projects are not explicitly modeled; and

- the existing models may lack appropriate detail to accurately cost the generally smaller, lower head resources identified in recent resource assessments (Zhang et al., 2012).

To address these existing gaps in the publically available literature on hydropower costing, better assess the viability of developing these significant untapped resources, and help identify key areas for research, development, and deployment (RD\&D), ORNL has developed a series of Baseline Cost Models (BCMs) and associated tools for estimating the initial capital cost (ICC) of developing hydropower in the U.S. based on historical project data. 
The primary objective is to develop tools which generate cost estimates that accurately reflect the economics of hydropower at a national scale. Examples of targeted end-uses include transparent comparisons of the cost and performance of electricity generating technologies (OpenEI, 2014 and EIA, 2013), long-term forecasting such as annual projections by the U.S. Energy Information Administration (EIA, 2014b), and strategic planning and technology potential evaluations by the U.S. Department of Energy (DOE), such as the recent Sunshot Vision (DOE, 2012) and Renewable Electricity Futures (NREL, 2012) studies.

Aside from DOE, the cost estimating tools can provide value to multiple other users such as utilities conducting resource planning studies that would benefit from contemporary hydropower cost estimates. While new costing tools may also be useful for high-level cost estimation for screening-level assessments, it is important to note that the site-specificity inherent in hydropower development limits the applicability for individual project feasibility.

To support these objects, this report documents the processes involved in collecting, processing, and analyzing the raw data to produce hydropower cost estimation models for six specific categories of hydropower projects. The first four categories are the addition of new hydropower resources where no powerhouse currently exists, including:

1. Non-powered Dams (NPD) - Encompassing the construction of a new powerhouse at existing dams or other facilities. This category of model may also be useful for estimating the costs of adding a powerhouse to an existing powered dam.

2. New Stream-reach Development (NSD) projects - Greenfield projects with no existing facilities.

3. Canal/Conduit projects - Involves power development at existing Canals or Conduits.

4. Pumped Storage Hydropower (PSH) projects -Connects an upper and lower reservoir via a pump-turbine arrangement to provide energy generation as well as pumping power for maintaining storage availability.

The last two cost estimating tools are derived to project the cost of modifying existing powerhouses-they cover only two specific types of modification:

5. Unit Addition projects - Involves existing plant renovation or expansion. The project should clearly involve a change in installed capacity. This type of project may include acquisition and installation of a new turbine-generator unit but excludes construction of a new powerhouse.

6. Generator Rewind projects - Generator refurbishment to improve efficiency and extend unit service life.

There are many other categories of improvement projects for the existing hydropower fleet, however, data limitations prevented the development of reliable models for this iteration of the BCM report.

To quantify the contemporary cost of developing resources and document model development, the data collection framework and sources used in this report are introduced and discussed in 
Section 2, while Section 3 details the generalized model development and evaluation framework. Section 4 presents the recommended BCM for each resource class, with additional validation and model alternatives are provided in Appendix $A$. The recommended models for NPD and NSD are also applied to recent DOE resource assessments to illustrate the national scale distribution of hydropower costs.

Ultimately, this report is intended to serve as a living document incrementally updated as continued DOE efforts to capture additional cost data and develop improved modeling techniques result in increasingly useful costing tools for the research community and hydropower industry.

\section{Data Collection}

\subsection{Framework}

The acquisition and validation of quality cost data is the foundation of any modeling exercise. In the development of the BCM, significant attention was paid to two key determinants of data quality: the scope of the cost estimate and the certainty of the estimate with respect to what would be expected from a finalized, constructed project.

\section{Cost Scope}

The cost of hydropower development can be broken down into variety of distinct components ranging from the substantial effort required to permit and design the plant, to the extensive construction and civil works and the acquisition and installation of generating equipment. Accurate comparisons and analyses of cost must necessarily draw clear distinctions on the scope of which the utilized cost estimates include and exclude.

To facilitate the systematic application of clear boundaries on collected cost data, a Cost Breakdown Structure (CBS) was developed that partitions the components of hydropower capital costs into a clear hierarchy. At the highest level (1) of this hierarchy is the Initial Capital Cost (ICC) representing the full capital outlay necessary for a hydropower plant to reach commercial operation. ICC is further divided into three subcomponents at level 2: The Generating Plant (all physical components directly necessary for power generation), Balance of Station (all development expenditures and additional costs, such as those required to meet environmental and regulatory requirements, or the construction of substations and transmission lines), and Financial Costs (the highly variable costs of obtaining and repaying the capital used in developing and constructing a hydropower project). The CBS is graphically depicted at level 3 in Figure 1. 


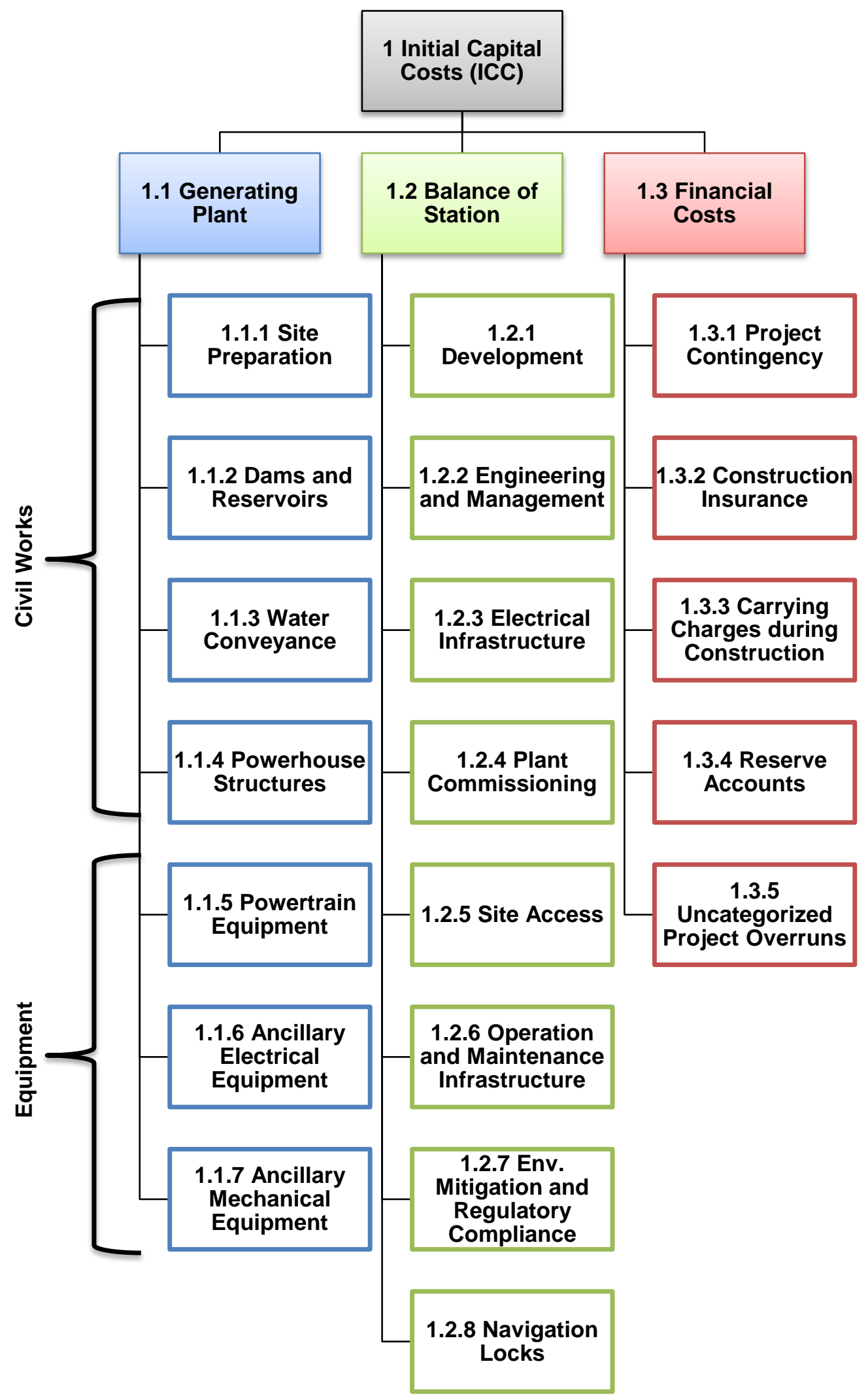

Figure 1. Hydropower Cost Breakdown Structure 
Figure 1 draws an additional distinction within the Generating Plant components between (a) site preparation and construction intensive structures ("Civil Works") and (b) the equipment portion of plant expenditures ("Electro-Mechanical Equipment" or "Equipment") as the sourcing and composition of these costs are distinct from one another. Generating plant breakdown costs are presented in these categories in Section 4 and Appendix A of the document to efficiently visualize cost distribution without overwhelming detail.

\section{Cost Certainty}

Understanding the source, rigor, and detail of an estimate can give a perspective on its certainty or accuracy. As an example. major cost engineering professional associations categorize project costs into distinct estimate stages based on project maturity and estimate end use (see AACE, 2013), assigning quantitative cost uncertainty to each stage. Ideally a similar quantitative system could be applied to the BCM to provide a mechanism for assessing the certainty and accuracy of collected data. However, in the development of the BCM, data has been collected from a variety of different sources (described in detail in Section 2.2), and access to the project development information necessary to place the project directly onto such a scale was typically unavailable. While this prevented the direct application of quantitative certainty to the data, it was still determined that capturing data on the stage of project development could provide useful modeling distinctions. To capture project development in a limited information environment, a simplified categorization system was adapted from an existing system in use by one of the BCM's primary data sources, Industrial Information Resources (IIR). IIR is introduced in more detail in Section 2.2, but its categorization system is described here to provide context for its use throughout the report.

IIR uses alphanumeric categories in the broad groups of Planning (P), Engineering $(E)$, and Construction (C). The definition of each stage within this "PEC" system is shown in Figure 2 (Cotchen, 2014). As shown in the IIR project activity diagram, P1 is a preliminary project activity and an initial step in the planning stage before starting a project. P1 includes site selection as well as preliminary design and economic analysis. P2 is the final step in the planning stage and mainly focuses on licensing activity for the project. After obtaining the project license, E1 represents an initial step in the engineering stage associated with the capital approval process. E2 is the final step in the engineering stage and typically includes detailed engineering design and cost estimation, planning, scheduling, and site preparation. $\mathrm{C} 1$ is the first step in the construction stage and includes all site construction activities until final commissioning of a project. C2 is the final step in the project activity chart and represents project completion with associated post-construction maintenance activities. Although hydropower costs are highly sitespecific with many factors contributing to cost uncertainty, cost accuracy is generally assumed to increase as project development nears completion. As such, construction stage cost estimates are necessarily considered the most accurate (and are quantitatively defined as such by AACE). 


\section{PICTRAX - PROJECT ACTIVITY FLOW CHART}

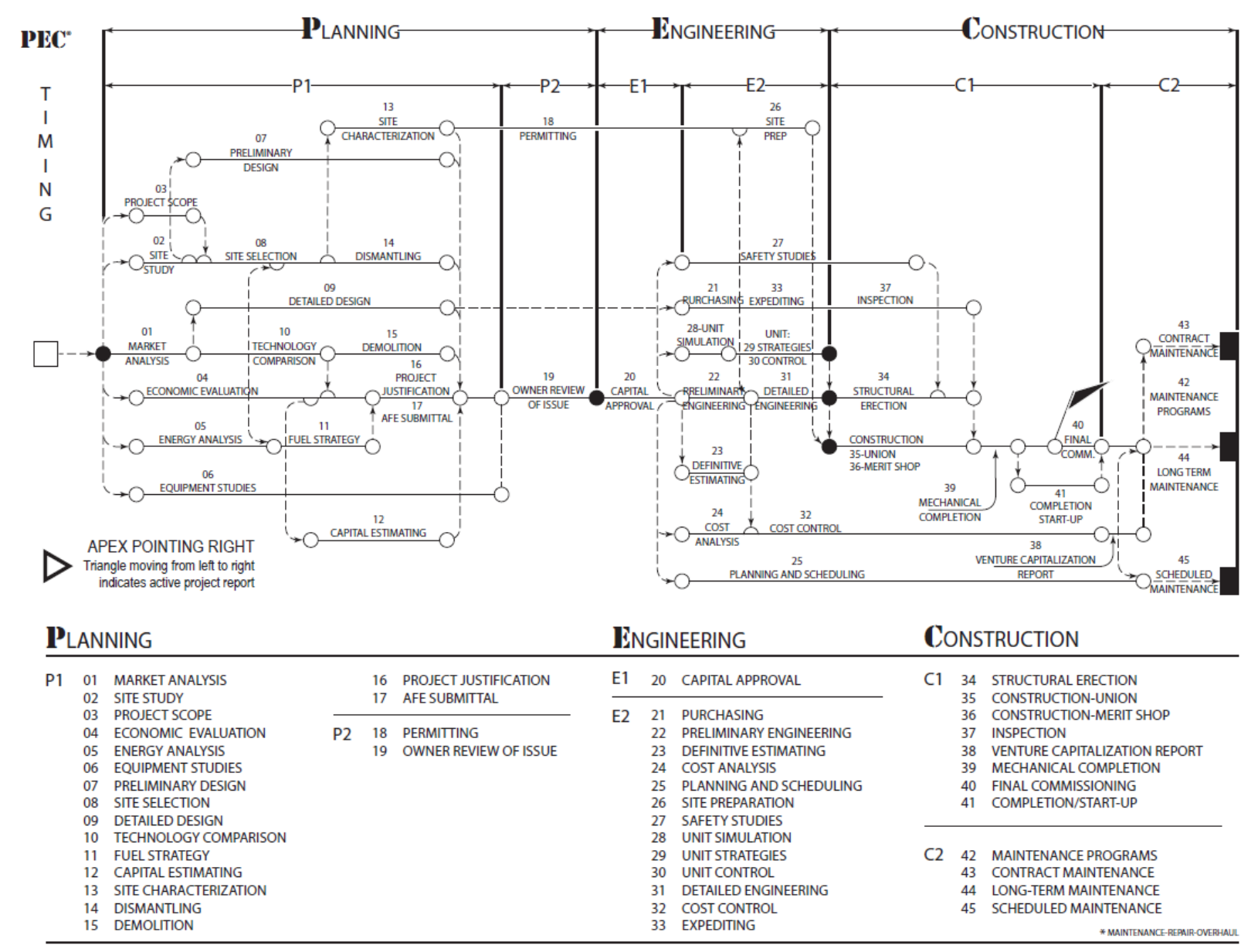

Figure 2. Project activity diagram for IIR database (Cotchen, 2014)

For Version 1 of the BCM, given data uncertainties, a simplified version of this categorization system has been used with projects identified solely as being in the $P$, E, and $C$ generic stages. Follow-on data collection efforts may add additional granularity that allows for the use of a more detailed categorization system.

\subsection{Data Sources}

Initial BCM efforts have focused primarily on the collection of data from publically and commercially available sources_-particularly those with substantial sample populations. Among the many data sources pursued, the most significant contributions came from license applications filed with the Federal Energy Regulatory Commission's (FERC) (FERC, 2014), IIR's PECWeb database (IIR, 2014), and a series of reports retrospectively detailing the activities of the Department of Energy's (DOE) small hydropower development efforts in the late 1970s and early 1980s (DOE and EPRI, 1985a, 1985b, 1986, 1987). Additional data sources include industry contacts and reports from various hydropower stakeholders. As the other data sources are numerous and represent small segments of the overall data collection inventory they are 
introduced briefly at the end of this section while more detailed description is provided for the FERC, IIR, and DOE sources.

\section{Federal Energy Regulatory Commission (FERC) Application Documents}

FERC issues preliminary permits, licenses, and relicenses (or in some cases grants exemptions) for the vast majority of non-federal hydropower projects. In applications for original or new licenses, most major projects above $5 \mathrm{MW}$ are required to submit actual or approximate original cost ${ }^{1}$. Major water projects whose installed capacity is less than $5 \mathrm{MW}$ and minor water projects of less than $1.5 \mathrm{MW}$ must include the estimated cost of the project and of each proposed environmental mitigation measure ${ }^{2}$. Some of the license application files containing cost information are not publicly available, and many of the licenses submitted before 2007 cannot be accessed. Preliminary permits typically do not include useful cost information, but may at times provide cost estimates for the studies to be performed before applying for a full license.

The license, preliminary permit, and exemption application documents are available through FERC's eLibrary regulatory document database. ${ }^{3}$ Documents submitted for preliminary permits, and to a lesser extent full license applications, are based on early cost estimates, and the corresponding cost accuracy will typically be low. So, in order to classify these FERC projects on the simplified PEC scale, those license applications with breakdown (component) cost estimates were classified as engineering (E) stage, while permit applications and license applications lacking component-level detail were classified as planning stage projects $(P)$. The total number of projects collected from FERC are shown in Table 1 based on hydro resource category and project development stage.

Table 1. Summary of projects collected from FERC

\begin{tabular}{|c|c|c|c|c|c|c|c|c|c|c|c|}
\hline \multirow{2}{*}{$\begin{array}{l}\text { Resource } \\
\text { Category }\end{array}$} & \multirow{2}{*}{$\begin{array}{c}\text { Project } \\
\text { Count }\end{array}$} & \multicolumn{3}{|c|}{$\begin{array}{l}\text { Development } \\
\text { Stage (count) }\end{array}$} & \multicolumn{3}{|c|}{ Capacity (MW) } & \multicolumn{3}{|c|}{ Head (ft) } & \multirow{2}{*}{$\begin{array}{c}\text { No. of } \\
\text { Projects } \\
\text { with } \\
\text { Breakdowr } \\
\text { Cost }\end{array}$} \\
\hline & & $\mathbf{P}$ & $\mathbf{E}$ & C & Min & Avg & Max & Min & Avg & Max & \\
\hline NSD & 8 & 2 & 6 & 0 & 0.4 & 51.71 & 121.5 & 57 & 376 & 966 & 6 \\
\hline NPD & 26 & 5 & 21 & 0 & 0.205 & 12.84 & 48 & 13 & 98 & 700 & 21 \\
\hline Canal & 9 & 4 & 5 & 0 & 0.225 & 1.72 & 6.15 & 34 & 211 & 445 & 5 \\
\hline PSH & 7 & 0 & 7 & 0 & 280 & 868.6 & 1,300 & 720 & 1,324 & 1,866 & 3 \\
\hline
\end{tabular}

\section{DOE National Small Hydropower Program}

In 1977, the DOE launched the National Small-Hydropower Program to promote the development of smaller, lower-impact hydropower. As a part of this program, DOE sponsored a number of small hydro projects at feasibility study, licensing, or construction stages, later joining with the Electric Power Research Institute (EPRI) to collect, organize, analyze, and summarize the results. During 1985-1987, the DOE and EPRI jointly published and made publicly available

\footnotetext{
${ }^{1}$ This information is found in a License application's "Exhibit D" and/or "Exhibit A"

2 This information is found in a License application's "Exhibit $A$ "

${ }^{3}$ To access the FERC e-Library, visit http://www.ferc.gov/docs-filing/elibrary.asp.
} 
"Small-Hydropower Development: The Process, Pitfalls, and Experience," a four-volume report documenting the scope and results of the collaboration with the goal of benefitting future hydropower development initiatives (DOE and EPRI, 1985a, 1985b, 1986, 1987).

Volume 1 of the DOE-EPRI report presents 240 feasibility studies and summarizes individual project information such as location, ownership, and hydrological and hydraulic features, as well as details related to the generating equipment, transmission, capital cost, and environmental and economic analyses performed (DOE and EPRI, 1985a). Volume 2 describes 41 projects which entered the licensing process and provides additional information related to licensing activities and enhanced project scope (DOE and EPRI, 1985b). The third Volume provides details on 23 projects, 17 which had completed construction and 6 which were under construction; this volume also includes detailed project design parameters, drawings, and descriptions, as well as comparisons between actual and feasibility study cost estimates (DOE and EPRI, 1987). Volume 4 provides a guide for developers (DOE and EPRI, 1986) and was not used for data collection purposes.

All project data available in Volumes 1 through 3 of the DOE-EPRI report were collected for ORNL BCM development purposes. As only preliminary feasibility was conducted as a part of Volume 1, those projects were classified as planning stage $(P)$. Though still in the licensing phase, projects from Volume 2 contained enhanced engineering design and detail and were classified as engineering (E) stage projects. Finally, since Volume 3 included actual or nearcompletion project costs, those projects were classified as construction stage $(\mathrm{C})$. The total number of projects based on hydro resource type and project development stage from the DOEEPRI report, along with project capacity and head statistics, are shown in Table 2.

Table 2. Summary of projects collected from the DOE-EPRI small-hydropower development report

\begin{tabular}{|c|c|c|c|c|c|c|c|c|c|c|c|}
\hline \multirow{2}{*}{$\begin{array}{l}\text { Resource } \\
\text { Category }\end{array}$} & \multirow{2}{*}{$\begin{array}{l}\text { Project } \\
\text { Count }\end{array}$} & \multicolumn{3}{|c|}{$\begin{array}{l}\text { Development } \\
\text { Stage (count) }\end{array}$} & \multicolumn{3}{|c|}{ Capacity (MW) } & \multicolumn{3}{|c|}{ Head (ft) } & \multirow{2}{*}{$\begin{array}{c}\text { No. of } \\
\text { Projects with } \\
\text { Breakdown } \\
\text { Cost }\end{array}$} \\
\hline & & $\mathbf{P}$ & $\mathbf{E}$ & C & Min & Avg & Max & Min & Avg & Max & \\
\hline NSD & 18 & 15 & 2 & 1 & 0.163 & 4.25 & 24 & 10 & 68 & 313 & 18 \\
\hline NPD & 147 & 118 & 21 & 8 & 0.07 & 4.52 & 40 & 8 & 77 & 1,040 & 147 \\
\hline Canal & 36 & 31 & 1 & 4 & 0.1 & 2.38 & 15 & 21 & 177 & 904 & 36 \\
\hline PSH & 1 & 1 & 0 & 0 & 0.76 & 0.76 & 0.76 & 563 & 563 & 563 & 1 \\
\hline
\end{tabular}

\section{Industrial Information Resources (IIR)}

Industrial Info Resources (IIR) is a market intelligence firm that tracks investments in various types of industrial and power projects, including information on historical, cancelled, on hold, and active hydropower projects in the U.S. These projects can range from the rehabilitation of an existing hydropower turbine to the construction of an entirely new hydroelectric facility. ORNL has collected this data under a commercial subscription with IIR .

A total of 1,277 U.S. hydropower projects were acquired from IIR including information on installed/planned capacity, initial capital cost (ICC), location, project development stage, project status, and project scope. The IIR projects contain different hydropower technologies, including 
hydrokinetic, tidal, and others. For categorization purposes, the IIR projects were first manually classified as either Hydropower (1029 projects), Pumped Storage (146 projects), or other technologies (Hydrokinetic, Tidal, and Hydrogen Plant - 102 projects) using individual project descriptions or supplemental information. The hydropower projects were then classified based on resource category (NSD, NPD, PSH, Canal/Conduit). In addition to the new development resource classes, additional project types were identified, which include unit additions at existing plants and a variety of activities related to upgrading facilities and components (i.e., modernization, upgrade, refurbishment, rebuild, rehabilitation, replacement, rewind). Within the IIR database, Unit Addition projects have a consistent scope with the original plant capacity and incremental unit capacity clearly identified. Similarly, the IIR Generator Rewind projects have similar scope throughout. However, the other project types (i.e. modernization, upgrade, refurbishment, rebuild, rehabilitation, replacement) contain inconsistent project scope which makes cost delineation difficult. As an example, the upgrade projects in the database contain a wide variety of upgrade activity related to electromechanical equipment and civil works. As a result, combining such diversified projects into a single category would lead to uncertain model results. Therefore, the final BCM models were developed for NSD, NPD, Canal/Conduit, PSH, Unit Addition, and Generator Rewind projects, while data available for the other categories were not used.

As the BCM utilizes a simplified version of the IIR PEC categorization system, project stage designations were used as-is from the IIR database.

The total number of projects based on hydro resource type and project development stage from the IIR database, along with project capacity and head statistics, are shown in Table 3. As listed in the table, 272 total projects are included in the finalized database after all duplicate and incomplete data were excluded.

Table 3. Summary of projects collected from the IIR database

\begin{tabular}{|c|c|c|c|c|c|c|c|c|c|c|c|}
\hline \multirow{2}{*}{$\begin{array}{l}\text { Resource } \\
\text { Category }\end{array}$} & \multirow{2}{*}{$\begin{array}{c}\text { Project } \\
\text { Count }\end{array}$} & \multicolumn{3}{|c|}{$\begin{array}{l}\text { Development } \\
\text { Stage (count) }\end{array}$} & \multicolumn{3}{|c|}{ Capacity (MW) } & \multicolumn{3}{|c|}{ Head (ft) } & \multirow{2}{*}{$\begin{array}{l}\text { No. of } \\
\text { Projects } \\
\text { with } \\
\text { Breakdown } \\
\text { Cost }\end{array}$} \\
\hline & & $\mathbf{P}$ & E & C & Min & Avg & Max & Min & Avg & Max & \\
\hline NSD & 36 & 32 & 1 & 3 & 3 & 45.88 & 600 & 21 & 792 & 3,050 & 5 \\
\hline NPD & 125 & 103 & 5 & 17 & 1.5 & 20.42 & 120 & 7 & 80 & 1,800 & 20 \\
\hline Canal & 4 & 3 & 0 & 1 & 1 & 5.65 & 13 & 146 & 689 & 1,971 & 1 \\
\hline PSH & 73 & 73 & 0 & 0 & 85 & 740.1 & 2,000 & 180 & 1,313 & 2,860 & 1 \\
\hline $\begin{array}{c}\text { Unit } \\
\text { Addition }\end{array}$ & 13 & 9 & 0 & 4 & 1.4 & 12.15 & 64 & & & & 0 \\
\hline $\begin{array}{l}\text { Generator } \\
\text { Rewind }\end{array}$ & 21 & 12 & 2 & 7 & 12 & 120 & 693 & & & & 0 \\
\hline
\end{tabular}

The IIR database does not provide breakdown cost or hydraulic head information as a part of the project summary. Attempts were made to obtain project hydraulic head data, when available, from ORNL's National Hydropower Asset Assessment Program (NHAAP, 2014), FERC application documents, and if necessary, reliable online resources. 


\section{Other Data Sources}

In addition to FERC, IIR, and the EPRI-DOE report, data were collected from a wide variety of other sources. These sources include individual project reports, feasibility study reports, conference presentations, and personal communication, among others as shown in Table 4.

Table 4. Summary of Other data sources

\begin{tabular}{|l|c|l|}
\hline \multicolumn{1}{|c|}{ Data Source } & Count & \multicolumn{1}{c|}{ Description } \\
\hline DOE (2014) & 2 & DOE ARRA grant recipients presentation \\
\hline ETO (2010) & 26 & Feasibility study report \\
\hline TVA (1941) & 1 & Constructed project report \\
\hline City of Boulder (2013) & 7 & Constructed projects report \\
\hline COID (2011) & 5 & Feasibility study report \\
\hline NUID (2009) & 4 & Feasibility study report \\
\hline USACE and MWH (2009) & 2 & Report \\
\hline USBR (1988) & 1 & Report \\
\hline Butterfield (2011) & 1 & Presentation \\
\hline Anonymous Consultants (A,B,C,D) & 27 & Written communication \\
\hline
\end{tabular}

The development stage for each project was assigned to ensure sources with less confidence were included as planning stage, while more detailed sources were classified as engineering stage. Projects identified as complete or under construction were included in the construction stage dataset. As many of these additional sources were used to complete the BCM database and they provided fewer projects individually, detailed description of each source is not effective. Table 5 provides summary statistics of projects collected from other data sources.

Table 5. Summary of projects collected from Other sources

\begin{tabular}{|c|c|c|c|c|c|c|c|c|c|c|c|}
\hline \multirow{2}{*}{$\begin{array}{l}\text { Resource } \\
\text { Category }\end{array}$} & \multirow{2}{*}{$\begin{array}{c}\text { Project } \\
\text { Count }\end{array}$} & \multicolumn{3}{|c|}{$\begin{array}{l}\text { Development } \\
\text { Stage (count) }\end{array}$} & \multicolumn{3}{|c|}{ Capacity (MW) } & \multicolumn{3}{|c|}{ Head (ft) } & \multirow{2}{*}{$\begin{array}{l}\text { No. of } \\
\text { Projects } \\
\text { with } \\
\text { Breakdown } \\
\text { Cost }\end{array}$} \\
\hline & & $\mathbf{P}$ & E & C & Min & Avg & Max & Min & Avg & Max & \\
\hline NSD & 22 & 0 & 9 & 13 & 0.5 & 67.33 & 824 & 10 & 523 & 1,896 & 4 \\
\hline NPD & 8 & 0 & 5 & 3 & 0.034 & 11.36 & 50 & 10 & 93 & 263 & 4 \\
\hline Canal & 43 & 0 & 36 & 7 & 0.041 & 0.998 & 7.15 & 5 & 213 & 1,554 & 35 \\
\hline PSH & 3 & 0 & 3 & 0 & 760 & 1,108 & 1,500 & 613 & 894 & 1,200 & 0 \\
\hline
\end{tabular}

\subsection{Cost Escalation}

The wide array of project cost data collected to develop these models spans from the latter part of the $20^{\text {th }}$ century to projects currently in the development process. Escalation of these estimates to a common, current cost is essential for developing updated cost equations. Cost indices are often used to convert a known historic cost into a current cost estimate.

Below is a list of commonly used cost indices for escalating costs related to construction activities, including hydropower: 
1. U.S. Bureau of Reclamation (USBR) Construction Cost Trends (CCT) (USBR, 2013)

2. U.S. Army Corps of Engineers (USACE) Civil Works Construction Cost Index System (CWCCIS) (USACE, 2013a)

3. Engineering News-Record (ENR) Construction Cost Indices (ENR, 2013)

4. RS Means Historical Cost Indices (RSMeans, 2013)

The USBR CCT reflects cost changes for construction activities relevant to the organization, which primarily include hydroelectric projects. The original indices were derived from the costs of plants constructed by the USBR. Since the mid-1980's, the USBR has engaged in fewer construction projects and no large hydropower projects. Accordingly, the CCT has since been based on data from the Producer Price Indices (PPI) (BLS, 2014), Price Trends for Federal-Aid Highway Construction (FHWA, 2014), and ENR, using actual field data to confirm its results when possible. The CCT consists of 35 construction index categories, a composite index, and land indices, all compiled quarterly. The construction index categories cover a variety of essential hydropower infrastructure components, including dams, pumping plants, power plants, pipelines, canals, tunnels, laterals and drains, switchyards and substations, transmission lines, roads, bridges, and property.

The USACE CWCCIS includes indices designed specifically for civil works construction. The CWCCIS provides 19 construction index categories and a composite index and uses several sources for index development. Quarterly indices have been compiled since 1980, while fiscal year (FY) values are available since 1968. The construction index categories include several hydropower-specific features, including reservoirs, dams, power plants, pumping plants, channels and canals, and floodway control and diversion structures.

ENR Construction Cost Indexes $(\mathrm{CCl})$ is one of the more frequently used (and oldest still in use) cost indices in the construction industry, (Remer et al., 2008). The CCl uses common labor and materials prices based on the 20 -city average rates and has not changed its calculation basis since its start in 1908.

RS Means Historical Cost Indexes also allows construction costs to be adjusted between different years. This index is based on a 30-city average and has been collected since 1963 .

Figure 3 provides a graphical representation of the different cost indexes described, as well as Consumer Price Index (CPI), from 1980 to 2012. All index values have been adjusted to a 1980 base year for comparison. In the figure, gray areas correspond to historical US economic recessions and 1980 represents a base year. 


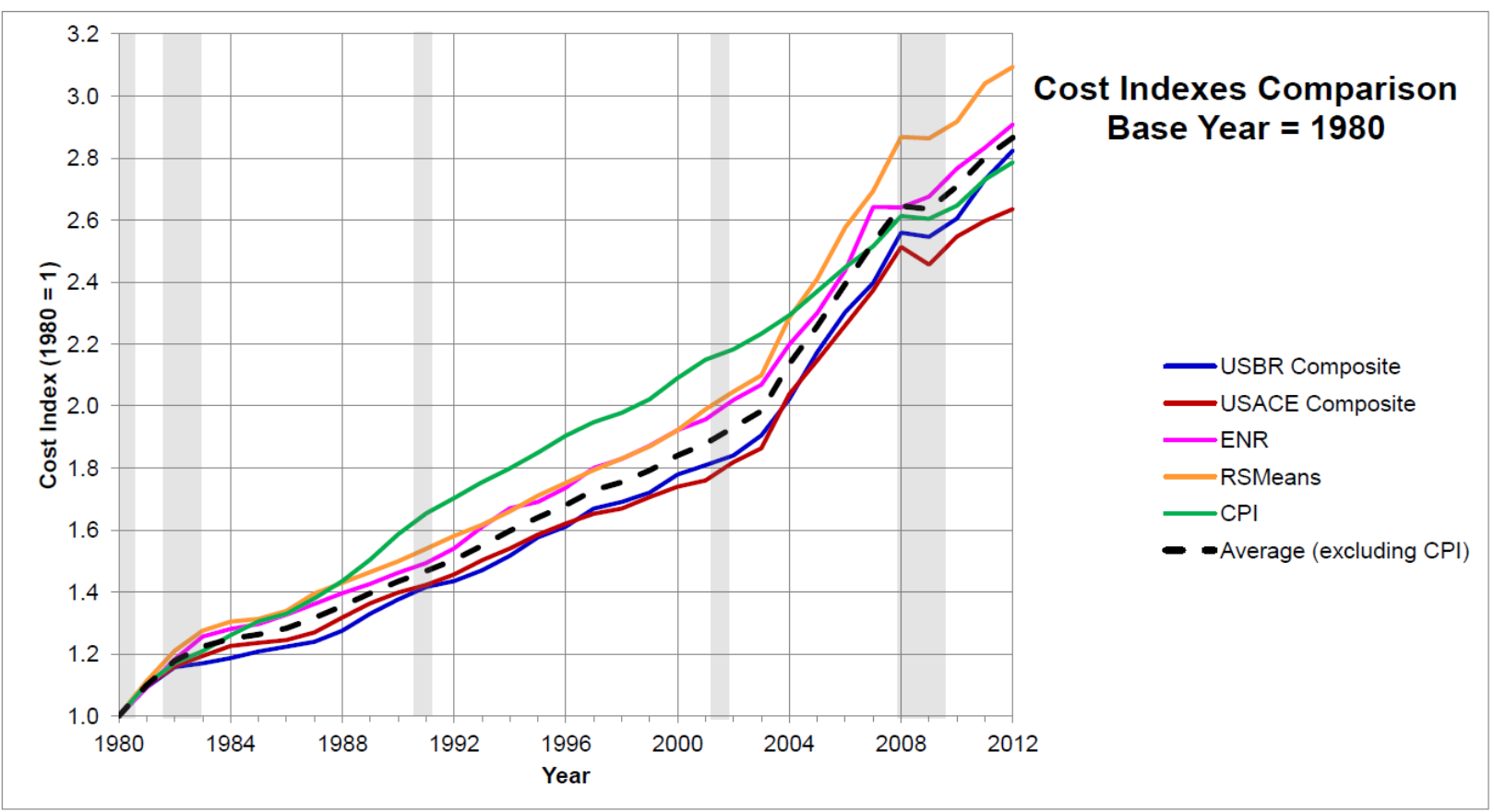

Figure 3. Cost indexes comparison

As it presents the most hydro-centric index basis among those available, the USBR CCT is used to escalate the historical costs collected to 2012 levels ${ }^{4}$. While the USBR CCT is used to escalate cost estimates, it is interesting to note that in recent years it has converged with general inflation (as measured by the $\mathrm{CPI}$ ), indicating that, at least at this moment in time, the cost of developing new hydropower plants has not changed in real terms since the early 1980s.

\subsection{Discussion}

\section{Data Collection Summary}

Altogether, a total of 599 projects for which adequate data were available are included in the final BCM database. Of these, 84 are NSD projects, 306 are NPDs, 92 are Canal/Conduit sites, 84 are PSH sites, and 34 are other project types (i.e., Unit Addition and Generator Rewind). As shown in Figure 4, the most significant sources of ICC data are from the DOE-EPRI reports and the IIR database. Additionally, the majority of data are derived from planning stage cost estimates, though engineering stage projects also represent a significant source of data (especially for Canal/Conduit projects). Though cost data from construction stage projects are not as numerous as from planning and engineering stages, those estimates are considered to contain the highest level of accuracy. As a result, given a large enough sample size, model development using only $\mathrm{C}$ level projects may be justified. Additional details related to the analysis methodology used for BCM development are provided in Section 3 of this report.

The availability and granularity of the breakdown costs varied significantly between resource type and data source. The DOE-EPRI reports were the only source with consistent reporting of cost at the component level, but it still suffered from inconsistent cost scope across many

\footnotetext{
${ }^{4}$ Unless otherwise noted, all costs included in this report are given in $2012 \$$.
} 
projects, primarily those in the planning stage. Within the other sources, a construction stage estimate may have been available from IIR, but breakdown costs were only available from outdated FERC cost estimates. Ultimately, costs were necessarily primarily handled at the level of total ICC, but issues of unclear scope suggest further data collection could improve the accuracy of the collected data. However, in Section 4, where breakdown cost data is available it is presented to add context to the models developed from the total ICC data. Future efforts will focus on detailed data collection to refine the boundaries of the ICC cost prediction tools.
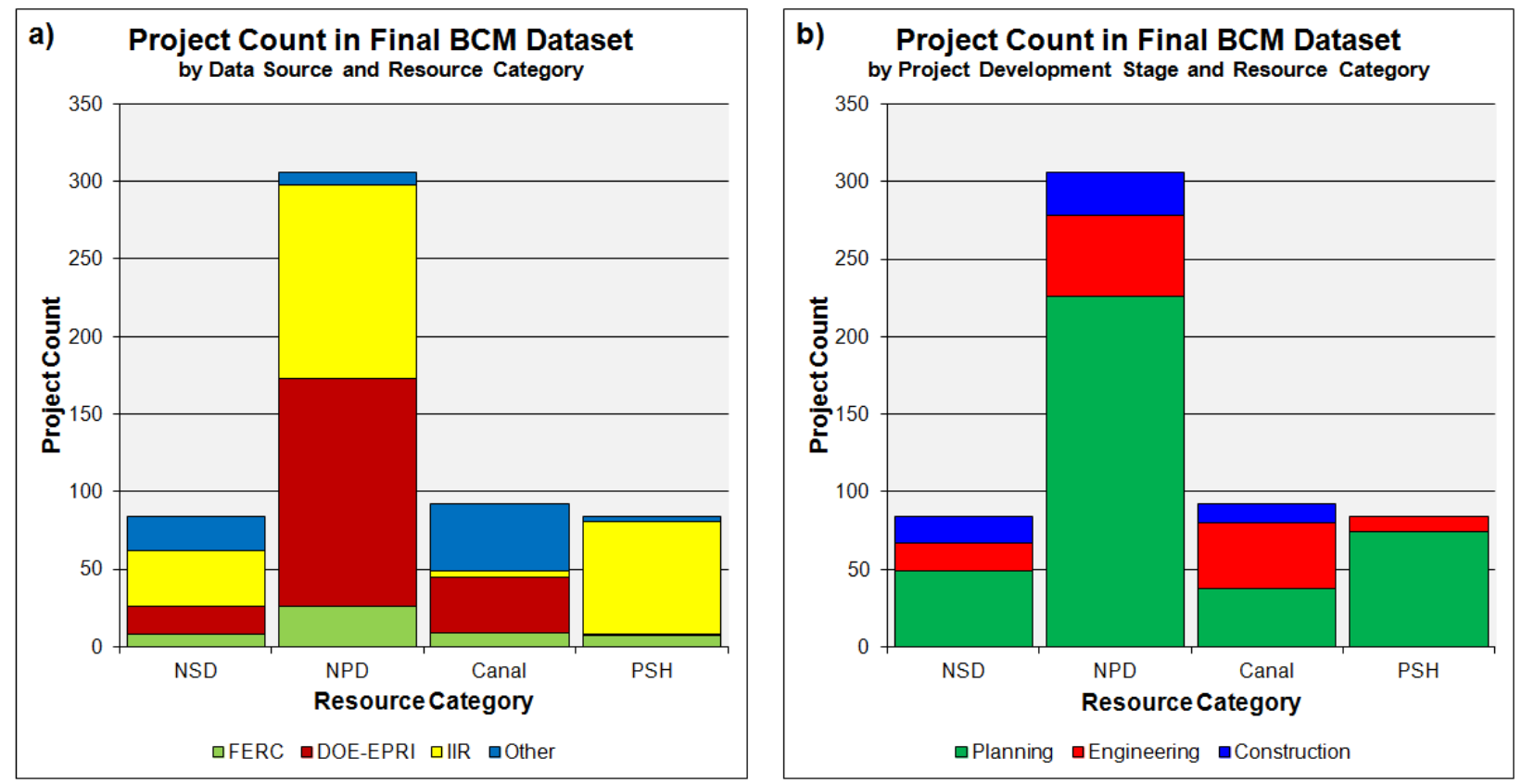

Figure 4. Finalized BCM data project count by data source, project development stage, and resource category

\section{The Current Cost of Constructing New Hydropower Resources}

Examining the subset of cost data collected from those projects that have either been constructed or are actively under construction (c-stage) provides insight into the relative economics of modern hydropower development. Table 6 describes the construction-stage data for recent hydropower projects in the U.S. ${ }^{5}$. The lack of recent pumped storage development in the U.S. resulted in a complete lack of c-stage PSH data, while completed existing generator rewind and unit addition projects were all taken from the IIR database. Overall, the bulk of the construction stage data collected for the development of the BCMs was focused on those resource classes that added power to unpowered sites and reaches (i.e. NSD, NPD, and Canals).

\section{Table 6 - Summary of projects with actual costs (C-stage)}

\footnotetext{
${ }^{5}$ Given limited U.S. data, Canadian projects are included in the development of the NSD ICC models. Due to the lack of generation data they are not visualized here.
} 


\begin{tabular}{|c|c|c|c|c|c|c|c|c|}
\hline \multirow{2}{*}{$\begin{array}{c}\text { Resource } \\
\text { Category }\end{array}$} & \multirow{2}{*}{$\begin{array}{c}\text { Project } \\
\text { Count }\end{array}$} & \multicolumn{3}{|c|}{ Capacity (MW) } & \multicolumn{3}{|c|}{ Head (ft) } & \multirow{2}{*}{$\begin{array}{c}\text { No. of Projects } \\
\text { with Breakdown } \\
\text { Cost }\end{array}$} \\
\cline { 3 - 9 } & & Min & Avg & Max & Min & Avg & Max & \\
\hline NSD & 17 & 3 & 86.09 & 824 & 19.3 & 791.5 & 1896 & 2 \\
\hline NPD & 28 & 0.66 & 21.86 & 105 & 14.1 & 117.5 & 356 & 9 \\
\hline Canal & 12 & 0.095 & 3.25 & 13 & 36.7 & 540.6 & 1554 & 5 \\
\hline PSH & 0 & & & & & & & 0 \\
\hline Unit Addition & 4 & 1.4 & 5.91 & 11.25 & & & & 0 \\
\hline Generator Rewind & 7 & 12.8 & 60.97 & 150 & & & & 0 \\
\hline
\end{tabular}

Figure 5 illustrates the distribution of the collected C-stage capital costs for those three new hydropower resource classes. The boxes represent the spread between $25^{\text {th }}$ and $75^{\text {th }}$ percentiles while the whiskers are the furthest data points within 1.5 times the interquartile range. NPD and Canal projects fall within the same capital cost range, with $50 \%$ of each (25 to 75 percentile) generally bracketed between $\$ 2,500 / \mathrm{kW}$ and $\$ 5,000 / \mathrm{kW}$, but with exceptional cases as low as $\$ 1,000 / \mathrm{kW}$ or as high as nearly $\$ 9,000 / \mathrm{kW}$. NSD projects, however, bear demonstrably higher, but more tightly distributed capital costs with all C-stage projects falling between $\$ 3,500$ and $\$ 6,500 / \mathrm{kW}$. This suggests that additional civil infrastructure necessary to develop on undeveloped stream-reaches renders projects more expensive, a finding that is examined statistically in Section 4. Overall, the average Canal project cost approximately $\$ 4100 / \mathrm{kW}$, the average NPD project cost approximately $\$ 3800 / \mathrm{kW}$, and the average NSD project cost $\$ 4900 / \mathrm{kW}$. 


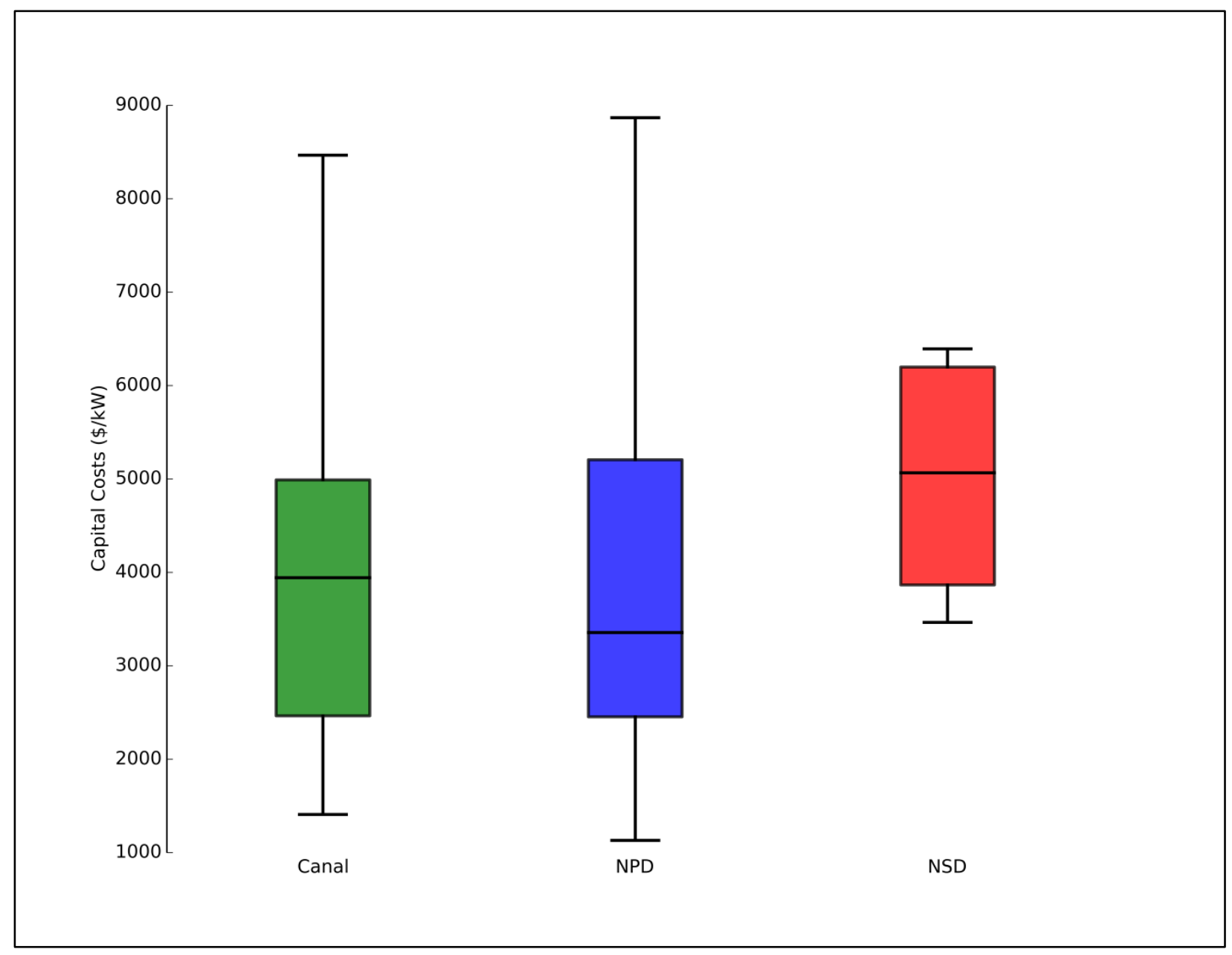

Figure 5 - Capital costs of recently developed hydropower facilities

Assessing project economics on a lifecycle basis using levelized cost of energy (LCOE) as a metric tells a different story. In order to estimate LCOE, plant-specific generation estimates for U.S. projects were collected along alongside capital costs, and operations and maintenance costs (O\&M) is approximated as $2 \%$ of ICC per year-Version 2 of this report will include explicit models for estimating $\mathrm{O} \& \mathrm{M}$ based on design characteristics.

As can be seen in Figure 6, the LCOE of recent developments in all three resources classes is generally similar. All have median LCOEs of approximately $\$ 110 / \mathrm{MWh}$, and generally fall within more narrow bounds than ICC alone-this convergence is driven by two factors: (1) the fact that only economically competitive projects will be developed and constructed-therefore high ICC projects require higher capacity factors for competitive LCOE_and (2) accordingly, that the NSD projects have higher capacity factors than the canal projects. Projects constructed on existing water supply infrastructure such as canals are only able to produce power when flows are scheduled to meet water demands. Oftentimes these projects may see entire seasons (such as winter) with no water available for electricity generation. 


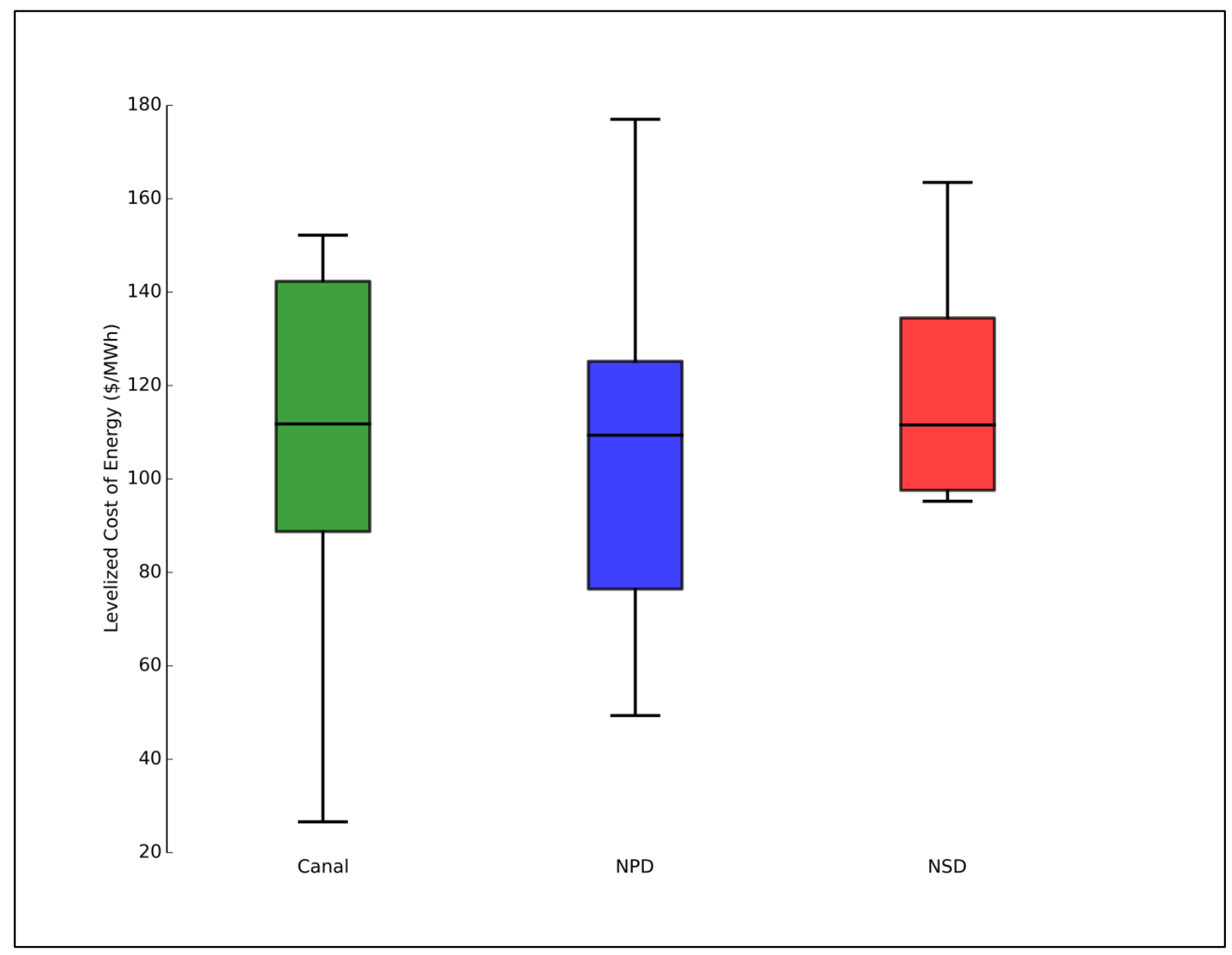

\section{Figure 6 - Levelized Cost of Energy (LCOE) of recently developed new hydropower resources}

LCOE is strongly driven by the assumed financing parameters. The financial assumptions used to generate Figure 6 are consistent with those used in the various U.S. Department of Energy renewable energy strategic planning studies (e.g. DOE, 2012 and NREL, 2012) and are generally considered to be representative of those seen $b$ y independent power producers at a $6.2 \%$ real weighted average cost of capital and 20-year economic lifetime. However, the actual financing of the constructed projects will vary, and many of those represented in Figure 6 likely have lower LCOEs owing to recent low interest rates and/or their development by public entities, such as municipal utilities, with access to lower-cost capital than independent power producers and planning/economic evaluation horizons much greater than 20 years.

\section{Uncertainties in Cost Estimating}

As an illustration of the cost estimating uncertainty issues discussed in Section 2.1 with regard to planning and engineering stage cost estimates (relative to construction stage estimates),data was collected from the DOE-EPRI and IIR databases for projects with which multi-stage cost 
estimates (from planning stage to construction stage) and compared. Table 7 provides comparative information for $8 \mathrm{DOE}-\mathrm{EPRI}$ projects for which planning $(\mathrm{P})$, engineering $(\mathrm{E})$, and construction $(\mathrm{C})$ data were available (that is, those projects present on all of Volumes 1, 2, and $3)$.

Table 7. Comparison between planning, engineering, and construction stage cost for DOE-EPRI dataset projects

\begin{tabular}{|c|c|c|c|c|c|c|}
\hline \multirow{2}{*}{ Project Name } & \multirow{2}{*}{$\begin{array}{c}\text { Project } \\
\text { Category }\end{array}$} & \multirow{2}{*}{$\begin{array}{c}\text { Construction } \\
\text { Year }\end{array}$} & \multirow{2}{*}{$\begin{array}{c}\text { Capacity } \\
\text { (MW) }\end{array}$} & \multicolumn{3}{|c|}{ ICC (\$/kW in 2012\$) } \\
\cline { 5 - 7 } & Canal/Conduit & 1984 & $\mathbf{P}$ & $\mathbf{E}$ & $\mathbf{C}$ \\
\hline Garland Canal & NPD & 1982 & 6.5 & 3,294 & 4,549 & 3,216 \\
\hline Garvins Falls & NPD & 1983 & 10.95 & 2,801 & 2,477 & 2,867 \\
\hline Great Falls & New & 1983 & 24 & 5,359 & 4,797 & 6,394 \\
\hline Idaho Falls & NPD & 1984 & 10.9 & 3,356 & 3,108 & 2,752 \\
\hline Jackson Bluff & NPD & 1982 & 4.112 & 4,097 & 1,644 & 3,124 \\
\hline Shawmut & NPD & 1981 & 3.26 & 3,668 & 3,307 & 3,590 \\
\hline Turlock & NPD & 1984 & 16.8 & 5,333 & 5,531 & 6,383 \\
\hline Upper Mechanicsville & Average & $\mathbf{9 . 9}$ & $\mathbf{3 , 8 0 8}$ & $\mathbf{3 , 5 3 9}$ & $\mathbf{3 , 8 9 0}$ \\
\hline
\end{tabular}

Similarly,

Table 8 demonstrates the differences in project cost across different project development stages for 13 IIR projects with historical estimates spanning all three stages of development

Table 8. Comparison between actual project cost, engineering stage, and feasibility stage cost for IIR dataset

\begin{tabular}{|c|c|c|c|c|c|c|}
\hline \multirow{2}{*}{ Project Name } & \multirow{2}{*}{$\begin{array}{c}\text { Project } \\
\text { Category }\end{array}$} & $\begin{array}{c}\text { Construction } \\
\text { Year }\end{array}$ & $\begin{array}{c}\text { Capacity } \\
\text { (MW) }\end{array}$ & \multicolumn{3}{|c|}{ ICC (\$/kW in 2012\$) } \\
\cline { 5 - 7 } & NPD & 2014 & 4.6 & 5,784 & 5,239 & 3,760 \\
\hline 1 & NPD & 2014 & 5.6 & 2,493 & 3,571 & 3,321 \\
\hline 2 & NPD & 2014 & 6 & 1,861 & 2,411 & 2,325 \\
\hline 3 & NPD & 2014 & 7 & 6,651 & 5,429 & 5,048 \\
\hline 4 & NPD & 2008 & 12 & 1,919 & 1,745 & 1,380 \\
\hline 5 & Canal/Conduit & 2011 & 13 & 1,850 & 2,502 & 2,387 \\
\hline 6 & NPD & 2014 & 16 & 5,748 & 2,104 & 2,092 \\
\hline 7 & NPD & 2013 & 30 & 1,110 & 1,724 & 2,250 \\
\hline 8 & NPD & 2012 & 31.5 & 1,684 & 2,678 & 2,413 \\
\hline 9 & NPD & 2014 & 35 & 2,660 & 8,868 & 7,971 \\
\hline 10 & NPD & 2013 & 75 & 2,455 & 6,506 & 5,786 \\
\hline 11 & NPD & 2014 & 84 & 1,754 & 5,370 & 4,605 \\
\hline 12 & NPD & 2014 & 105 & 3,699 & 3,614 & 4,464 \\
\hline 13 & Average & $\mathbf{3 2 . 7}$ & $\mathbf{3 , 0 5 1}$ & $\mathbf{3 , 9 8 2}$ & $\mathbf{3 , 6 7 7}$ \\
\hline
\end{tabular}


Comparison of estimate cost trajectories reveals two major characteristics: 1) final construction costs are not uniformly higher or lower than earlier stage estimates and 2) relative stage cost varies between the data sources. The second characteristic noted derives from the observation that DOE-EPRI projects generally contain more variation in how cost changes from $\mathrm{P}$ to $\mathrm{E}$ to $\mathrm{C}$ stage. This can likely be partially attributed to differences in data collection practices, however, in the case of the DOE-EPRI data set, the unique volatile inflation environment in late1970s and early 1980s may have contributed to decreased accuracy for cost estimates at planning or engineering stages of development. The more recent IIR dataset shows that engineering stage data is generally more accurate than those derived from planning stage estimates, as would be expected.

\section{Analysis Methodology}

\subsection{Model Development}

Historically, hydropower costs have been well-represented by power-law relationships between ICC and key plant parameters, such as installed capacity (INL, 2003) or to capture the cost dynamics of high and low-head hydropower plants, both capacity and design head (Gordon, 1979). Except where otherwise discussed, the development of the cost models in this document relies on the capacity-head relationship (shown below) to better cost the relatively low-head resources remaining in the U.S.

$$
I C C=a P^{b} H^{c}
$$

where

$$
\begin{aligned}
& \text { ICC }=\text { Initial Capital Cost }, \\
& P=\text { Capacity (in MW) }, \\
& H=\text { Hydraulic Head (in } \mathrm{ft} \text { ) }, \\
& a=\text { Slope coefficient }, \\
& b=\text { Capacity exponent, and } \\
& c=\text { Head exponent. }
\end{aligned}
$$

Methodologically, power-law relationships can be fit using a variety of methods. Traditionally, this has been done using log-transformed variables in a linear regression or directly via nonlinear least squares regression. The appropriate choice of method is contingent on the distribution of error in order to avoid violating the assumptions of least squares regression methods (Xiao et al, 2011) - geometric (multiplicative) errors become normal on a log-scale, while additive (arithmetic) errors are only appropriately modeled when untransformed. Conceptually, error for ICC data should be multiplicative (i.e. $\$ 10,000,000$ project should expect cost deviations from prediction to be $10 x$ a $\$ 1,000,000$ project); this is also consistent with the AACE practice of using percentage based estimating ranges. Therefore, log transformed linear regression is used to fit the ICC power law models. 
The use of linear regression requires a linear relationship between the dependent and independent variables, and so, the power relationship is converted to a linear relationship by taking log values of the variables (ICC, $\mathrm{P}$, and $\mathrm{H}$ ) on both the left and right sides the equation :

$$
\log (I C C)=\log (a)+b \log (P)+c \log (H)+\varepsilon
$$

The mean of error term $(\varepsilon)$ of log transformed data will be zero, but this assumption does not necessarily hold upon retransformation of the data into the original untransformed scale (Newman, 1993), biasing any estimates derived from the directly retransformed model.

Therefore, the error term needs to be explicitly incorporated by adjusting the power relationship:

$$
I C C=a P^{b} H^{c} e^{\varepsilon}
$$

For this study, the Smearing Estimator (Duan, 1983), a non-parametric method, is used to calculate the bias correction, $e^{\varepsilon}$ :.

$$
e^{\varepsilon}=\frac{\sum_{i=1}^{i=N} \exp \left(e_{i}\right)}{N}
$$

where, $e_{i}=$ Residuals from regression model, $N=$ Sample size. The error term $e^{\varepsilon}$ is called smear correction and is also referred to as bias correction.

\subsection{Model Selection and Evaluation}

\section{Model Confidence Scoring}

In the development of the BCMs, a variety of different data subsets were evaluated both to understand the sources of cost variation and to ultimately select the models that best represent the cost of developing the remaining U.S. hydropower resources. To consistently evaluate the alternative model options within each resource class, a quantitative evaluation system was developed to rank models based on the following series of metrics related to (1) attributes of the data used in the development of the model, and (2) the overall quality of the model itself:

\section{- Data}

- Data Quality (project development stage)

- Data Scope and Consistency

- Data Vintage (age of cost estimate)

\section{- Model Quality}

- Sample Size

- Data QA/QC

- Goodness of Fit

- Validation

- Application Range 
Table 9 shows how the metrics used for evaluating model confidence are quantified. The confidence level associated with each data source are quantified using Items 1 through 3, while the overall model results, reliability, and application are scored using Items 4 through 8.

Individual model scores for Items 1 and 3 are weighted according to the number of projects included from each development stage and vintage category, respectively. A model confidence score in this report is sum of score of each item 1 to 8 . Overall, the range of potential confidence scores range from 0 to 17. 
Table 9. Confidence Score Criteria

\begin{tabular}{|c|c|c|}
\hline Item & Confidence Description & $\begin{array}{l}\text { Confidence } \\
\text { Scores }\end{array}$ \\
\hline \multicolumn{3}{|c|}{ 1. Raw Data Quality (Weighted average) } \\
\hline Construction stage & Very High & 17 \\
\hline Engineering stage & High & 15 \\
\hline Planning stage & Low & 12 \\
\hline \multicolumn{3}{|l|}{ 2. Raw Data Scope and Consistency } \\
\hline Known and consistent & $\begin{array}{l}\text { Known and consistent cost } \\
\text { scope - all major cost-related } \\
\text { variables are obtained for } \\
\text { correlation analysis }\end{array}$ & 0 \\
\hline Unknown and inconsistent & $\begin{array}{l}\text { Unknown and inconsistent cost } \\
\text { scope - one or more cost-related } \\
\text { variables are omitted for } \\
\text { correlation analysis }\end{array}$ & -1 \\
\hline \multicolumn{3}{|l|}{ 3. Data Vintage (Weighted average) } \\
\hline Recent data $(<10$ yrs old $)$ & & 0 \\
\hline Old data (10 - 30 yrs old) & & -1 \\
\hline Very old data ( $>30$ yrs old) & & -3 \\
\hline \multicolumn{3}{|l|}{ 4. Data Sample Size (Equation-based) } \\
\hline Adequate & $\geq 50$ & 0 \\
\hline Unrepresentative /Anecdotal & $\frac{-3(51-N)^{2}}{50^{2}}$ & range from -3 to 0 \\
\hline \multicolumn{3}{|c|}{ 5. Data QA/QC Before Regression Analysis } \\
\hline Performed & & 0 \\
\hline Not performed & & -1 \\
\hline \multicolumn{3}{|c|}{ 6. Regression Analysis Results (Equation-based) } \\
\hline $\mathrm{R}^{2}$ adjustment & $-\left(1-R^{2}\right)^{2}$ & range from -1 to 0 \\
\hline max p-value adjustment & $-\left(\text { pvalue }_{\max }\right)^{0.5}$ & range from -1 to 0 \\
\hline \multicolumn{3}{|l|}{ 7. Model Validations } \\
\hline Yes (in sample \& out of sample) & & 0 \\
\hline Yes ( in sample only) & & -0.5 \\
\hline No & & -1 \\
\hline \multicolumn{3}{|l|}{ 8. Model Application Ranges } \\
\hline Clearly defined application ranges & & 0 \\
\hline Unclear application ranges & & -1 \\
\hline Overall Confidence Level & $\begin{array}{l}\text { Sum of scores of each item } \\
1 \text { to } 8\end{array}$ & $\begin{array}{l}\text { Ranges from } 0 \\
\text { to } 17\end{array}$ \\
\hline
\end{tabular}

\section{Model Evaluation and Validation}

For each of the resource categories for which BCMs are developed, a consistent evaluation and validation process is employed. After properly identifying the extent of raw data applicable for a 
particular category, projects which are identified as duplicates or outliers are removed, while additional data limitations (e.g., lack of head data) may limit the final database size. The finalized database is then evaluated across various development stages to identify the major independent variables to include in the models based on graphical representations and regression analysis. The resulting cost model equations are assessed for validity, while the coefficient of determination $\left(\mathrm{R}^{2}\right)$ and $\mathrm{p}$-values are compared to assess overall model performance and suitability. In the end, a recommended model is identified based on confidence score results, though alternative models are presented in Appendix A.

In addition to presenting the recommended model, the recommended NPD and NSD models are also compared against other available cost models: INL models (INL, 2003), USACE model (USACE, 2013b), both from this BCM effort and from literature. In-sample validation is also performed (see Appendix A). Finally, average categorical breakdown costs are presented for the models, with breakdowns for alternative models provided in Appendix A.

\section{Model Results}

Section 4 describes the evaluation and validation for the NPD, NSD, Canal/Conduit, PSH, Unit Addition, and Generator Rewind baseline cost models and presents average project breakdown costs. The application ranges of a cost model should be clearly defined and validated based on the scope of raw cost data that are used to derive the model. When using any cost model, whether found in literature or in this report, caution should be exercised if extrapolating the cost curve beyond its intended application ranges (e.g., some cost equations were developed for large hydro only and will bring "bias" for small hydro cost estimating). In an attempt to adequately identify application ranges for the recommended models, information is provided for each resource category in Section 4.

\subsection{Non-powered Dams (NPDs)}

Starting with a total of 436 NPD projects, 119 were identified as duplicates, with another 10 excluded due to a lack of hydraulic head information. In addition, 1 project containing a per-kW cost above $\$ 78,000$ was identified as an outlier and subsequently removed. The final NPD database comprises information from a total of 306 projects, which were disaggregated into various categories based on project development stage, project capacity, and hydraulic head. The results herein represent the finalized dataset containing 306 NPD projects.

\section{Data Statistics}

Table 10 provides summary statistics for the NPD projects by data source. The majority of data were taken from EPRI or IIR, and the project capacities range from $34 \mathrm{~kW}$ to $120 \mathrm{MW}$. Over $70 \%$ of the data contain planning stage development costs. In addition, breakdown costs were collected for a total of 192 NPD projects. 
Table 10. NPD Project Summary Statistics ${ }^{6}$

\begin{tabular}{|c|c|c|c|c|c|c|c|c|c|c|c|}
\hline \multirow{2}{*}{$\begin{array}{l}\text { Data } \\
\text { source }\end{array}$} & \multirow{2}{*}{$\begin{array}{c}\text { Project } \\
\text { Count }\end{array}$} & \multicolumn{3}{|c|}{$\begin{array}{l}\text { Development } \\
\text { Stage (count) }\end{array}$} & \multicolumn{3}{|c|}{ Capacity (MW) } & \multicolumn{3}{|c|}{ Head (ft) } & \multirow{2}{*}{$\begin{array}{l}\text { No. of } \\
\text { Projects } \\
\text { with } \\
\text { Breakdown } \\
\text { Cost }\end{array}$} \\
\hline & & $\mathbf{P}$ & E & C & Min & Avg & Max & Min & Avg & Max & \\
\hline EPRI & 147 & 118 & 21 & 8 & 0.07 & 4.52 & 40 & 8 & 77 & 1,040 & 147 \\
\hline IIR & 125 & 103 & 5 & 17 & 1.50 & 20.42 & 120 & 7 & 80 & 1,800 & 20 \\
\hline FERC & 26 & 5 & 21 & 0 & 0.21 & 12.84 & 48 & 13 & 98 & 700 & 21 \\
\hline Other & 8 & 0 & 5 & 3 & 0.034 & 11.36 & 50 & 10 & 93 & 262 & 4 \\
\hline
\end{tabular}

Other data sources : DOE (2014) - 2 projects, ETO (2010) - 2 projects, Consultant A - 3 projects, Consultant B - 1 project

Figure 7 shows the distribution of NPD projects across different ranges of ICC, capacity, and head. As seen in the figure, the majority of projects range from 1 to $30 \mathrm{MW}$ and have heads below $200 \mathrm{ft}$. The ICC varies significantly, though most projects are between 1,000 and 10,000 $2012 \$ / \mathrm{kW}$. Additionally, the 16 projects which contain ICC above $\$ 10,000^{7}$ per $\mathrm{kW}$ are all planning stage projects. Figure 8 provides several scatter plots to illustrate the distribution of and relationships between various project parameters, including ICC, capacity, and hydraulic head. As seen in Figure 8b, an apparent positive correlation exists between ICC and capacity, which demonstrates the increase in cost associated with larger hydropower development projects. In addition, Figure $8 \mathrm{c}$ reveals that per kW, ICC generally decreases with capacity, indicating that larger NPD projects benefit from the economies of scale associated with large hydropower development. Though not as strongly correlated to ICC, hydraulic head is negatively correlated with ICC, as shown in Figure 8d.

\footnotetext{
${ }^{6}$ Project Development Stage: $\mathrm{P}$ - planning, E - engineering, and C - construction

${ }^{7}$ Unless otherwise noted, all costs included in this report are given in 2012\$.
} 

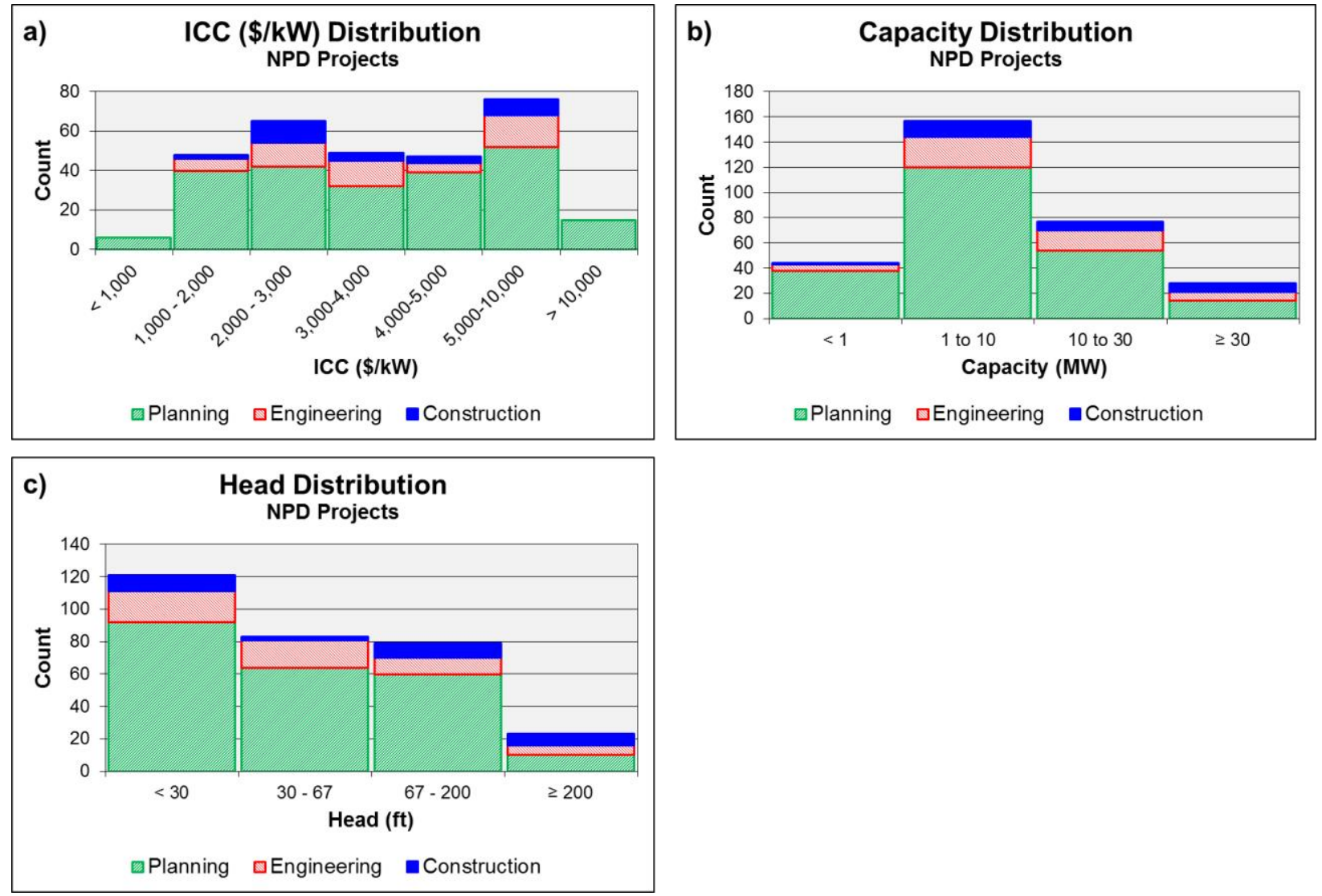

Figure 7. NPD data distribution histograms 

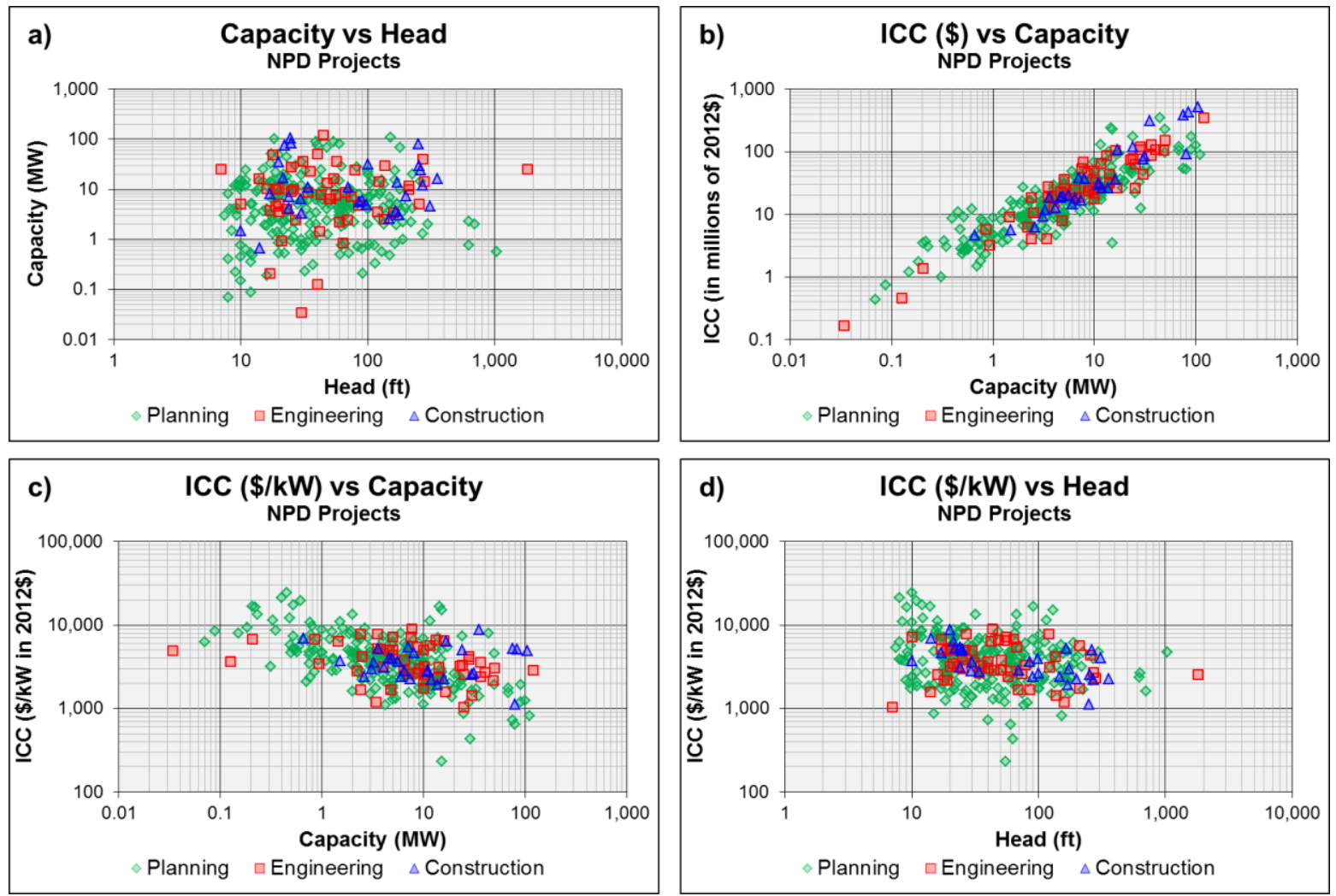

Figure 8. NPD project raw data scatter plots

\section{NPD Model}

After comparing several different models for estimating NPD project costs and assessing confidence scores, it was decided to use the model resulting from the $C$ Dataset. The model results from multivariate regression analysis using construction stage project data (planning and engineering stage data were not included). A total of 28 projects were used in developing this model, and a summary of basic model features is provided in Table 11. Of these 28 projects, 8 are from EPRI, 17 are from IIR, and 3 are from other data sources. The project capacities range from $66 \mathrm{~kW}$ to $105 \mathrm{MW}$ with an average value of $21.86 \mathrm{MW}$, while the hydraulic heads range from 14 to $356 \mathrm{ft}$ with an average value of $117 \mathrm{ft}$. The recommended ICC model formula is provided below:

$$
\text { ICC }(\text { in } 2012 \$)=12,038,038 P^{0.980} H^{-0.265}
$$

Table 11. NPD recommended model summary

\begin{tabular}{|c|c|c|c|c|c|c|c|}
\hline $\begin{array}{c}\text { Resource } \\
\text { Category }\end{array}$ & $\begin{array}{c}\text { Project } \\
\text { Development } \\
\text { Stage }\end{array}$ & Coefficient & $\begin{array}{c}\text { Capacity } \\
\text { Exponent }\end{array}$ & $\begin{array}{c}\text { Head } \\
\text { Exponent }\end{array}$ & $\mathbf{R}^{2}$ & $\begin{array}{c}\text { Sample } \\
\text { Size }\end{array}$ & $\begin{array}{c}\text { Confidence } \\
\text { Score }\end{array}$ \\
\hline NPD & C & $12,038,038$ & 0.980 & -0.265 & 0.92 & 28 & 13.34 \\
\hline
\end{tabular}


Overall, the $\mathrm{C}$ model provides the highest confidence score of 13.34 , which exceeds the $\mathrm{EC}$ and PEC model scores of 12.35 and 9.18, respectively, identifying the $C$ model as the ORNL recommended model for NPDs.

To further validate the model, graphical in-sample validation was performed with no noticeable bias identified. Figure 9 provides a comparison between the recommended NPD model developed for this report, the alternative NPD model developed from the EC dataset included given the closeness in confidence score, the INL model (INL, 2003) developed for construction of dams without power, the USACE resource assessment model (USACE, 2013b) ${ }^{8}$, and the actual project costs included in the $C$ Dataset. As seen in Figure 9, for most projects the ORNL recommended model estimates higher ICC compared to the other models. Compared with actual cost, the ORNL recommended model tends to better approximate project costs than the other models. In addition, the C model generally overestimates ICC for the lower per kW cost projects and underestimates ICC for the higher per kW cost projects (Figure 9a). As seen in Figure 9b and Figure 9c, the recommended model's relative error is largely independent of variation in capacity and head. Compared with the EC model, the recommended model provides very similar ICC estimates, though a more noticeable difference is seen for the lower head projects (Figure 9c). As expected, the INL model shows significant bias in estimating ICC for low head projects, as the model provides only a univariate estimate based on capacity (Figure 9c). The average actual project ICC for the 28 constructed projects is $\$ 3,833$, while the recommended ORNL, INL, and USACE models produce average per $\mathrm{kW}$ costs of $\$ 3,844$, $\$ 2,199$, and $\$ 2,530$, respectively. As the recommended ORNL model was developed based on regression analysis using the same set of 28 constructed projects, the model necessarily produces the best approximation for the actual cost, and further data collection will allow for the model to be benchmarked against out of sample data points, and more robustly identify cost drivers at the component level.

\footnotetext{
${ }^{8}$ It is important to note that the USACE model explicitly attempts to size plants and select turbine number and type based on site head and capacity parameters. In its application here to the $\mathrm{C}$ data set, static values of head and capacity are used. As discussed in the executive summary and introduction, this and other more sophisticated modeling approaches should yield estimates with increased accuracy if detailed site-specific data such as flow and head duration curves were available.
} 

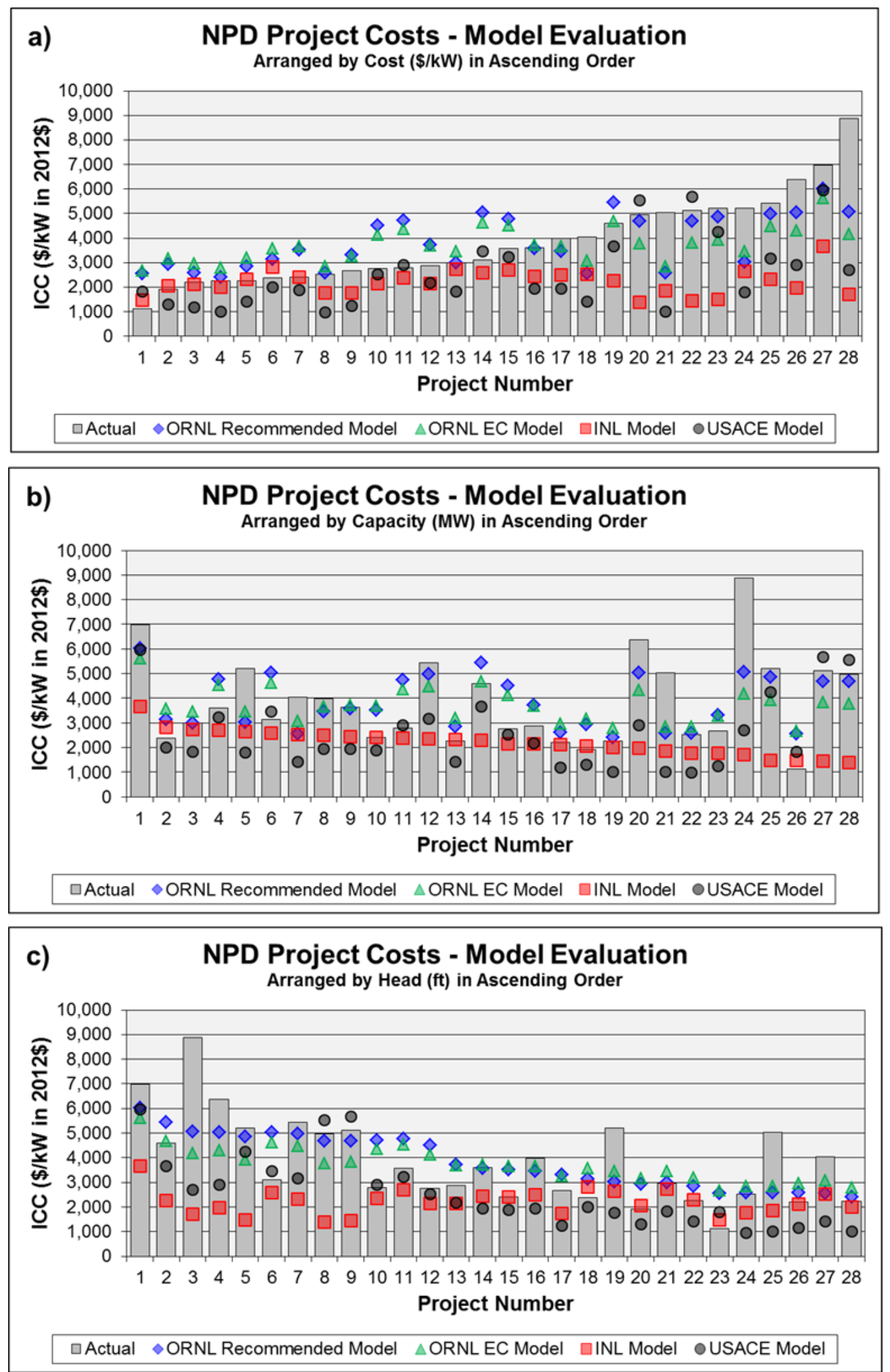

Figure 9. Comparison of ORNL and INL model-estimated costs with actual NPD costs 
Although the $\mathrm{C}$ model is recommended for NPD costing application, numerous other models were developed and compared during the model development and validation stages. Details on the additional NPD models evaluated and more specific discussion are provided in Appendix A.

\section{Breakdown Costs}

Although the recommended ICC model for NPDs uses just $C$ stage projects, breakdown cost data were only available for 2 construction stage NPD projects; consequently, both $E$ and $C$ stage projects are used for illustration. Figure 10 provides average breakdown cost statistics for 36 engineering and 2 construction stage NPD projects. As seen in the chart, the civil works and equipment costs constitute about $81 \%$ of the total NPD project development cost, with equipment costs representing the primary cost driver. Additional breakdown cost distributions based on hydraulic head and capacity ranges were developed and are provided in Appendix A.

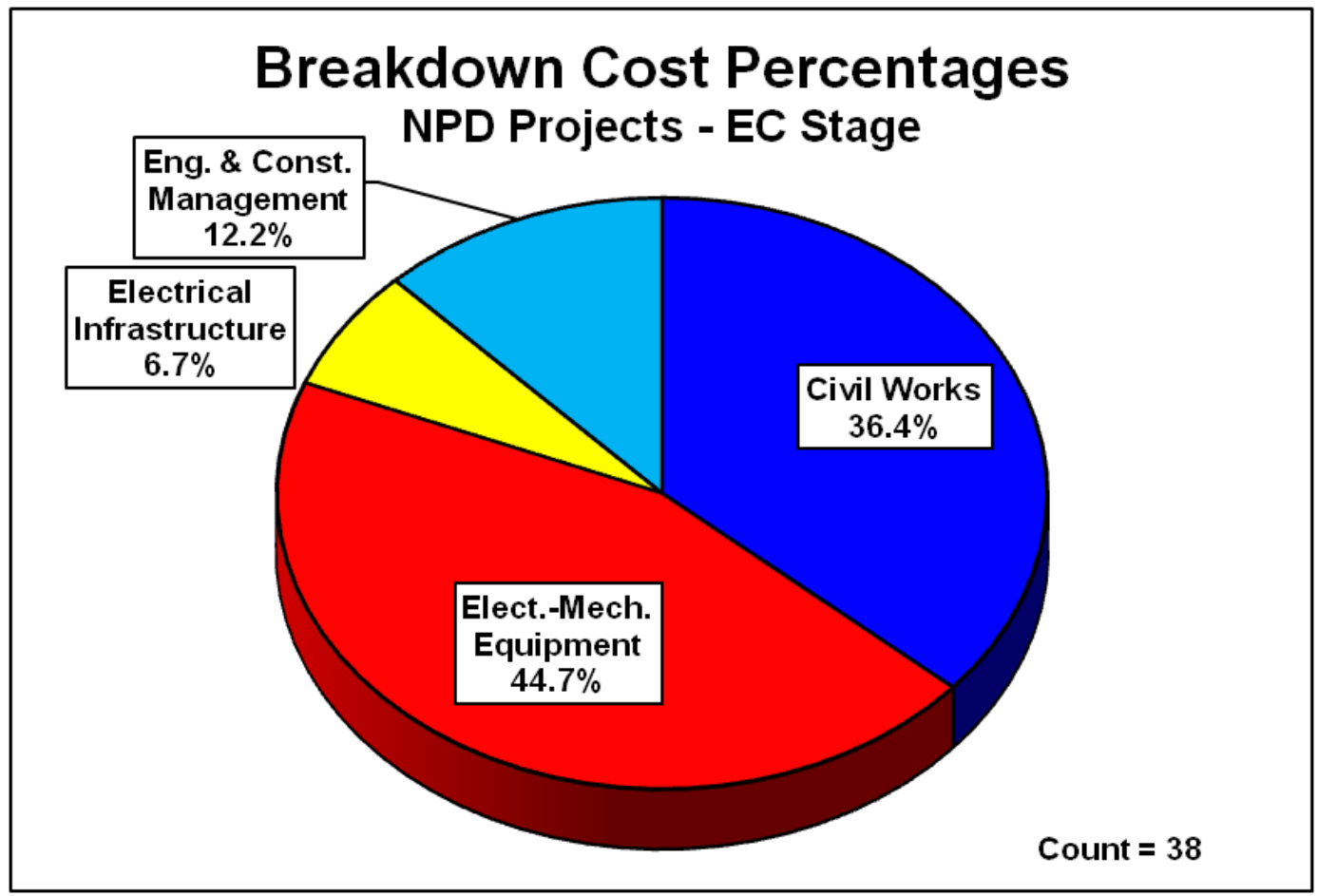

Figure 10. Breakdown cost distribution for NPD projects (EC dataset)

\subsection{New Stream-reach Development (NSDs)}

Starting with a total of 95 NSD projects, 7 were identified as duplicates, with another 3 excluded due to a lack of hydraulic head information. In addition, 1 project containing a per-kW cost above $\$ 96,000$ was identified as an outlier and subsequently removed. The final NSD database comprises information from a total of 84 projects, which were disaggregated into various categories based on project development stage, project capacity, and hydraulic head. The results herein represent the finalized dataset containing the 84 NSD projects. 


\section{Data Statistics}

Table 12 provides summary statistics for the NSD projects by data source. The majority of data were taken from EPRI, IIR, or other data sources and the project capacities range from $163 \mathrm{~kW}$ to $824 \mathrm{MW}$. Nearly $60 \%$ of the data contain planning stage development costs. In addition, breakdown costs were collected for a total of 33 NSD projects.

Table 12. NSD project summary statistics ${ }^{9}$

\begin{tabular}{|c|c|c|c|c|c|c|c|c|c|c|c|}
\hline \multirow{2}{*}{$\begin{array}{l}\text { Data } \\
\text { source }\end{array}$} & \multirow{2}{*}{$\begin{array}{l}\text { Project } \\
\text { Count }\end{array}$} & \multicolumn{3}{|c|}{$\begin{array}{l}\text { Development } \\
\text { Stage (count) }\end{array}$} & \multicolumn{3}{|c|}{ Capacity (MW) } & \multicolumn{3}{|c|}{ Head (ft) } & \multirow{2}{*}{$\begin{array}{l}\text { No. of } \\
\text { Projects } \\
\text { with } \\
\text { Breakdown } \\
\text { Cost }\end{array}$} \\
\hline & & $\mathbf{P}$ & E & C & Min & Avg & Max & Min & Avg & Max & \\
\hline EPRI & 18 & 15 & 2 & 1 & 0.163 & 4.25 & 24 & 10 & 68 & 313 & 18 \\
\hline IIR & 36 & 32 & 1 & 3 & 3 & 45.88 & 600 & 21 & 792 & 3,050 & 5 \\
\hline FERC & 8 & 2 & 6 & 0 & 0.4 & 51.71 & 121.5 & 57 & 376 & 966 & 6 \\
\hline Other & 22 & 0 & 9 & 13 & 0.5 & 67.33 & 824 & 10 & 523 & 1,896 & 4 \\
\hline
\end{tabular}

Other data sources: Consultant A - 3 projects, Consultant B - 18 projects, TVA (1941) - 1 project

Figure 11 shows the distribution of NSD projects across different ranges of ICC, capacity, and head. As seen in the figure, the project capacities vary substantially, while most contain hydraulic heads above $200 \mathrm{ft}$. The ICC varies significantly, though most projects are between 1,000 and $10,0002012 \$ / \mathrm{kW}$. Additionally, 9 out of 10 projects which contain ICC above $\$ 10,000$ per kW are planning stage projects, which typically suffer from lower data accuracy and confidence. Figure 12 provides several scatter plots to illustrate the distribution of and relationships between various project parameters, including ICC, capacity, and hydraulic head. Figure $12 \mathrm{c}$ reveals that per kW, ICC generally decreases with capacity, indicating that larger NSD projects may benefit from the economies of scale associated with large hydropower development. Similarly, hydraulic head is negatively correlated with ICC, as shown in Figure $12 d$.

\footnotetext{
${ }^{9}$ Project Development Stage: $\mathrm{P}$ - planning; E - engineering; C - construction
} 

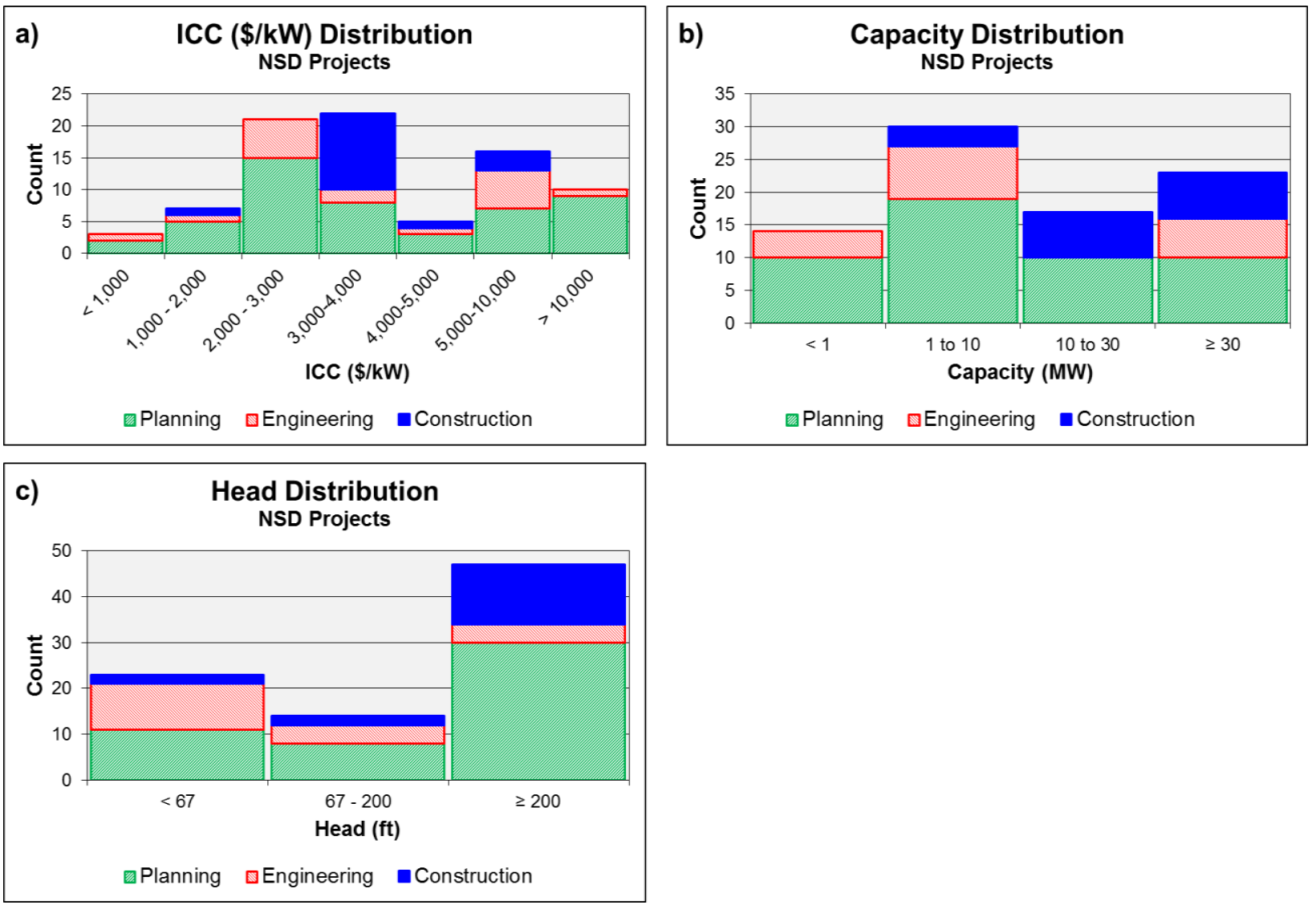

Figure 11. NSD project raw data distribution histograms 

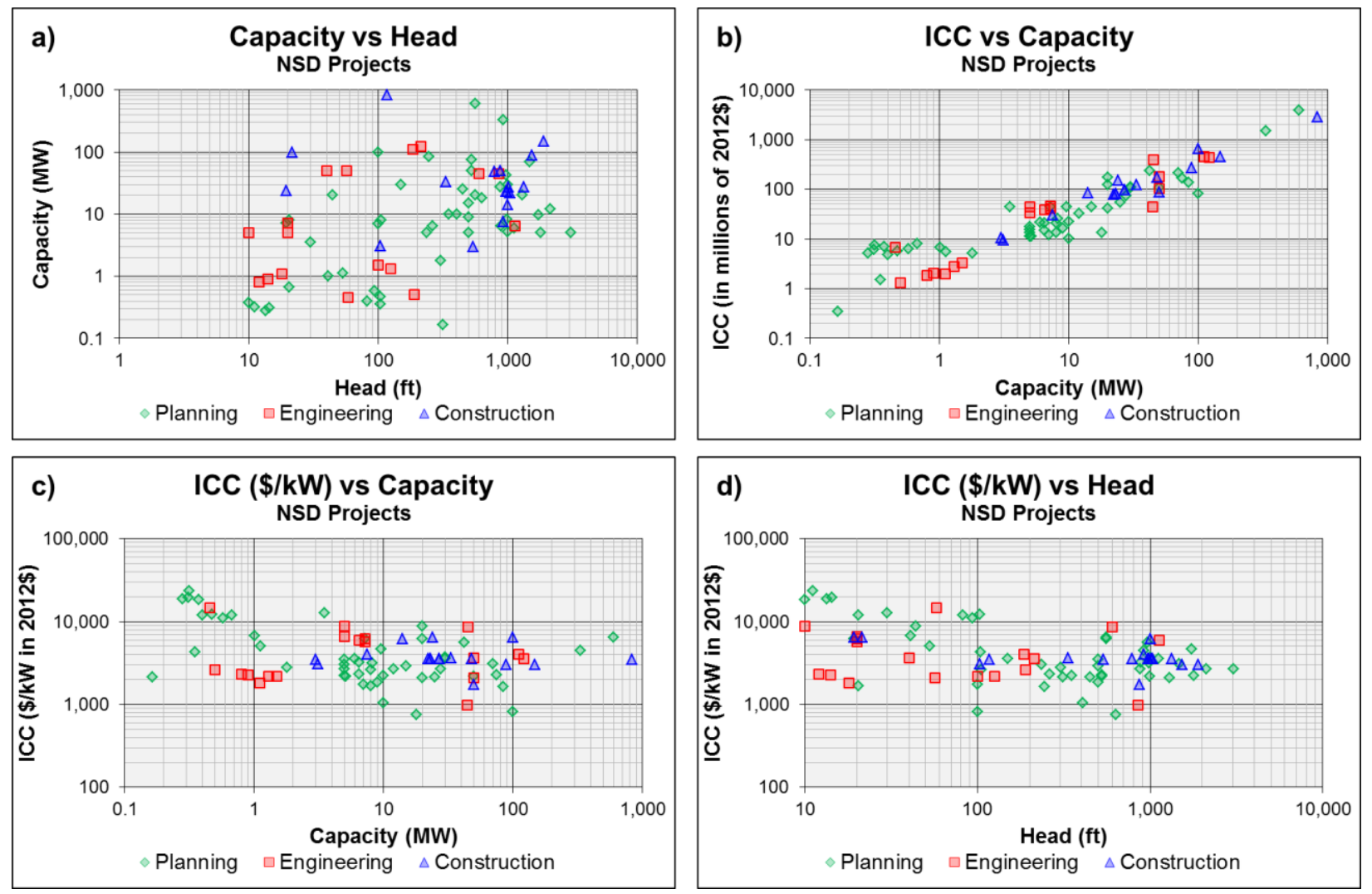

Figure 12. NSD project raw data scatter plots

\section{NSD Model}

After comparing several different models for estimating NSD project costs and assessing confidence scores, it was decided to use the model resulting from the $C$ Dataset. The model results from multivariate regression analysis using construction stage project data (planning and engineering stage data were not included). A total of 17 projects were used in developing this model, and a summary of basic model features is provided in Table 13. Of these 17 projects, 1 is from EPRI, 3 are from IIR, and 13 are from other data sources. The project capacities range from 3 to $824 \mathrm{MW}$ with an average value of $86.09 \mathrm{MW}$, while the hydraulic head range from 19 to $1,896 \mathrm{ft}$ with an average value of $792 \mathrm{ft}$. The recommended ICC model formula is provided below:

$$
\text { ICC }(\text { in } 2012 \$)=8,717,830 P^{0.975} H^{-0.120}
$$

Table 13. NSD recommended model summary

\begin{tabular}{|c|c|c|c|c|c|c|c|}
\hline $\begin{array}{c}\text { Resource } \\
\text { Category }\end{array}$ & $\begin{array}{c}\text { Project } \\
\text { Development } \\
\text { Stage }\end{array}$ & Coefficient & $\begin{array}{c}\text { Capacity } \\
\text { Exponent }\end{array}$ & $\begin{array}{c}\text { Head } \\
\text { Exponent }\end{array}$ & $\mathbf{R}^{2}$ & $\begin{array}{c}\text { Sample } \\
\text { Size }\end{array}$ & $\begin{array}{c}\text { Confidence } \\
\text { Score }\end{array}$ \\
\hline NSD & C & $8,717,830$ & 0.975 & -0.120 & 0.96 & 17 & 10.65 \\
\hline
\end{tabular}


Overall, the $\mathrm{C}$ model provides the highest confidence score of 12.65 , which exceeds the $\mathrm{EC}$ and PEC model scores of 11.97 and 10.19, respectively; this identifies the $\mathrm{C}$ model as the ORNL recommended model for NSDs.

To further validate the model, graphical in-sample validation was performed, with no noticeable bias identified. Figure 13 provides a comparison between the recommended NSD model developed for this report, the alternative NSD model developed from the EC dataset, the INL model (INL, 2003) developed for construction of undeveloped sites, and the actual project costs included in the C Dataset. As seen in Figure 13, for most projects with actual cost data available, the ORNL recommended model generally estimates similar or slightly higher ICC compared to the other models. Compared with actual cost, the ORNL recommended model tends to better approximate project costs than the INL model. In addition, the C model generally overestimates ICC for the lower per kW cost projects and underestimates ICC for the higher per kW cost projects (Figure 13a). As seen in Figure 13b, the recommended model's relative error is largely independent of variation in capacity, though the model displays more bias (both positive and negative) for the lower head projects (Figure 13c). Compared with the EC model, the recommended model provides very similar ICC estimates, though a more noticeable difference is seen for the higher head projects (Figure 13c). As expected, the INL model shows significant bias in estimating ICC for low head projects, as the model provides only simplified univariate estimation based on capacity (Figure 13c). The average actual project ICC for the 17 constructed projects is $\$ 3,885$, while the recommended ORNL and INL models produce average per $\mathrm{kW}$ costs of $\$ 3,882$ and $\$ 3,631$, respectively. As the recommended ORNL model was developed based on regression analysis using the same set of 17 constructed projects, the model necessarily produces the best approximation for the actual cost, and in the future, out-ofsample validation should be performed to further evaluate model accuracy. 


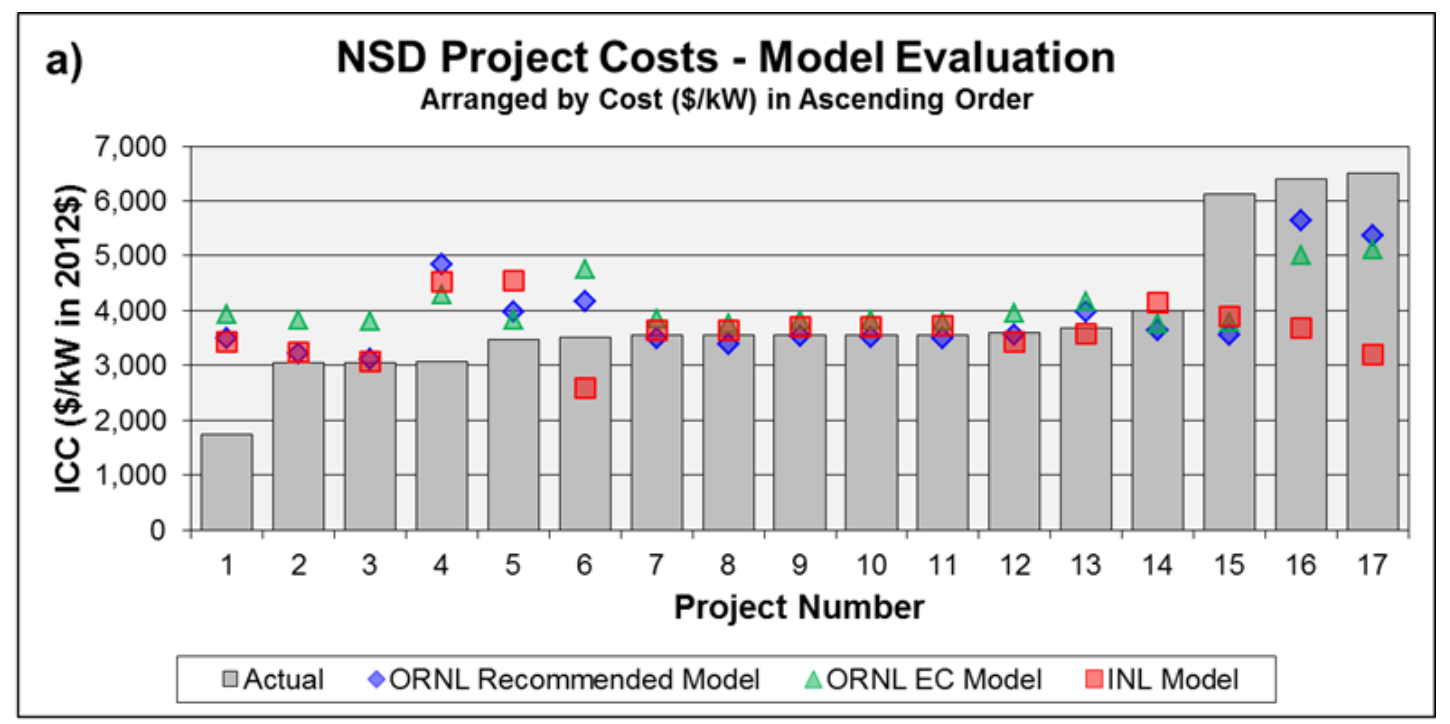

b) NSD Project Costs - Model Evaluation

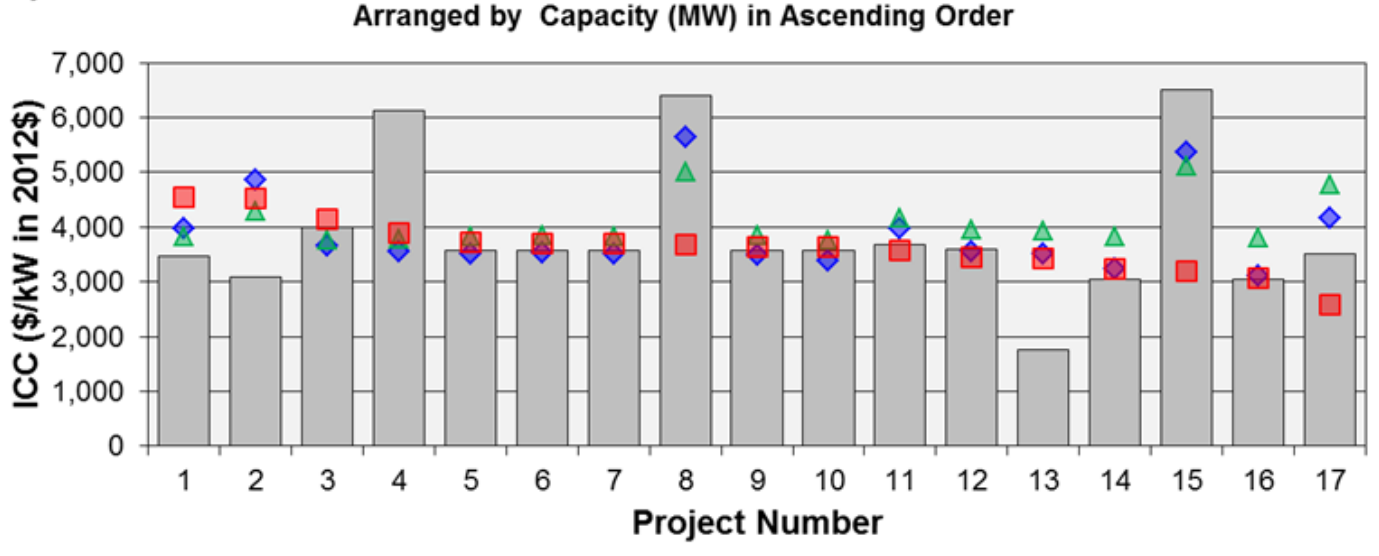

$\square$ Actual $\diamond$ ORNL Recommended Model $\triangle$ ORNL EC Model $\quad$ INL Model

\section{c) NSD Project Costs - Model Evaluation \\ Arranged by Head (ft) in Ascending Order}

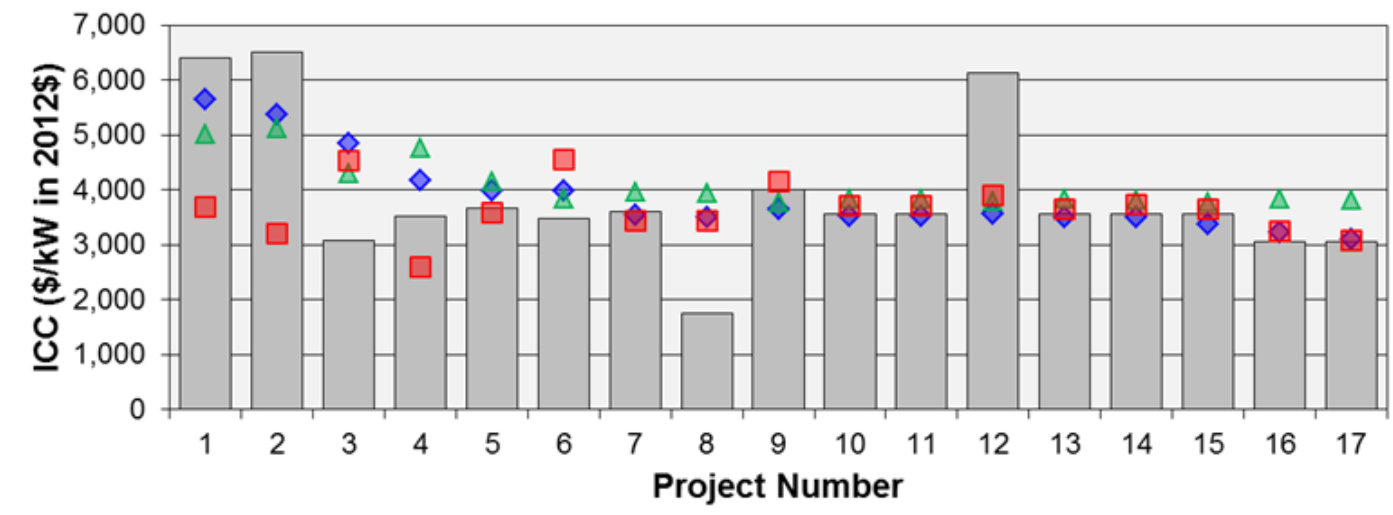

$\square$ Actual $\diamond$ ORNL Recommended Model $\triangle$ ORNL EC Model $\square$ INL Model

Figure 13. Comparison of ORNL and INL model-estimated costs with actual NSD costs 
Although the C model is recommended for NSD costing application, numerous other models were developed and compared during the model development and validation stages. Details on the additional NSD models that were developed and more specific discussions are provided in Appendix A.

\section{Breakdown Costs}

Figure 14 provides average breakdown cost statistics for 3 engineering and 1 construction stage NSD projects. As seen in the chart, the civil works and equipment costs constitute about $80 \%$ of the total NSD project development cost, with civil works representing the primary cost driver. Additional breakdown cost distributions based on hydraulic head and capacity ranges were developed and are provided in Appendix A.

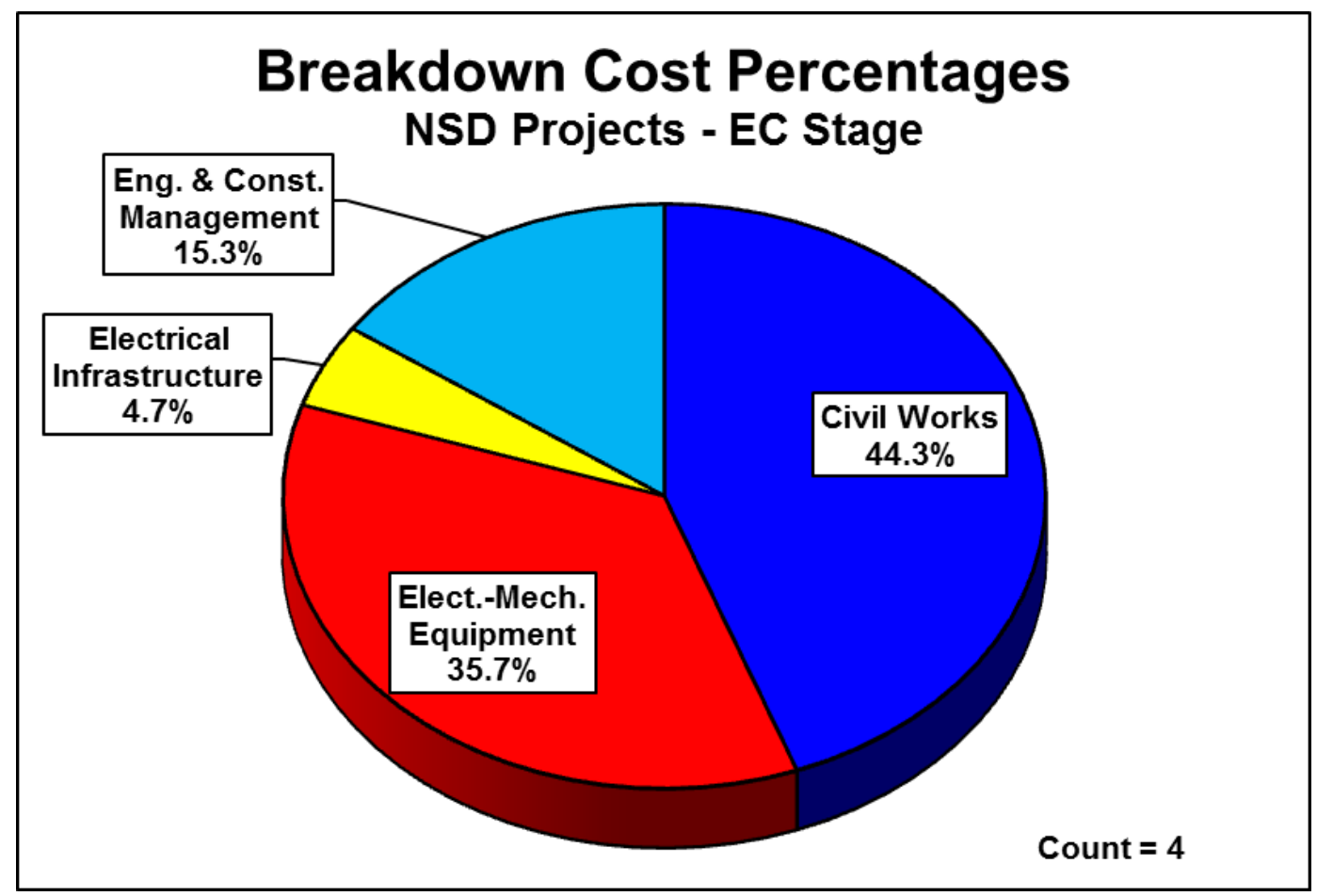

Figure 14. Breakdown cost distribution for NSD projects (EC dataset)

\subsection{Canal/Conduits}

Starting with a total of $102 \mathrm{Canal} /$ Conduit projects, 9 were identified as duplicates. In addition, a $150-M W$ project with project development cost exceeding $\$ 1$ billion was identified as an outlier and subsequently removed. The final Canal/Conduit database comprises information from a total of 92 projects, which were disaggregated into various categories based on project development stage, project capacity, and hydraulic head.

\section{Data Statistics}

Table 14 provides summary statistics for the Canal/Conduit projects by data source. The majority of data were taken from EPRI or Other sources, and the project capacities range from 
$41 \mathrm{~kW}$ to $15 \mathrm{MW}$. About $41 \%$ of the data contain planning stage development costs. In addition, breakdown costs were collected for a total of $77 \mathrm{Canal} /$ Conduit projects.

Table 14. Canal/Conduit project summary statistics ${ }^{10}$

\begin{tabular}{|c|c|c|c|c|c|c|c|c|c|c|c|}
\hline \multirow{2}{*}{$\begin{array}{l}\text { Data } \\
\text { source }\end{array}$} & \multirow{2}{*}{$\begin{array}{c}\text { Project } \\
\text { Count }\end{array}$} & \multicolumn{3}{|c|}{$\begin{array}{l}\text { Development } \\
\text { Stage (count) }\end{array}$} & \multicolumn{3}{|c|}{ Capacity (MW) } & \multicolumn{3}{|c|}{ Head (ft) } & \multirow{2}{*}{$\begin{array}{l}\text { No. of } \\
\text { Projects } \\
\text { with } \\
\text { Breakdown } \\
\text { Cost }\end{array}$} \\
\hline & & $\mathbf{P}$ & E & C & Min & Avg & Max & Min & Avg & Max & \\
\hline EPRI & 36 & 31 & 1 & 4 & 0.1 & 2.378 & 15 & 21 & 176.6 & 904 & 36 \\
\hline IIR & 4 & 3 & 0 & 1 & 1 & 5.645 & 13 & 146 & 689.3 & 1,971 & 1 \\
\hline FERC & 9 & 4 & 5 & 0 & 0.225 & 1.72 & 6.15 & 34 & 211.2 & 445 & 5 \\
\hline Other & 43 & 0 & 36 & 7 & 0.041 & 0.998 & 7.15 & 5 & 212.7 & 1,554 & 35 \\
\hline
\end{tabular}

Other data sources: City of Boulder (2013) - 7 projects, COID (2011) - 5 projects, ETO (2010): 24 projects, NUID (2009) - 4 projects, Butterfield (2011) - 1 project, Consultant C - 1 project, Consultant D - 1 project.

Figure 15 shows the distribution of Canal/Conduit projects across different ranges of ICC, capacity, and head. Most projects are below $10 \mathrm{MW}$, but head varies significantly; the constructed projects generally design heads greater than $200 \mathrm{ft}$. The ICC varies significantly, though many project costs are between $\$ 5,000$ and $\$ 10,000$ per $\mathrm{kW}$ (constructed projects have generally lower ICC). 10 of the projects which contain ICC above $\$ 10,000$ per kW are engineering stage, while the other 3 are planning stage projects. Figure 16 provides several scatter plots with the distribution of various project parameters, including ICC, capacity, and hydraulic head. Figure 16c reveals that per kW, ICC generally decreases with capacity, indicating that larger Canal/Conduit projects benefit from the economies of scale associated with large hydropower development. Similarly, hydraulic head is negatively correlated with ICC, as shown in Figure 16d.

\footnotetext{
${ }^{10}$ Project Development Stage: $\mathrm{P}$ - planning; E - engineering; C - construction
} 
$\mathrm{X}$
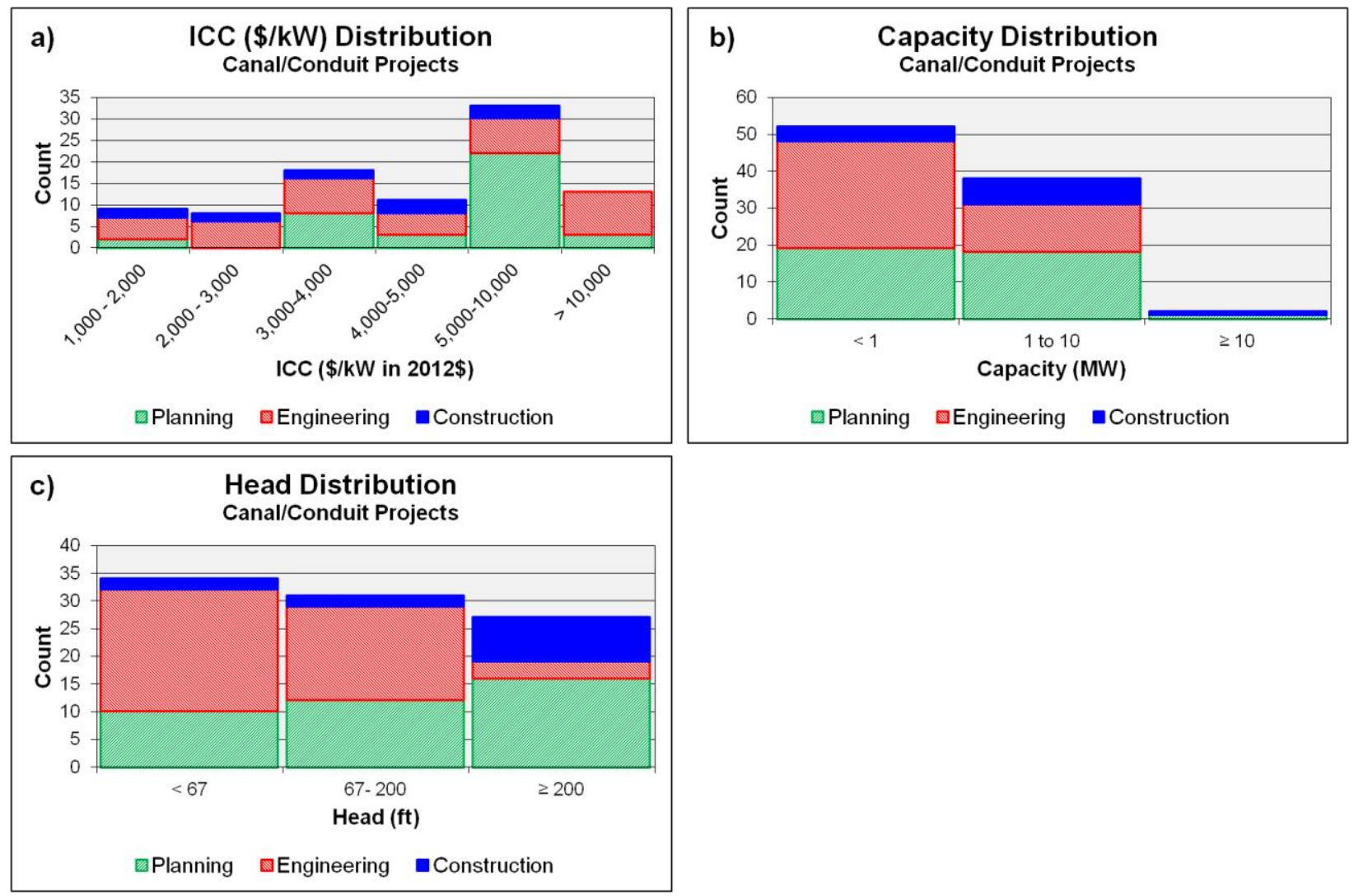

Figure 15. Canal/Conduit project raw data distribution histograms 

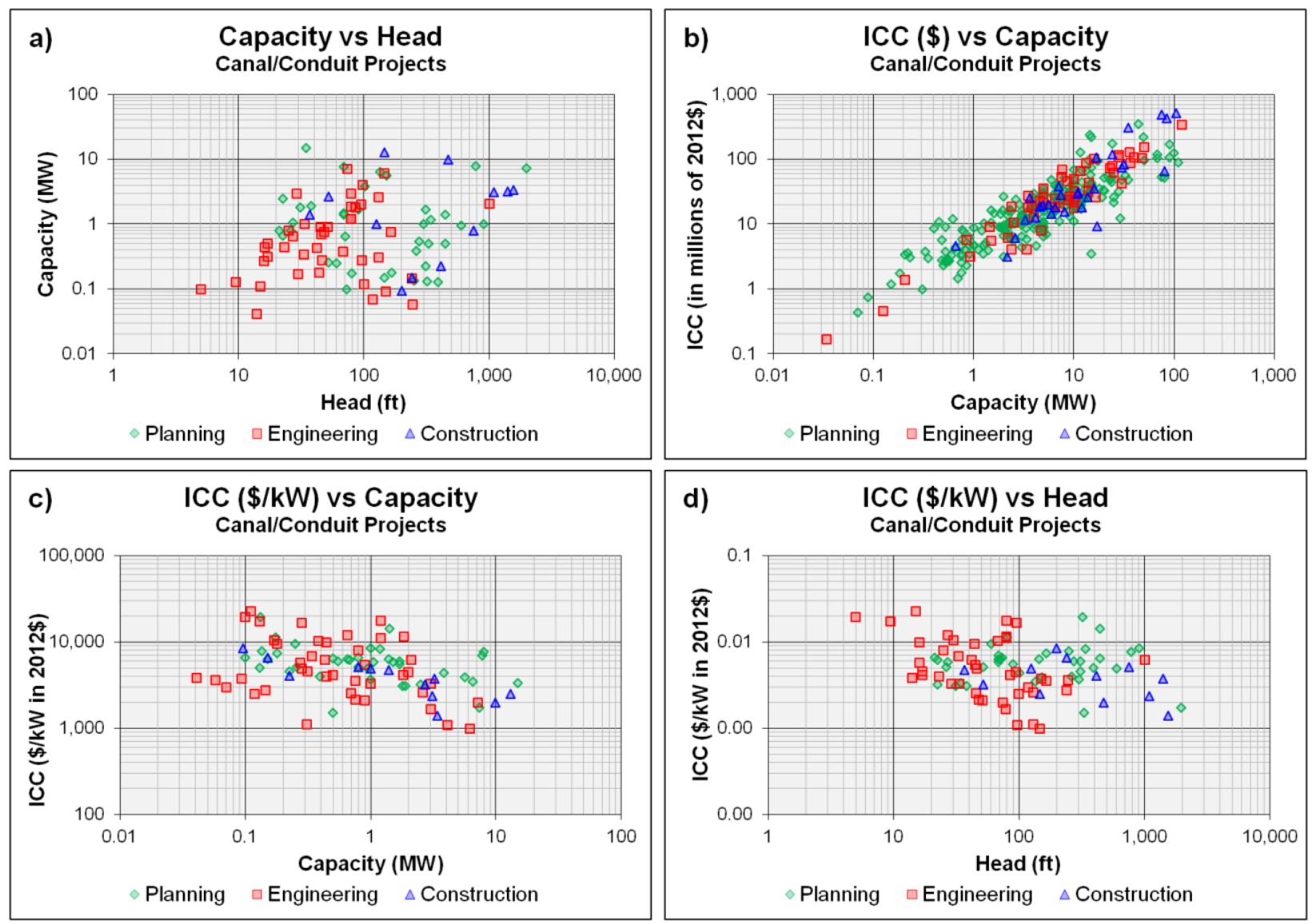

Figure 16. Canal/Conduit project raw data scatter plots

\section{Canal/Conduit Model}

After comparing several different models for estimating Canal/Conduit project costs and assessing confidence scores, it was decided to use the model resulting from the EC Dataset. The selected model results from multivariate regression analysis using engineering and construction stage project data (planning stage data were not included). A total of 54 projects were used in developing this model, and a summary of basic model features is provided in Table 15. Of these 54 projects, 5 are from EPRI, 1 is from IIR, 5 are from FERC, and 43 are from other data sources. The project capacities range from $41 \mathrm{~kW}$ to $13 \mathrm{MW}$ with an average value of $1.6 \mathrm{MW}$, while the hydraulic head range from 5 to $1,554 \mathrm{ft}$ with an average value of 192 $\mathrm{ft}$. The recommended ICC model formula is provided below:

$$
\text { ICC }(\text { in } 2012 \$)=11,277,566 P^{0.819} H^{-0.177}
$$


Table 15. Canal/Conduit recommended model summary

\begin{tabular}{|c|c|c|c|c|c|c|c|}
\hline $\begin{array}{c}\text { Resource } \\
\text { Category }\end{array}$ & $\begin{array}{c}\text { Project } \\
\text { Development } \\
\text { Stage }\end{array}$ & Coefficient & $\begin{array}{c}\text { Capacity } \\
\text { Exponent }\end{array}$ & $\begin{array}{c}\text { Head } \\
\text { Exponent }\end{array}$ & $\mathbf{R}^{2}$ & $\begin{array}{c}\text { Sample } \\
\text { Size }\end{array}$ & $\begin{array}{c}\text { Confidence } \\
\text { Score }\end{array}$ \\
\hline Canal/Conduit & EC & $11,277,566$ & 0.819 & -0.177 & 0.74 & 54 & 11.19 \\
\hline
\end{tabular}

Overall, the EC model provides the highest confidence score of 12.41, which exceeds the $C$ and PEC model scores of 11.18 and 10.06 , respectively. While it would be preferable to rely solely on "C" level data for certainty purposes as was done for NPD and NSD projects, only 12 construction stage were included in the final data set and this limited sample did not yield statistically significant results for head. Further data collection should improve on this gap, allowing for a more refined and certain modeling approach in the future.

Alternative models results are available in Appendix A.

\section{Breakdown Costs}

Figure 17 provides average breakdown cost statistics for 39 engineering and 4 construction stage Canal/Conduit projects. As seen in the chart, the civil works and equipment costs constitute about $77 \%$ of the total Canal/Conduit project development cost, with civil works representing the primary cost driver. Additional breakdown cost distributions based on hydraulic head and capacity ranges were developed and are provided in Appendix A.

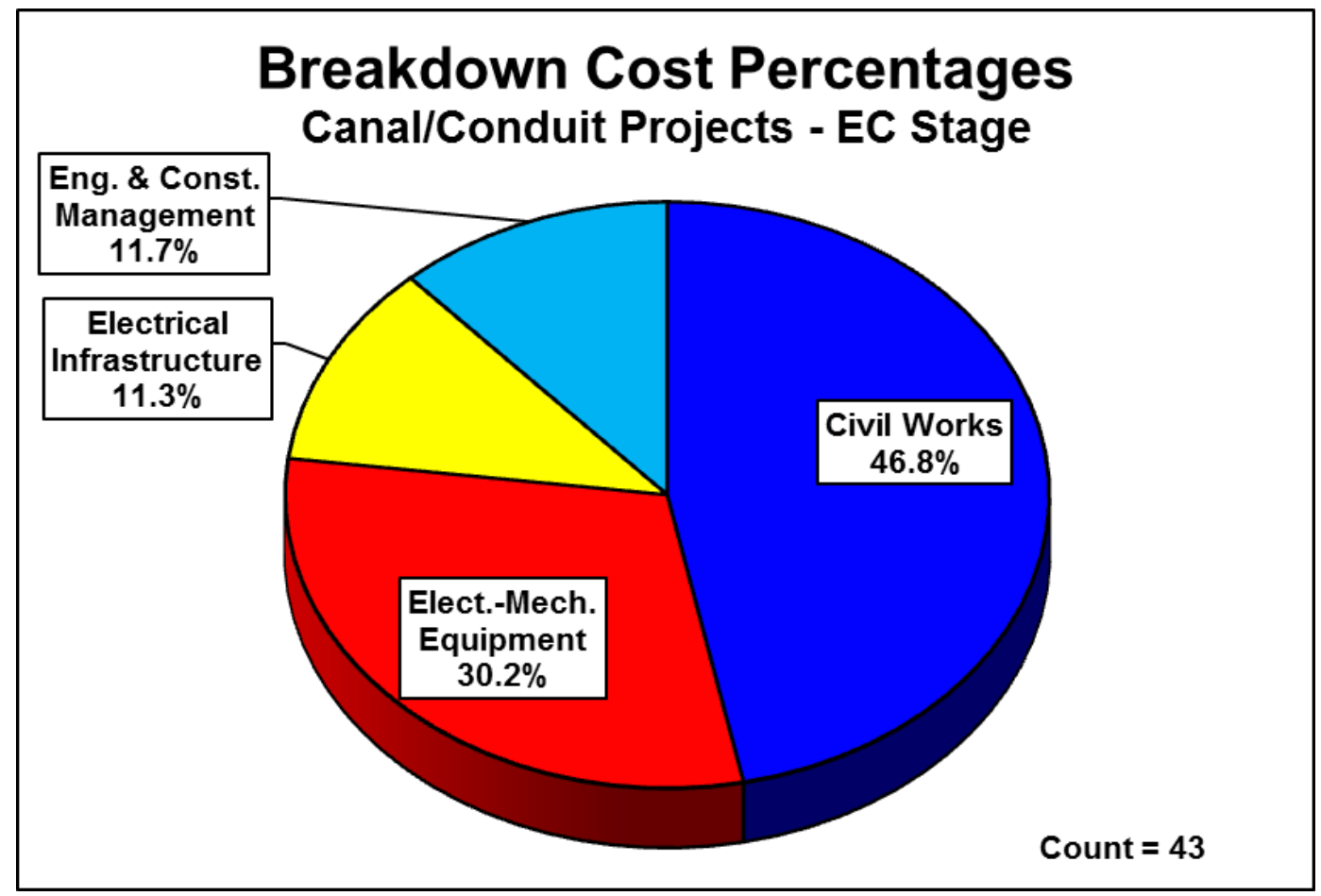

Figure 17. Breakdown cost distribution for Canal/Conduit projects (EC dataset) 


\subsection{Pumped Storage Hydropower (PSH)}

Starting with a total of $135 \mathrm{PSH}$ projects, 30 were identified as duplicates, with another 6 excluded due to a lack of capital cost or hydraulic head information. One project with a cost above $\$ 11,000$ per $\mathrm{kW}$ was removed as an outlier, as was a $760 \mathrm{~kW}$ planning stage project from the DOE-EPRI report. This latter project is over 100 times smaller than the next smallest project (85 MW) and heavily biased model results prior to removal. Additionally, all 14 construction stage data points were removed-these projects were U.S. historical build, and even when escalated using the USBR CCT index, were substantially less expensive on a per kW basis than the remainder of the dataset. This result is consistent with the observation in EPRI (2011) that $\mathrm{PSH}$ costs have appeared to increase at a rate faster than would be expected from general hydropower cost indices.

The final PSH database comprises information from a total of 83 projects. The data were disaggregated into various categories based on project development stage, project capacity, and hydraulic head.

\section{Data Statistics}

Table 16 provides summary statistics for the PSH projects by data source. The majority of data were taken from IIR or FERC data sources, and the project capacities range from $85 \mathrm{MW}$ to $2,000 \mathrm{MW}$. Roughly $88 \%$ of the data contain planning stage development costs. In addition, breakdown costs were collected for a total of $4 \mathrm{PSH}$ projects.

Table 16. PSH project summary statistics ${ }^{11}$

\begin{tabular}{|c|c|c|c|c|c|c|c|c|c|c|c|}
\hline \multirow{2}{*}{$\begin{array}{l}\text { Data } \\
\text { source }\end{array}$} & \multirow{2}{*}{$\begin{array}{c}\text { Project } \\
\text { Count }\end{array}$} & \multicolumn{3}{|c|}{$\begin{array}{l}\text { Development } \\
\text { Stage (count) }\end{array}$} & \multicolumn{3}{|c|}{ Capacity (MW) } & \multicolumn{3}{|c|}{ Head (ft) } & \multirow{2}{*}{$\begin{array}{l}\text { No. of } \\
\text { Projects } \\
\text { with } \\
\text { Breakdown } \\
\text { Cost }\end{array}$} \\
\hline & & $\mathbf{P}$ & E & C & Min & Avg & Max & Min & Avg & Max & \\
\hline IIR & 73 & 73 & 0 & 0 & 85 & 740.1 & 2,000 & 180 & 1,313 & 2,860 & 1 \\
\hline FERC & 7 & 0 & 7 & 0 & 280 & 868.6 & 1,300 & 720 & 1,324 & 1,866 & 3 \\
\hline Other & 3 & 0 & 3 & 0 & 760 & 1,108 & 1,500 & 613 & 894 & 1,200 & 0 \\
\hline
\end{tabular}

Other data sources: USACE and MWH (2009) - 2 projects, USBR (1988) - 1 project.

Figure 18 shows the distribution of PSH projects across different ranges of ICC, capacity, and head. As seen in the figure, the project capacities and heads vary substantially, while most project ICCs range between $\$ 1,000$ and $\$ 2,000$ per $\mathrm{kW}$. All of the projects which with an ICC below $\$ 1,000$ per $\mathrm{kW}$ are planning stage projects. Figure 19 provides several scatter plots to illustrate the distribution of and relationships between various project parameters, including ICC, capacity, and hydraulic head. Figure 19c suggests that per kW, ICC does not decrease noticeably as the project capacity increases, and the hydraulic head is not strongly correlated with ICC (Figure 19d).

\footnotetext{
${ }^{11}$ Project Development Stage: $\mathrm{P}$ - planning; E - engineering; C - construction
} 

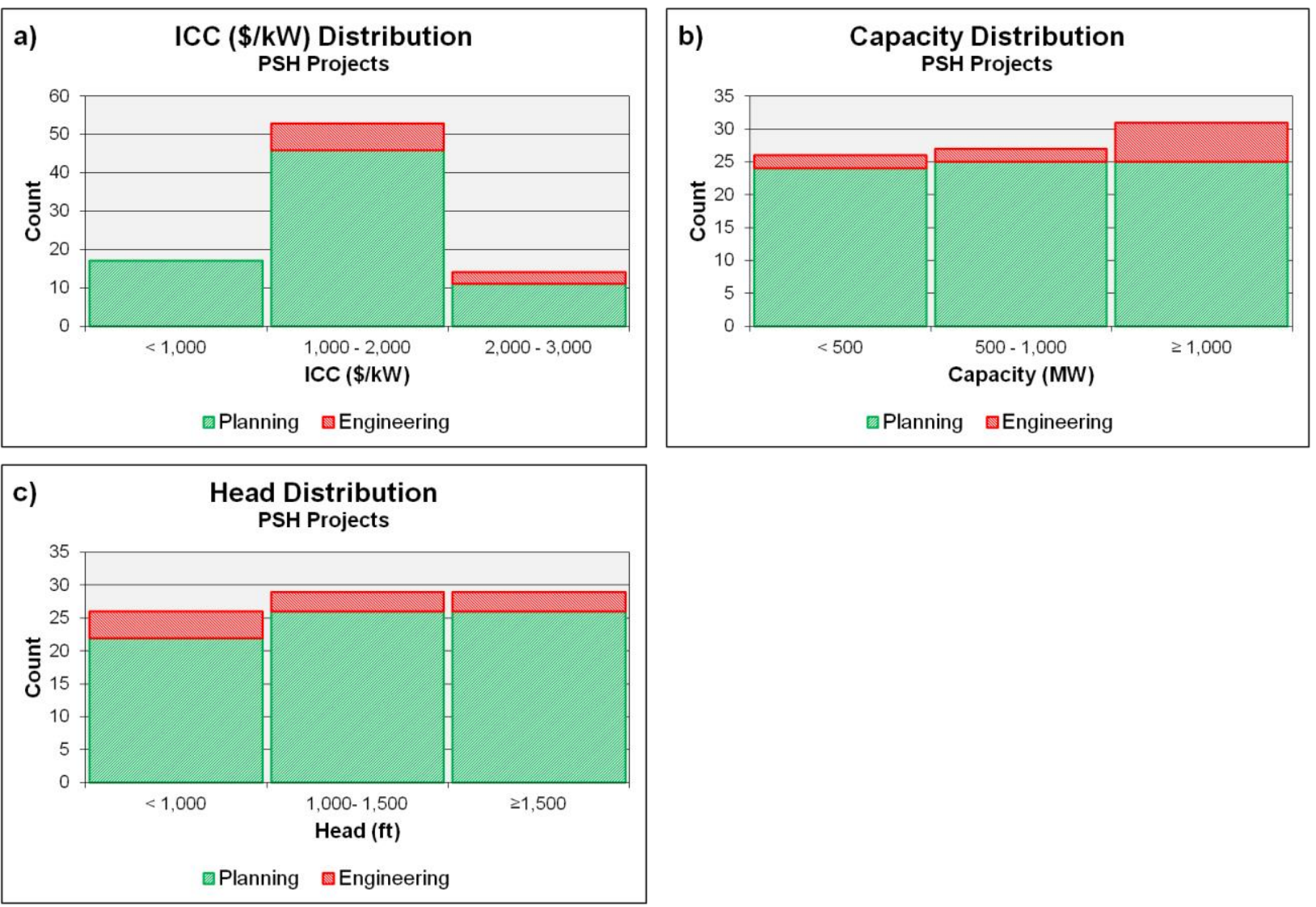

Figure 18. PSH project raw data distribution histograms 

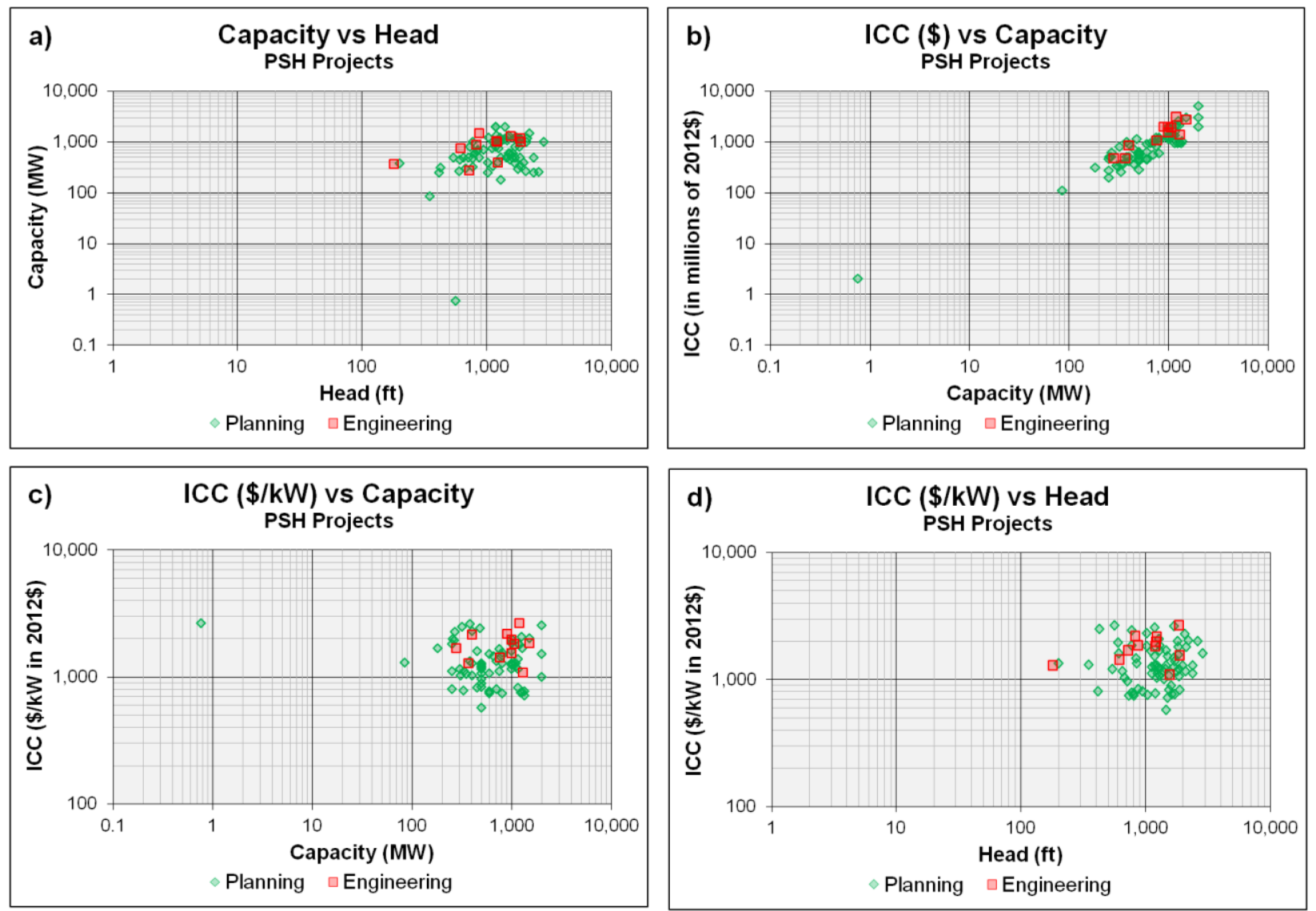

Figure 19. PSH project raw data scatter plots

\section{PSH Model}

After comparing several different models for estimating PSH project costs and assessing confidence scores, it was decided to use a single variable model based on capacity and the Estage subset of the collected data. A total of 84 projects were used in developing this model, and a summary of basic model features is provided in Table 17. Of these 83 projects, 1 is from EPRI, 73 are from IIR, 7 are from FERC, and 3 are from other data sources. The project capacities range from $760 \mathrm{~kW}$ to $2,000 \mathrm{MW}$ with an average value of $755 \mathrm{MW}$. The recommended ICC model formula is provided below:

$$
\text { ICC }(\text { in } 2012 \$)=2,442,817 P^{0.959}
$$

Table 17. PSH recommended model summary

\begin{tabular}{|c|c|c|c|c|c|c|}
\hline $\begin{array}{c}\text { Resource } \\
\text { Category }\end{array}$ & $\begin{array}{c}\text { Project } \\
\text { Development } \\
\text { Stage }\end{array}$ & Coefficient & $\begin{array}{c}\text { Capacity } \\
\text { Exponent }\end{array}$ & $\mathbf{R}^{2}$ & $\begin{array}{c}\text { Sample } \\
\text { Size }\end{array}$ & $\begin{array}{c}\text { Confidence } \\
\text { Score }\end{array}$ \\
\hline PSH & $\mathrm{E}$ & $2,442,817$ & 0.959 & 0.81 & 10 & 10.33 \\
\hline
\end{tabular}


Head was ultimately dropped as a predictive variable after showing virtually no statistical significance when tested against a suite set of project stage, head, and capacity data subsets.

Of the final single variable models, the $E$ model provides the highest confidence score of 10.33 , which exceeds the PE model score of 9.77. Alternative models results are available in Appendix A.

Overall the lack of recent PSH construction in the U.S. is a primary barrier to the development a more reliable costing model. Future iterations of this report will attempt to incorporate international project costs a means of collecting construction stage project data.

\section{Breakdown Costs}

Figure 20 provides average breakdown cost statistics for 3 planning and 1 engineering stage $\mathrm{PSH}$ projects. As seen in the chart, the civil works and equipment costs constitute about $82 \%$ of the total PSH project development cost, with civil works representing the primary cost driver. Additional breakdown cost distributions based on hydraulic head and capacity ranges were developed and are provided in Appendix A.

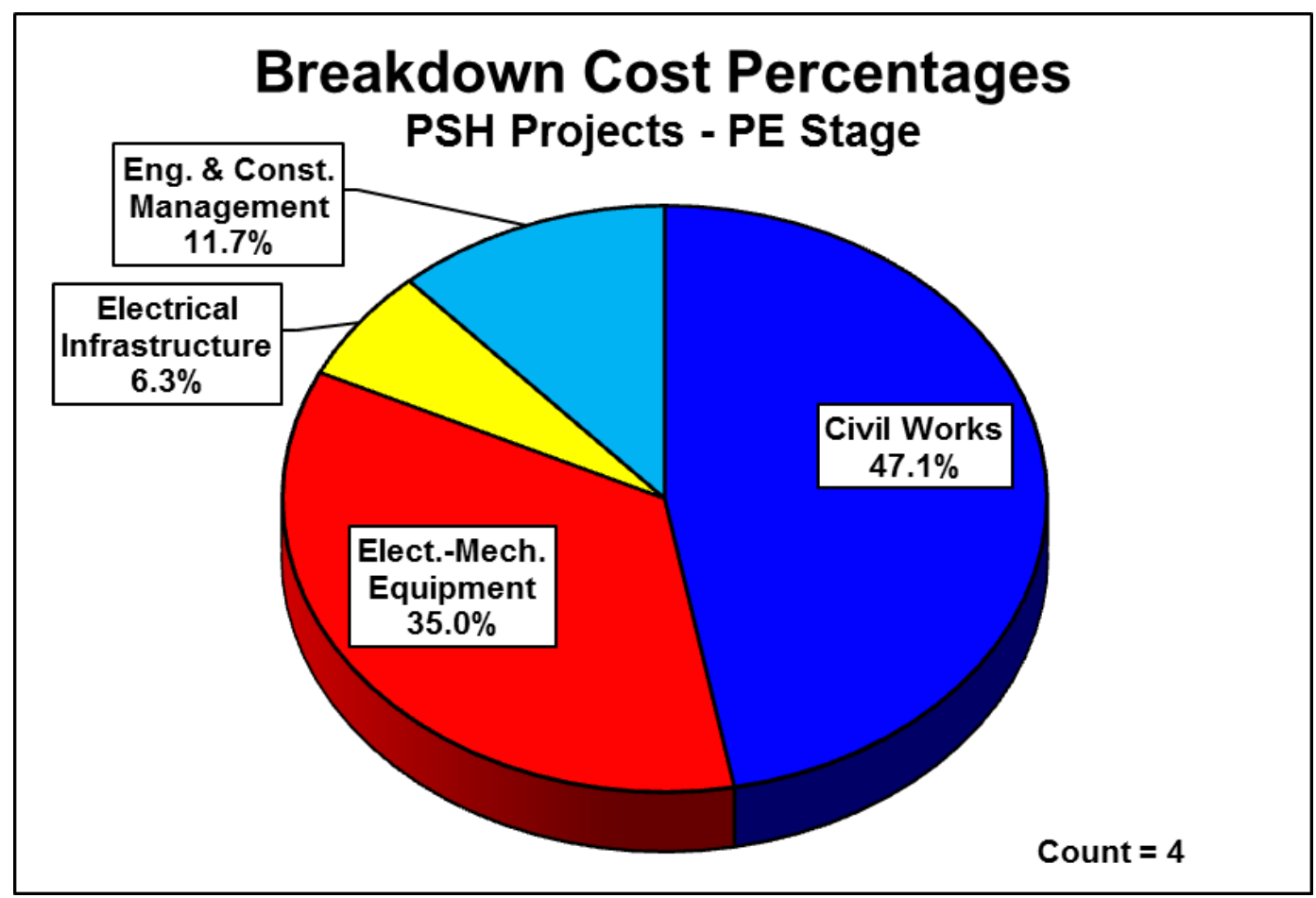

Figure 20. Breakdown cost distribution for PSH projects (PE dataset)

\subsection{Unit Addition}

Most of the Unit Addition projects used for this analysis involve installation of a new turbinegenerator unit in an existing hydropower plant powerhouse with an empty turbine bay or space for expansion. Data for 13 unit addition projects were collected from the IIR database, 9 of 
which are planning stage and 4 are construction stage projects. A total of 13 projects were used in developing this model, and a summary of basic model features is provided in Table 18. The project capacities range from 1.4 to $64 \mathrm{MW}$ with an average value of $12.15 \mathrm{MW}$. The recommended ICC model was developed using all available data, and the resulting formula is provided below ${ }^{12}$ :

$$
\text { ICC }(\text { in } 2012 \$)=3,030,671 P^{0.811}
$$

Table 18. Unit Addition recommended model summary ${ }^{13}$

\begin{tabular}{|c|c|c|c|c|c|c|}
\hline $\begin{array}{c}\text { Resource } \\
\text { Category }\end{array}$ & $\begin{array}{c}\text { Project } \\
\text { Development } \\
\text { Stage }\end{array}$ & Coefficient & $\begin{array}{c}\text { Capacity } \\
\text { Exponent }\end{array}$ & $\mathbf{R}^{2}$ & $\begin{array}{c}\text { Sample } \\
\text { Size }\end{array}$ & $\begin{array}{c}\text { Confidence } \\
\text { Score }\end{array}$ \\
\hline $\begin{array}{c}\text { Unit } \\
\text { Addition }\end{array}$ & PEC & $3,030,671$ & 0.811 & 0.77 & 13 & 8.63 \\
\hline
\end{tabular}

Head was ultimately dropped as a predictive variable after showing no statistical significance when tested against a suite set of project stage, head, and capacity data subsets.

\subsection{Generator Rewind}

Initially, data for 27 Generator Rewind projects were collected from the IIR database. Of these projects, 4 were identified as duplicates and 2 represented similar project activity occurring at the same location (e.g., multiple generators being rewound at the same plant, for which data of only one was retained). The final database for Generator Rewind projects comprises information from 21 projects. The database contains 12 planning stage, 2 engineering stage, and 7 construction stage data. A total of 21 projects were used in developing this model, and a summary of basic model features is provided in Table 19. The project capacities range from 12 to $693 \mathrm{MW}$ with an average value of $120.04 \mathrm{MW}$. The recommended ICC model formula is provided below:

$$
\text { ICC }(\text { in } 2012 \$)=299,461 P^{0.753}
$$

Table 19. Generator Rewind recommended model summary

\begin{tabular}{|c|c|c|c|c|c|c|}
\hline $\begin{array}{c}\text { Resource } \\
\text { Category }\end{array}$ & $\begin{array}{c}\text { Project } \\
\text { Development } \\
\text { Stage }\end{array}$ & Coefficient & $\begin{array}{c}\text { Capacity } \\
\text { Exponent }\end{array}$ & $\mathbf{R}^{2}$ & $\begin{array}{c}\text { Sample } \\
\text { Size }\end{array}$ & $\begin{array}{c}\text { Confidence } \\
\text { Score }\end{array}$ \\
\hline Generator Rewind & PEC & 299,461 & 0.753 & 0.71 & 21 & 9.52 \\
\hline
\end{tabular}

Head was ultimately dropped as a predictive variable after showing virtually no statistical significance when tested against a suite set of project stage, head, and capacity data subsets. Generator RPM may be a better predictor (it is for initial generator costs in INL, 2003)

\footnotetext{
${ }^{12}$ All Unit Addition models use incremental capacity (capacity added by any new units) as an independent variable

${ }^{13}$ Project Development Stage: P - planning; E - engineering; C - construction
} 


\subsection{Results Summary, Discussion, and Application}

The recommended ICC model results for the six different resource categories are provided in Table 20.

Table 20. Baseline cost model results by resource category

\begin{tabular}{|l|l|}
\hline Resource Category & $\begin{array}{l}\text { Cost Model Equation } \\
\text { ICC in 2012\$; } P \text { in MW; } H \text { in ft })\end{array}$ \\
\hline Non-powered Dams & $I C C=12,038,038 P^{0.980} H^{-0.265}$ \\
\hline New Site Development projects & $I C C=8,717,830 P^{0.975} H^{-0.120}$ \\
\hline Canal/Conduit projects & $I C C=11,277,566 P^{0.819} H^{-0.177}$ \\
\hline Pumped Storage Hydropower projects & $I C C=2,442,817 P^{0.959}$ \\
\hline Unit Addition projects & $I C C=3,030,671 P^{0.811}$ \\
\hline Generator Rewind projects & $I C C=299,461 P^{0.753}$ \\
\hline
\end{tabular}

Looking across the resources classes, the most notable was the unexpectedly weak economies of scale associated with project capacity for the powering of non-powered dams and development of new stream-reaches and pumped storage. In the NPD model a project twice the size of another would only be $1.4 \%$ less expensive on $\$$ per $\mathrm{kW}$ basis; this is similar for NSD projects at $1.7 \%$. While the economies of scale in pump storage development are marginally higher-a doubling of capacity reduces costs by $2.9 \%$--the difference in predicated cost between the largest (2000 MW) and smallest ( $85 \mathrm{MW}$ ) projects in the dataset would only be $13.8 \%$. And in many cases, the alternative models explored for each of these three resource classes in Appendix A result in capacity exponents greater than 1, implying, contrary to expectations, diseconomies of scale.

Previous studies have found strong economies of scale specifically in generating equipment (INL, 2003; EPRI, 2011), which is supported by the findings with respect to unit additions and generator rewinds. In light of this, the case may be that while equipment enjoys economy of scale, the unique, site-specific nature of hydropower civil works "averages out" in the end, with per kW costs minimally affected by the size of a project—at least for recent developments.

Additionally, the lack of head dependency for $\mathrm{PSH}$, unit addition, and generator rewind projects is surprising, but the data collected for these resource classes is the most scarce, and least certain (as measured by amount C-stage data) of the 6 resources modeled. The PSH data also mix projects with varying unique site attributes, such as existing upper or lower reservoirs or the presence of other beneficial pre-existing infrastructure.

Ultimately, a model is only as good as the parts used to construct it, and the current versions of the BCM models would benefit substantially from improvements in data availability, cost uniformity, and validation. As described in previous sections, the majority of the cost data available for this effort are from early planning and engineering stage. Ideally, more data would be available to enhance raw cost accuracy, and the confidence scoring methodology attempts to address this concern. In the end, exploring additional avenues for obtaining quality cost data 
is of primary importance to ORNL's cost modeling efforts and may be achieved through significant industry collaboration.

In spite of these limitations and opportunities for improvement, the models developed in this report can be used to assess the relative economics of remaining U.S. hydropower resources. Figure 21 below compares the historical LCOEs introduced in Section 2.4 to the LCOE of NPD (from Hadjerioua et. al., 2012) ${ }^{14}$ and NSD (from Kao et. al., 2014) resources greater than $1 \mathrm{MW}$ in size available in the U.S. when their costs are estimated using the new models ${ }^{15}$. Boxes represent the spread between $25^{\text {th }}$ and $75^{\text {th }}$ percentiles and whiskers are the furthest points within 1.5 times the interquartile range

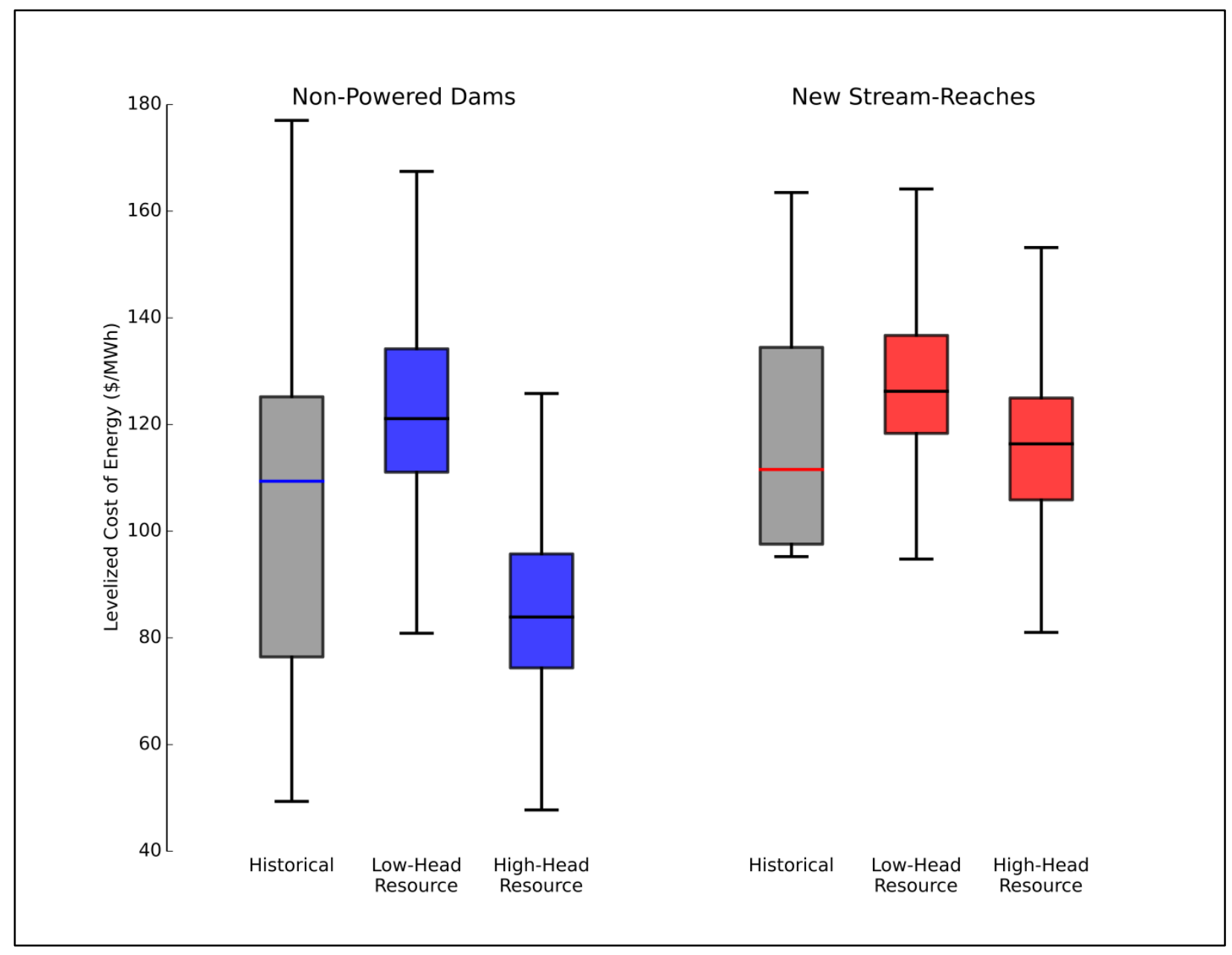

Figure 21 - Application of NSD and NPD BCMs to U.S. undeveloped resources > $1 \mathrm{MW}$

\footnotetext{
${ }^{14}$ The costs in Figure 21 are based on dams identified in Hadjerioua et al. (2012) but the sizing and annual generation forecasts for the hydropower plants have been modified according to the NSD methodology in Kao et. al. (2014).

${ }^{15}$ An availability of factors of $93 \%$ is applied to the resource assessment raw generation potential for consistency with the hydropower assumptions in DOE (2012) and NREL (2012), derived from historical NERC GADS reporting.
} 
The modeled costs for the resource assessments sit within the general bounds of the historical data. Low-head ( $\leq 33 \mathrm{ft}$ ) NPDs range from \$80/MWh to \$170/MWh while their higher-head counterparts ( > 33ft) have LCOEs between $\$ 50 / \mathrm{MWh}$ and $\$ 130 / \mathrm{MWh}$. The NSD resource has a less substantial difference between head classes given the dynamics of the NPD equation and its stronger economies of scale at higher heads. Low-head NSD LCOEs range from $\$ 100$ to $\$ 180 / \mathrm{MWh}$ while higher head reaches range from $\$ 80 / \mathrm{MWh}$ to $\$ 160 / \mathrm{MWh}$. That the extremes of the historical data (particularly the upper extremes) are larger than those in the models is not unexpected. Using parametric prediction is inherently averaging-uncertainties around these predictions as determined in industry practice (AACE, 2014), the data collected from this report (see Section 2.4), and the residuals from the developed models themselves can span from $50 \%$ to $+100 \%$ given the highly site-specific nature of hydropower development.

Similar caveats with respect to financing as those discussed in 2.4 still apply as hydropower development undertaken in recent years or by non-IPP investors has tended to come in at lower cost of energy owing to lower financing rates. The financing assumptions included here are for comparison and illustration purposes only.

\section{Conclusions and Future Work}

This report documented the cost of recent hydropower facilities and the development of relevant, contemporary cost models to aid in evaluating hydropower project economics at a national scale. Using data from a variety of sources, significant data collection, processing, and analysis efforts were conducted across a multitude of different hydropower resources important in today's markets. Given the breadth of data collected, significant care was taken to evaluate and categorize data to ensure objectivity and accuracy.

The recommended models presented in this report provide tools for estimating hydropower development costs across multiple resource categories. The NPD and NSD regression results provide updated cost models that may be married with DOE-sponsored resource assessments which have previously identified potential sites within the U.S. The multivariate cost models that have been developed represent improvements over prior cost models in that they provide cost estimation using multiple project characteristics, were developed with consideration to raw data scope and quality, estimate costs at higher ICC compared to other existing models (which is more in-line with recent trends in hydropower development), and rely on diversified data sources. The cost models developed for Canal/Conduit, PSH, and Other project types benefit from similar distinctions. As this report is intended to be a living document, changes may be made to the recommended cost models based upon future improvements.. With the addition of more diverse data and advance validation, future model iterations should provide improved results.

While the recommended models provide the most robust set of tools for estimating development costs, additional models were developed based on additional variations of project size, head, and development as found in Appendix A. Ideally, these alternative models may prove beneficial to some users, as more narrow definitions could enable more targeted application in select circumstances. 
For all of the models presented, consideration should be made to limitations related to raw data breadth, and attempts have been made to identify such limitations. One key limitation to the models presented in this report is the lack of estimating tools for operations and maintenance, licensing and permitting, and explicit costing of environmental mitigation technologies. Work to fill these gaps is ongoing, but for immediate practical application, historical models such as those developed in INL (2003) are recommended. Additionally, future iterations of the report will include the collection of more robust component cost data that will form the basis of "typical plant" cost profiles demonstrating the distribution of costs within a project. 


\section{References}

AACE (2013). Cost Estimate Classification System - As Applied in Engineering, Procurement, and Construction for the Hydropower Industry. AACE International Recommended Practice No. 69R-12. January, 2013.

BLS (Bureau of Labor Statistics) (2014). Producer Price Indexes, available online at http://www.bls.gov/ppi/, accessed online September 2014.

Butterfield, S. (2011). Presentation on Swalley Irrigation District's Ponderosa Hydroelectric Project during the Deschutes River Basin Site Visit. Swalley Irrigation District, June 1, 2011.

City of Boulder (2013), City of Boulder Hydroelectric Facility Summary Sheet, available at https://www-static.bouldercolorado.gov/docs/Agenda 5 - Hydroelectric Program Update-1201307111316.pdf, accessed online March 2014.

COID (Central Oregon Irrigation District) and ODE (Oregon Department of Energy) (2011). Feasibility Study for Six Central Oregon Irrigation District Potential Hydroelectric Power Generation Sites, Oregon.

Cotchen, D. (2014). PECTRAX - Project Activity Flow Chart, Industrial Info Resources, Written Communications.

DOE (Department of Energy) and, EPRI (Electric Power Research Institute) (1985a). SmallHydropower Development: The Process, Pitfalls, and Experience Volume 1: Feasibility Studies Summary and Analysis, EPRI EM-4036.

DOE (Department of Energy) and EPRI (Electric Power Research Institute) (1985b). SmallHydropower Development: The Process, Pitfalls, and Experience Volume 2: Licensing Activities Summary and Analysis, EPRI EM-4036.

DOE (Department of Energy) and EPRI (Electric Power Research Institute) (1986). SmallHydropower Development: The Process, Pitfalls, and Experience Volume 4: Guide for Developers, EPRI EM-4036.

DOE (Department of Energy) and, EPRI (Electric Power Research Institute) (1987). SmallHydropower Development: The Process, Pitfalls, and Experience Volume 3: Summary and Analysis of Technology Development Projects, EPRI EM-4036.

DOE (Department of Energy) (2012). SunShot Vision Study, NREL Report No. BK-5200-47927, DOE/GO-102012-3037, Washington DC.

DOE (Department of Energy) (2014). Presentation on Recovery Act: Hydroelectric Facility Modernization Project, accessed on February, 2014.

Duan, N. (1983). Smearing Estimate: A Nonparametric retransformation Method, J. of the American Statistical Association, 78(383), 605-610. 
EIA (Energy Information Administration) (2013). Updated Capital Cost Estimates for Utility Scale Electricity Generating Plants, available at

http://www.eia.gov/forecasts/capitalcost/pdf/updated capcost.pdf, accessed online January 2014.

EIA (Energy Information Administration) (2014a). Nonhydro Renewable Now Routinely Surpass Hydropower Generation, available at http://www.eia.gov/todayinenergy/, accessed online August 2014.

EIA (Energy Information Administration) (2014b). Annual Energy Outlook 2014: with Projections to 2040, DOE/EIA-0383(2014). Washington, DC.

ENR (Engineering News Record) (2013). Construction Cost Indices, Engineering News Record, available online at http://enr.construction.com/economics/, accessed online June 2013.

EPRI (2011) Quantifying the Value of Hydropower in the Electric Grid: Plant Cost Elements. EPRI, Palo Alto, CA: 2011. 1023140.

ETO (Energy Trust of Oregon) (2010). Irrigation Water Providers of Oregon: Hydropower Potential and Energy Savings Evaluation, Oregon.

FERC (Federal Energy Regulatory Commission) (2014). Federal Energy Regulatory Commission, available at http://www.ferc.gov/, accessed online January 2014.

FHWA (Federal Highway Administration) (2014). Price Trends for Federal-Aid Highway Construction, available online at http://fhwa.dot.gov, accessed online September 2014.

Gordon, J.L. and Penman, A.C. (1979). Quick Estimating Techniques for Small Hydro Potential, J. of Power Dam Constr., 31 (1979) pp.46-55.

Hadjerioua, B., Wei, Y., and Kao, S.C. (2012). An Assessment of Energy Potential at Nonpowered Dams in the United States, GPO DOE/EE-0711, Wind and Water Power Program, Department of Energy, DC.

IIR (Industrial Info Resources) (2014). PECWeb - A Searchable Database, available at http://www.industrialinfo.com/database , accessed online March 2014.

INL (Idaho National Lab) (2003). Estimation of Economic Parameters of U.S. Hydropower Resources, INEEL/EXT-03-00662.

Kao, S.C., McManamay, R.A., Stewart, K.M., Samu, N.M., Hadjerioua, B., DeNeale, S.T., Yeasmin, D., Pasha, M.F. K., Oubeidillah, A.A., and Smith, B.T. (2014). New Stream-reach Development: A Comprehensive Assessment of Hydropower Energy Potential in the United States, GPO DOE/EE-1063, Wind and Water Power Program, Department of Energy, Washington, DC.

Newman, M.C. (1993). Regression Analysis of Log-transformed Data: Statistical Bias and its Correction, Environmental Toxicology and Chemistry, vol. 12, 1129-1133.

NHAAP (National Hydropower Asset Assessment Program) (2014). Oak Ridge National Laboratory, available at http://nhaap.ornl.gov/, accessed online June 2014. 
NREL (National Renewable Energy Laboratory) (2012). Renewable Electricity Futures Study, 4 vols. NREL/TP-6A20-52409, Golden, Colorado.

NUID (North Unit Irrigation District) (2009). Feasibility Study on Five Potential Hydroelectric Power Generation Locations in the North Unit Irrigation District, Oregon, August 2009.

OpenEl (Open Energy Forum) (2014). Transparent Cost Database, available at http://en.openei.org/wiki/Transparent Cost Database, accessed online August 2014.

Remer, D., Lin, S., Yu, N., and Hsin, K. (2008). An Update on Cost and Scale-up Factors, International Inflation, Int. J. Production Economics, 333-346.

RSMeans (2013). Historical Cost Indices, RSMeans, available online at http://www.rsmeansonline.com, accessed online June 2013.

TVA (Tennessee Valley Authority) (1941). The Guntersville Project: A Comprehensive Report on the Planning, Design, Construction, and Initial Operations of the Guntersville Project, Technical Report No. 4, Knoxville, Tennessee.

USACE (United States Army Corps of Engineers) and MWH (2009). Technical Analysis of Pumped Storage and Integration with Wind Power in the Pacific Northwest. MWH Prepared for U.S. Army Corps of Engineers, Northwest Division, Hydroelectric Design Center.

USACE (United States Army Corps of Engineers) (2013a). Civil Works Construction Cost Index System, Army Corps of Engineers, available online at http://www.nww.usace.army.mil/Missions/CostEngineering.aspx, accessed online June 2013.

USACE (United States Army Corps of Engineers) (2013b). Hydropower Resource Assessment At Non-Powered USACE Sites.

USBR (United States Bureau of Reclamation) (1988). Spring Canyon Pumped Storage Project, Bureau of Reclamation, Lower Colorado Region, Boulder City, Nevada, October 1988.

USBR (United States Bureau of Reclamation) (2013). Hydropower Construction Costs Trends, Bureau of Reclamation, available online at http://www.usbr.gov/pmts/estimate/cost trend.html, accessed online June 2013.

Xiao, X., White, E.P., Hooten, M.B., and Durham, S.L. (2011). On the use of LogTransformation vs. Nonlinear Regression for Analyzing Biological Power Laws, Ecology 92, 1887-1894.

Zhang, Q.F., Smith, B., and Zhang, W. (2012). Small Hydropower Cost Reference Model, ORNL/TM-2012/501. 
Appendix A - Alternative Models, Detailed Comparison, and Validation 


\section{Raw Data}

The previous discussion on raw data illustrates the primary data sources for each resource but provides no comparison on the overall raw data. Figure 22 shows statistical distribution of cost data, providing the number of projects in each resource category, along with the average ICC. As shown in the Figure 22, NSD, NPD, and Canal/Conduit projects tend to have the highest per $\mathrm{kW}$ development costs, while the plant overhaul-related projects tend to be much lower cost. As the plot is shown on a logarithmic scale, the magnitude of cost variation is somewhat skewed. With careful thought, one can see that certain types of projects (NPDs for instance) contain relatively high variability, while others (such as $\mathrm{PSH}$ ) are relatively consistent in terms of cost.

A total of 600 projects were used for the final analysis. 575 out of 600 projects were located in the U.S. with the remaining 25 projects from Non-US. As shown in the Figure 23 map, the United States was divided into six market regions: Southwest, Midwest, Rocky Mountains, Pacific, Southeast, and Northeast.

For each of the resource categories, Appendix A provides information on regional cost data distributions, alternative models, in-sample model validation, and breakdown cost distributions. The regional raw cost data distribution diagram provides statistics on the U.S. (six regions) and Non-US data. However, the discussion on raw cost data are focused on the U.S. regions only. Alternative models which were developed based on project development stage, installed capacity and hydraulic head ranges are documented. The raw costs vs. model estimated costs are compared using in-sample validation plots. The breakdown costs are categorized into 4 different components, including=1) Civil Works 2) Electro Mechanical Equipment 3) Electrical infrastructure, and 4) Engineering \& Construction Management. Only those projects having cost data for all four components are included in the analysis. 


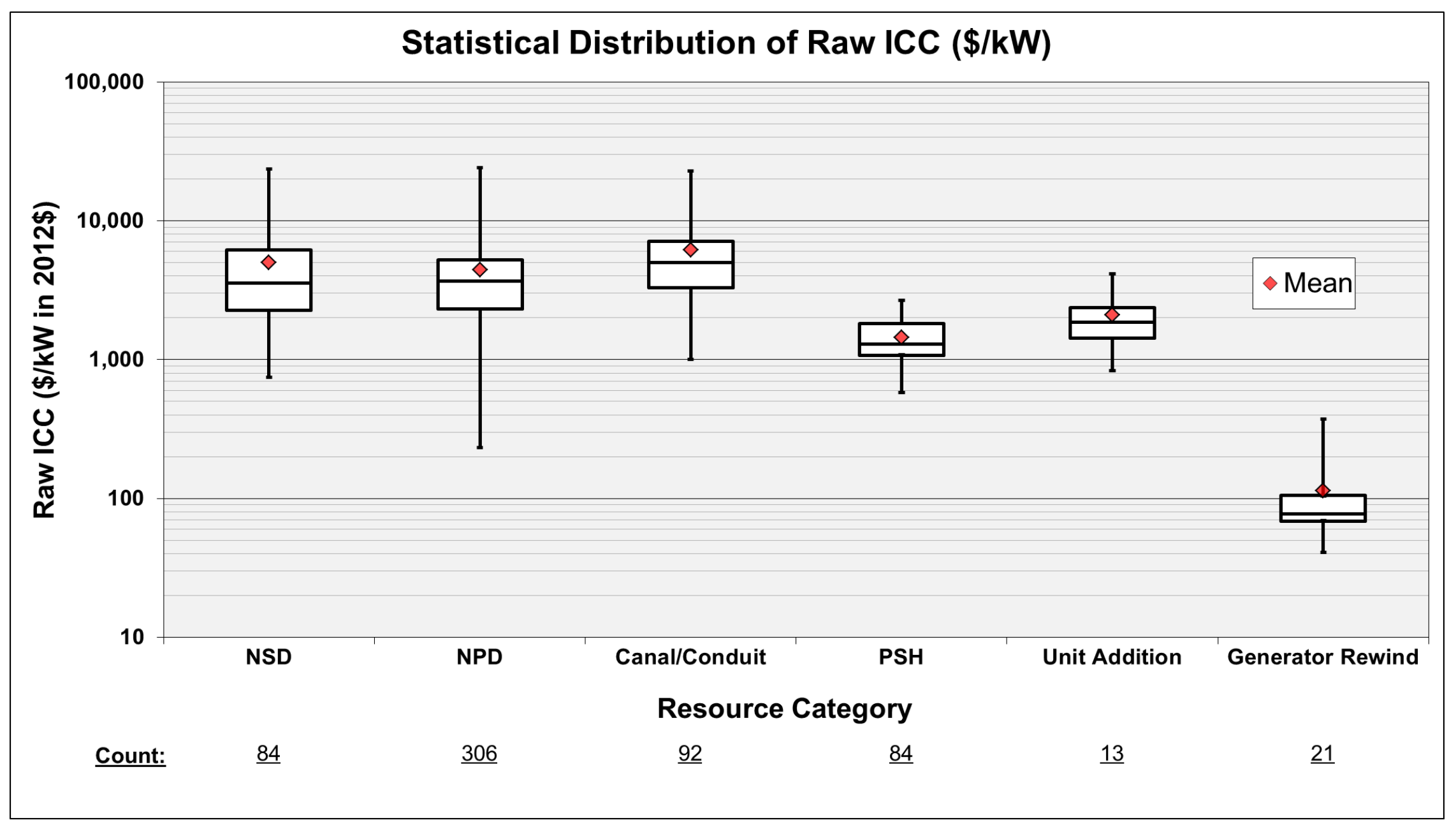

Figure 22. Raw data statistics 


\section{U.S. Hydropower Market Regions}

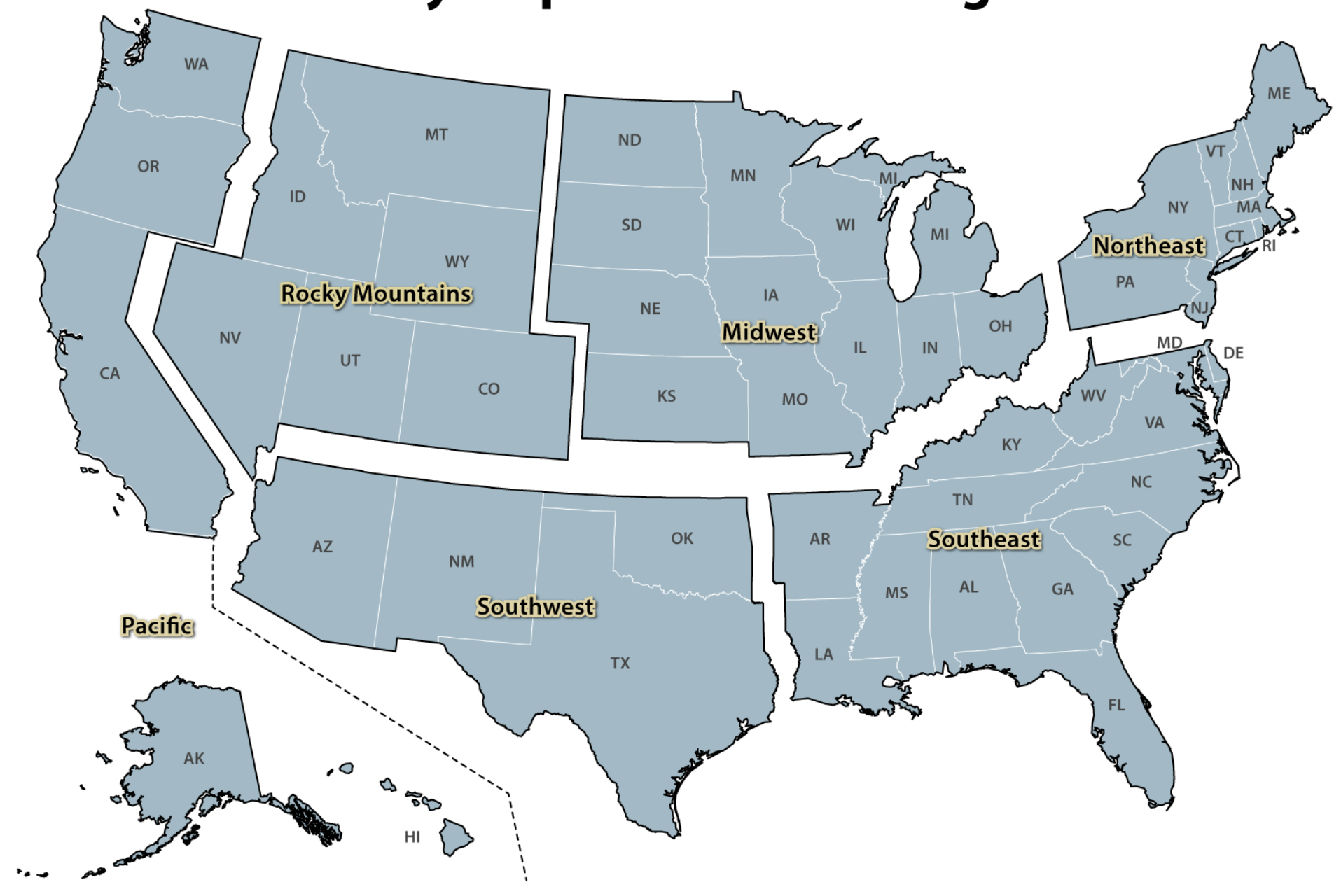

Figure 23. Regional classification of the United States 


\section{Non-powered Dams}

The previous discussion on NPD data illustrates the primary data sources but provides no details on the project locations included. As shown in the Figure 23 map, the United States was divided into six market regions: Southwest, Midwest, Rocky Mountains, Pacific, Southeast, and Northeast. Figure 24 shows regional distribution of cost data, providing the number of NPD projects in each region, along with the average ICC, capacity, and hydraulic head. A total of 306 NPDs projects were used for the final analysis. 302 out of 306 projects were located in the U.S. with the remaining 4 projects from Non-US. A minimum of 10 projects were located in the Southwest region, while a maximum of 79 projects were located in the Northeast region. Cumulative regional project capacity ranges from $84 \mathrm{MW}$ in the Southwest to $1,565 \mathrm{MW}$ in the Southeast, while regionally-averaged hydraulic head ranges from $27 \mathrm{ft}$ in the Midwest to $254 \mathrm{ft}$ in the Rocky Mountains region. The ICC varies significantly among the regions, with a minimum of $2,788 \$ / \mathrm{kW}$ in the Southwest and a maximum of $5,725 \$ / \mathrm{kW}$ in the Midwest.

As described in Section 4 of this report, the recommended cost model for NPD ICC estimation is the $C$ Dataset model, which used construction stage project data only. However, numerous other models were evaluated as a part of the BCM development efforts. Table 21 provides various statistics for multiple models that were developed. Correlation and regression results are provided to help inform users of the relative benefits and limitations of using alternative NPD models.

Figure 25 shows multiple in-sample validation plots that demonstrate the results for the PEC, EC, and C models for NPDs. The top plots (Figure 25a-c) show modeled vs. raw ICC for each model. The diagonal 1:1 line represents where the modeled and raw costs are equal and is the ideal case for estimating cost using a model. The bottom plots (Figure $25 \mathrm{~d}$-f) show raw and modeled cost data relative to the combined capacity and head power forms. The blue points represent raw cost, while the black diagonal line represents modeled ICC. The red diagonal lines represent the upper and lower 95\% confidence interval ICC. Ideally, all raw data would lie within the confidence interval, though sample size, correlation, and other factors influence the results.

Figure 26 shows NPD breakdown cost distributions across a variety of different capacity ranges. These breakdown costs are categorized into 4 different groups according to the major sources of development cost. As seen in the plots, the major cost drivers for NPDs are civil works and equipment costs. For the smaller projects (below $1 \mathrm{MW}$ ), equipment costs are significantly high (nearly $50 \%$ on average). Though Civil Works constitute an incrementally higher portion of total ICC for projects above $1 \mathrm{MW}$, equipment cost remains higher than the Civil Works for all capacity ranges evaluated. For the larger projects (above $30 \mathrm{MW}$ ), engineering and construction management costs are relatively minor, as the overall scope involved in such activities remains similar between large and small projects. Since consideration should be given to the number of projects from which these plots were made, the project count is provided in the lower corner of each plot. 
Similarly, Figure 27 shows breakdown cost distributions for NPDs across various head ranges. The low head projects (below $30 \mathrm{ft}$ ) demonstrate high equipment cost contribution. High head projects, on the other hand, show similar equipment and civil works cost percentages. 


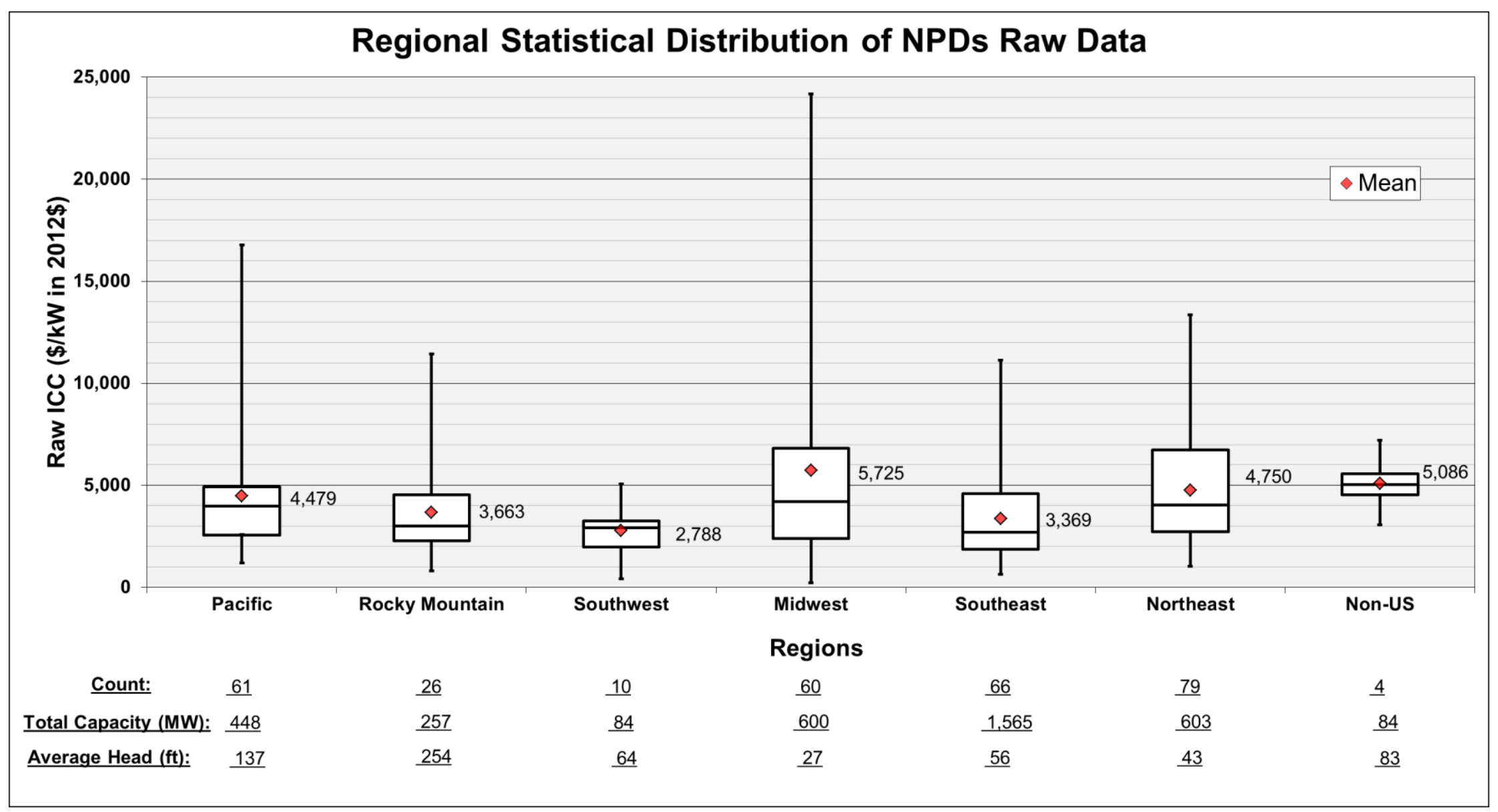

Figure 24. Regional distribution of Non Powered Dams (NPDs) cost data 
Table 21. Summary regression results for NPDs

\begin{tabular}{|c|c|c|c|c|c|c|c|c|c|c|c|c|c|c|}
\hline \multirow{2}{*}{ Category } & \multirow{2}{*}{$\begin{array}{l}\text { Model Estimated Cost } \\
\text { (in 2012\$) }\end{array}$} & \multirow{2}{*}{$\mathbf{R}^{2}$} & \multirow{2}{*}{$\begin{array}{l}\text { Sample } \\
\text { Size }\end{array}$} & \multirow{2}{*}{$\begin{array}{l}\text { Confidence } \\
\text { Score }\end{array}$} & \multirow{2}{*}{$\begin{array}{l}\text { Bias } \\
\text { Correction }\end{array}$} & \multirow{2}{*}{$\begin{array}{c}\text { Coefficien } \\
\quad \text { l log } \\
\text { (Intercept) }\end{array}$} & \multirow{2}{*}{$\begin{array}{c}\text { Coefficien } \\
\text { t log } \\
\text { (Capacity) }\end{array}$} & \multirow{2}{*}{$\begin{array}{c}\text { Coefficient } \\
\text { log } \\
\text { (Head) }\end{array}$} & \multicolumn{3}{|c|}{$t$ - statistic value } & \multicolumn{3}{|c|}{$p$-value } \\
\hline & & & & & & & & & $\begin{array}{c}\text { Log } \\
\text { (Constant) }\end{array}$ & $\log (\mathrm{P})$ & $\log (\mathrm{H})$ & $\begin{array}{c}\text { Log } \\
\text { (Constant) }\end{array}$ & $\log (\mathrm{P})$ & $\log (\mathrm{H})$ \\
\hline \multicolumn{15}{|c|}{ Modeling Results by Project Development Stage } \\
\hline All data (PEC) & $9,723,751 \mathrm{P}^{0.77} \mathrm{H}^{-0.13}$ & 0.80 & 306 & 9.18 & 1.16 & 15.94 & 0.77 & -0.13 & 129.69 & 34.9 & -4.1 & 1.65E-267 & 3.9E-108 & $5.5 \mathrm{E}-05$ \\
\hline $\begin{array}{c}\text { Eng. \& } \\
\text { Construction }\end{array}$ & $8,279,590 \mathrm{P}^{0.94} \mathrm{H}^{-0.16}$ & 0.90 & 80 & 12.35 & 1.09 & 15.84 & 0.94 & -0.16 & 79.41 & 26.9 & -3.3 & $1.25 \mathrm{E}-75$ & $7.1 \mathrm{E}-41$ & $1.6 \mathrm{E}-03$ \\
\hline Construction & $12,038,038 \mathrm{P}^{0.98} \mathrm{H}^{-0.27}$ & 0.92 & 28 & 13.34 & 1.06 & 16.24 & 0.98 & -0.27 & 50.50 & 16.7 & -4.0 & $1.10 \mathrm{E}-26$ & $4.4 \mathrm{E}-15$ & 4.6E-04 \\
\hline \multicolumn{15}{|c|}{ Modeling Results by Project Capacity (MW) } \\
\hline$<1 \mathrm{MW}$ & $16,806,429 \mathrm{P}^{0.95} \mathrm{H}^{-0.23}$ & 0.64 & 44 & & 1.14 & 16.50 & 0.95 & -0.23 & 50.68 & 8.5 & -3.0 & $1.31 \mathrm{E}-38$ & $1.6 \mathrm{E}-10$ & 4.6E-03 \\
\hline 1 to $<10 \mathrm{MW}$ & $10,461,047 \mathrm{P}^{0.76} \mathrm{H}^{-0.15}$ & 0.51 & 157 & & 1.10 & 16.07 & 0.76 & -0.15 & 93.42 & 12.1 & -4.1 & 1.65E-137 & $4.9 \mathrm{E}-24$ & $6.0 \mathrm{E}-05$ \\
\hline 10 to $<30 \mathrm{MW}$ & $7,688,334 \mathrm{P}^{0.71} \mathrm{H}^{-0.01}$ & 0.10 & 77 & & 1.26 & 15.63 & 0.71 & -0.01 & 23.36 & 2.9 & -0.1 & $1.65 \mathrm{E}-137$ & $4.5 \mathrm{E}-03$ & $8.9 \mathrm{E}-01$ \\
\hline$\geq 30 \mathrm{MW}$ & $33,301,325 \mathrm{P}^{0.64} \mathrm{H}^{-0.29}$ & 0.30 & 28 & & 1.19 & 17.15 & 0.64 & -0.29 & 14.25 & 2.4 & -2.1 & $6.91 \mathrm{E}-36$ & $2.3 \mathrm{E}-02$ & $4.6 \mathrm{E}-02$ \\
\hline \multicolumn{15}{|c|}{ Modeling Results by Head (ft) } \\
\hline$<30 \mathrm{ft}$ & $7,779,007 \mathrm{P}^{0.76} \mathrm{H}^{-0.02}$ & 0.81 & 121 & & 1.18 & 15.70 & 0.76 & -0.02 & 39.41 & 21.5 & -0.1 & $9.28 \mathrm{E}-70$ & $1.5 \mathrm{E}-42$ & $9.1 \mathrm{E}-01$ \\
\hline 30 to $<67 \mathrm{ft}$ & $9,673,784 \mathrm{P}^{0.79} \mathrm{H}^{-0.16}$ & 0.81 & 83 & & 1.16 & 15.94 & 0.79 & -0.16 & 16.81 & 18.3 & -0.6 & $5.52 E-28$ & $2.5 \mathrm{E}-30$ & $5.2 \mathrm{E}-01$ \\
\hline$<67 \mathrm{ft}$ & $12,680,066 \mathrm{P}^{0.78} \mathrm{H}^{-0.22}$ & 0.81 & 204 & & 1.17 & 16.20 & 0.78 & -0.22 & 72.30 & 28.9 & -3.1 & $7.80 \mathrm{E}-146$ & $1.5 \mathrm{E}-73$ & $2.2 \mathrm{E}-03$ \\
\hline $67 \mathrm{to}<200 \mathrm{ft}$ & $11,071,568 \mathrm{P}^{0.7} \mathrm{H}^{-0.13}$ & 0.75 & 79 & & 1.14 & 16.09 & 0.70 & -0.13 & 20.28 & 15.0 & -0.8 & $2.18 \mathrm{E}-32$ & $2.4 \mathrm{E}-24$ & 4.3E-01 \\
\hline$\geq 200 \mathrm{ft}$ & $9,010,765 \mathrm{P}^{0.85} \mathrm{H}^{-0.14}$ & 0.90 & 23 & & 1.07 & 15.94 & 0.85 & -0.14 & 16.20 & 12.2 & -0.9 & $5.75 \mathrm{E}-13$ & $9.6 \mathrm{E}-11$ & 4.0E-01 \\
\hline
\end{tabular}

Note: the model estimated cost includes bias correction. 

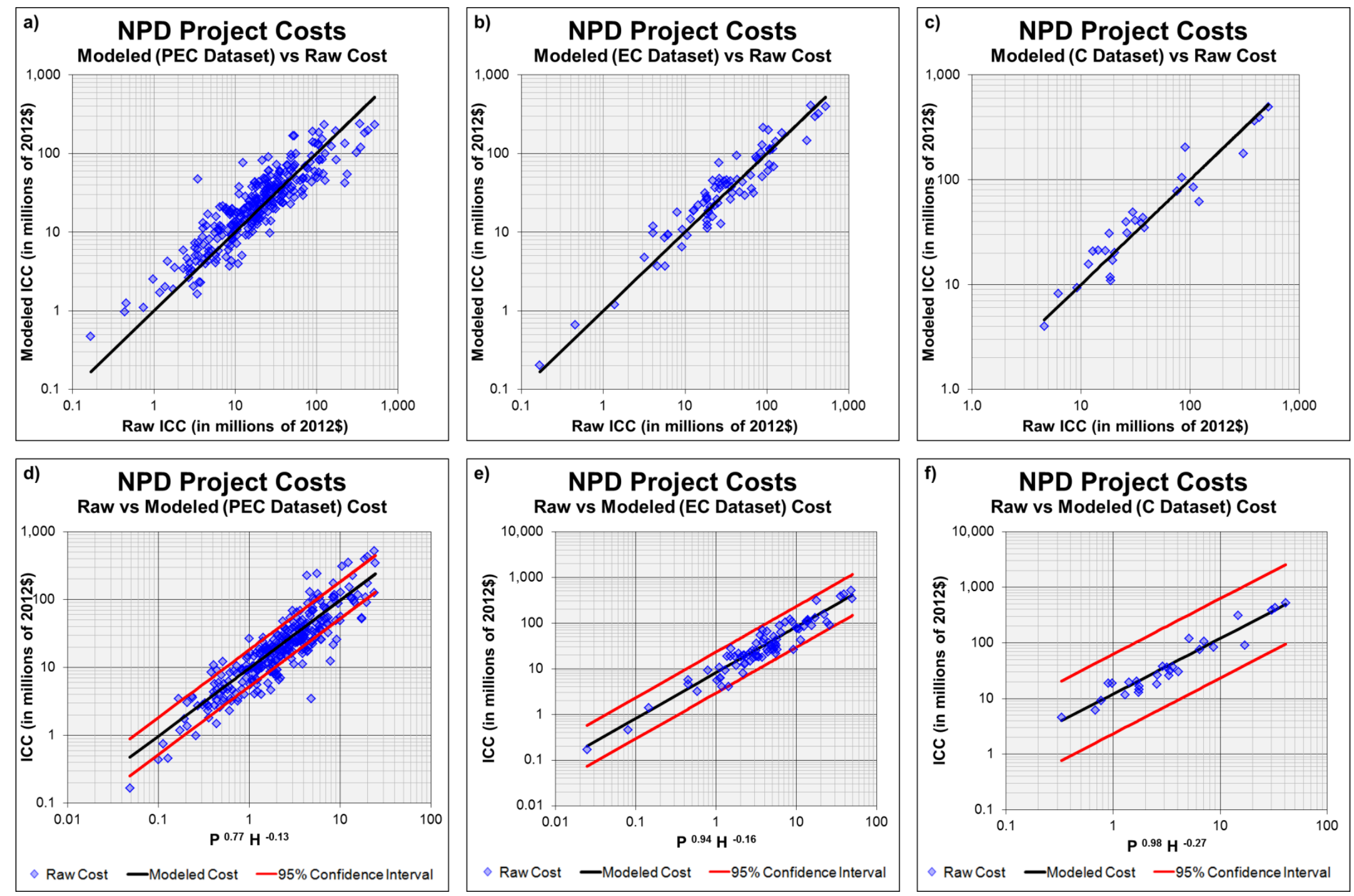

Figure 25. NPD in-sample model validation 

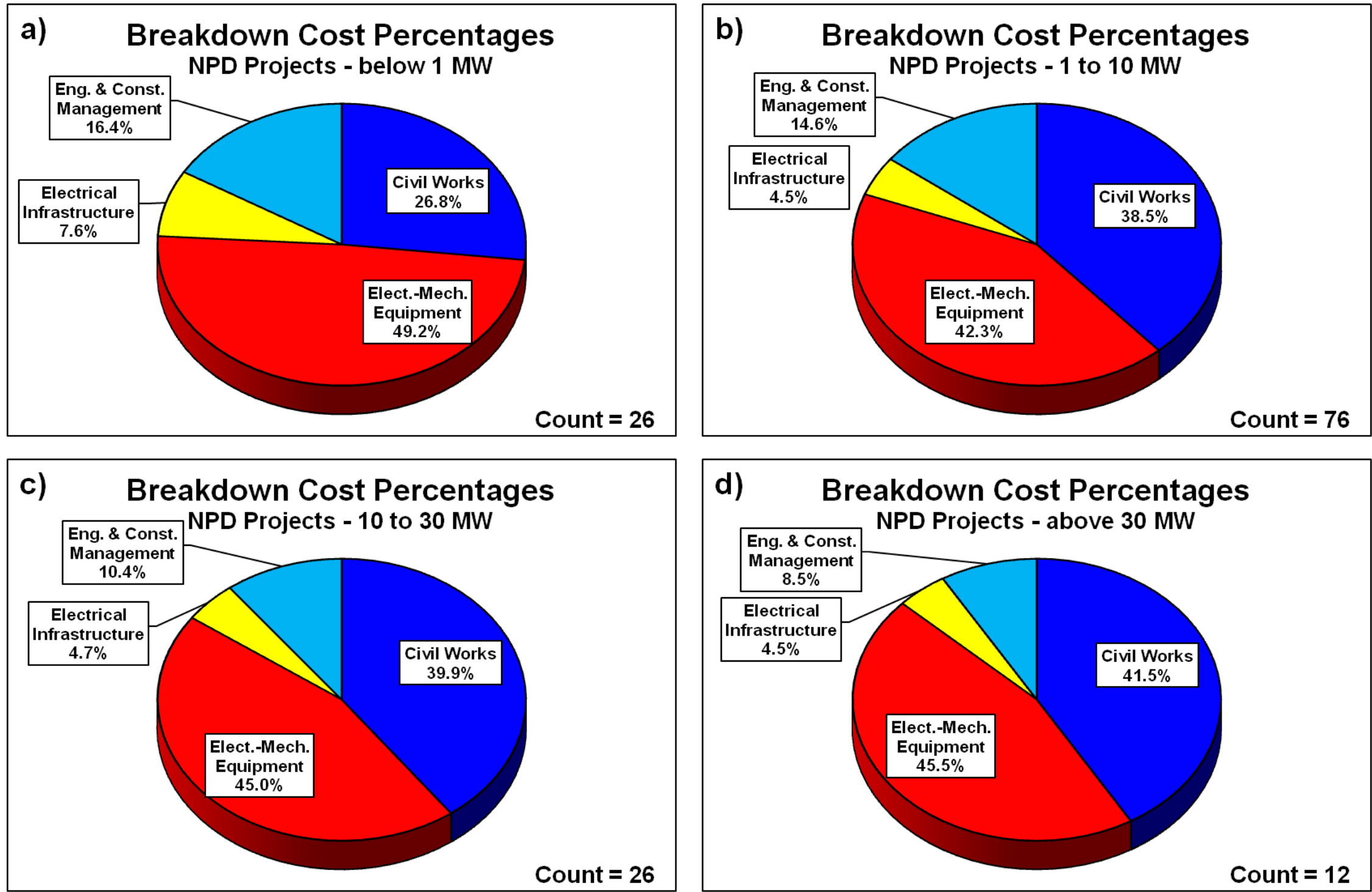

Figure 26. NPD breakdown cost distributions by Capacity range 

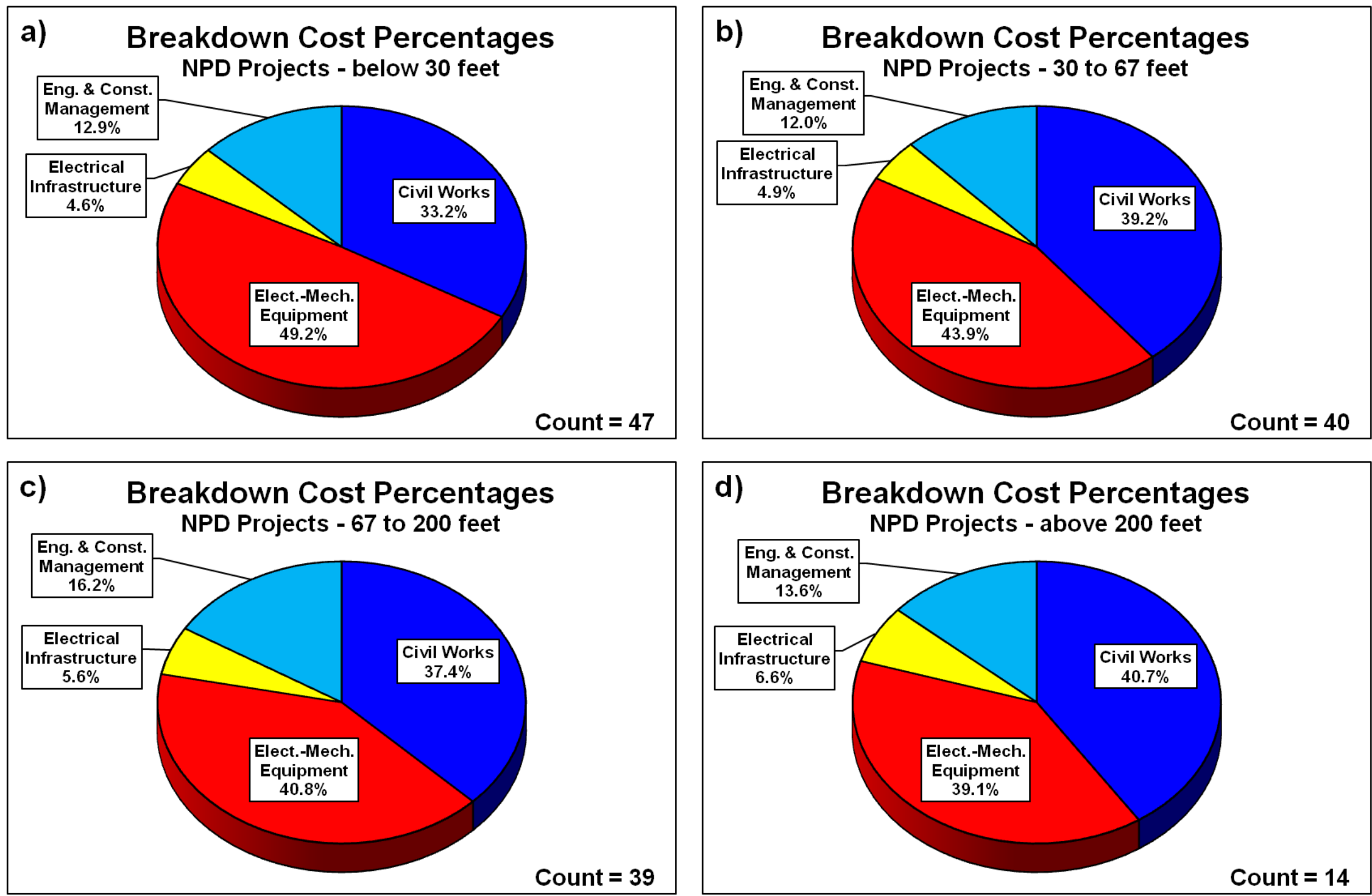

Figure 27. NPD breakdown cost distributions by Head range 


\section{New Stream-reach Developments (NSDs)}

The previous discussion on NSD data illustrates the primary data sources but provides no details on the project locations included. As shown in the Figure 23 map, the United States was divided into six market regions: Southwest, Midwest, Rocky Mountains, Pacific, Southeast, and Northeast. Figure 28 shows regional distribution of cost data, providing the number of NSD projects in each region, along with the average ICC, capacity, and hydraulic head. A total of 84 NSD projects were used for the final analysis. 63 out of 84 projects were located in the U.S. with the remaining 21 projects from Non-US. No project data were available for the Southwest region. A minimum of 5 projects were located in the Midwest region, while a maximum of 34 projects were located in the Pacific region. The cumulative regional project capacity ranges from $2 \mathrm{MW}$ in the Midwest to $1,555 \mathrm{MW}$ in the Pacific, while the regionally-averaged hydraulic head ranges from $14 \mathrm{ft}$ in the Midwest to $838 \mathrm{ft}$ in the Pacific. The ICC varies significantly among the regions, $3,573 \$ / \mathrm{kW}$ in the Pacific to $18,425 \$ / \mathrm{kW}$ in the Midwest.

As described in Section 4 of this report, the recommended cost model for NSD ICC estimation is the $C$ Dataset model, which used construction stage project data only. However, numerous other models were evaluated as a part of the BCM development efforts. Table 22 provides various statistics for multiple models that were developed. Correlation and regression results are provided to help inform users of the relative benefits and limitations of using alternative NSD models.

Figure 29 shows multiple in-sample validation plots that demonstrate the results for the PEC, EC, and C models for NSDs. The top plots (Figure 29a-C) show modeled vs. raw ICC for each model. The diagonal 1:1 line represents where the modeled and raw costs are equal and is the ideal case for estimating cost using a model. The bottom plots (Figure 29d-f) show raw and modeled cost data relative to the combined capacity and head power forms. The blue points represent raw cost, while the black diagonal line represents modeled ICC. The red diagonal lines represent the upper and lower 95\% confidence interval ICC. Ideally, all raw data would lie within the confidence interval, though sample size, correlation, and other factors influence the results.

Figure 30 shows NSD breakdown cost distributions across a variety of different capacity ranges. These breakdown costs are categorized into 4 different groups according to the major source of development cost. As seen in the plots, the major cost drivers for NSDs are civil works and equipment costs. For the smaller projects (below $1 \mathrm{MW}$ ), equipment costs are significantly high (nearly $55 \%$ on average); however, for larger projects (above $30 \mathrm{MW}$ ), civil works contribute more to overall ICC (nearly $47 \%$ on average) due to construction of a new dam or diversion structure and waterway facilities. The engineering \& construction management costs are relatively minor for all projects. Since consideration should be given to the number of projects from which these plots were made, the project count is provided in the lower corner of each plot.

Similarly, Figure 31 shows breakdown cost distributions for NSDs across various head ranges. The low head projects (below $67 \mathrm{ft}$ ) as well as high head (above $200 \mathrm{ft}$ ) demonstrate high civil works cost contribution. The equipment cost contribution remains similar for both low and high 
head projects. The breakdown cost distribution for medium head (67 to $200 \mathrm{ft}$ ) NSD projects is not provided due to unavailability of the data. 


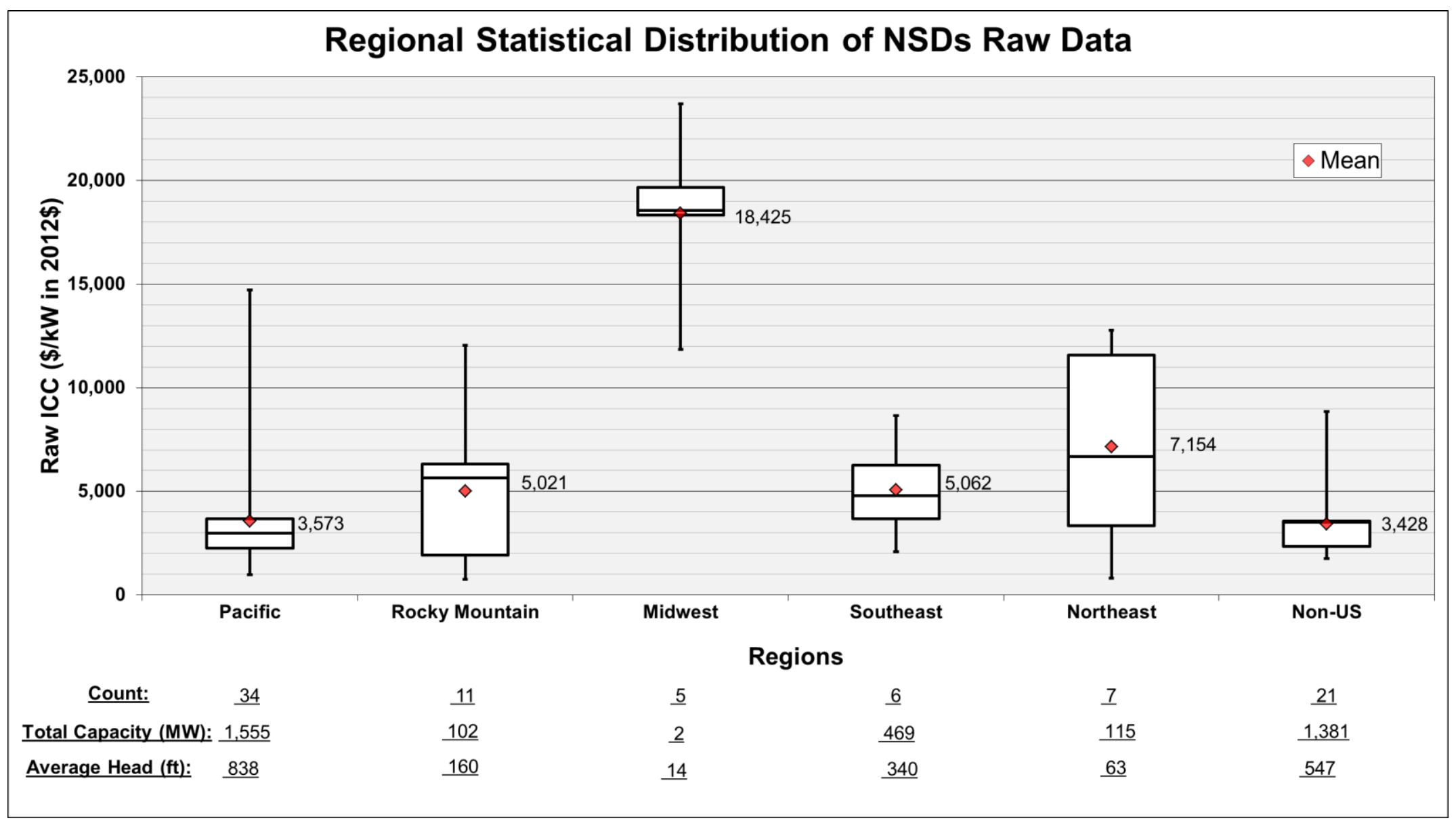

Figure 28. Regional distribution of New Stream-reach Development (NSDs) cost data 
Table 22. Summary regression results for NSDs

\begin{tabular}{|c|c|c|c|c|c|c|c|c|c|c|c|c|c|c|}
\hline \multirow{2}{*}{ Category } & \multirow{2}{*}{$\begin{array}{l}\text { Model Estimated Cost } \\
\text { (in 2012\$) }\end{array}$} & \multirow{2}{*}{$\mathbf{R}^{2}$} & \multirow{2}{*}{$\begin{array}{l}\text { Sample } \\
\text { Size }\end{array}$} & \multirow{2}{*}{$\begin{array}{l}\text { Confidence } \\
\text { Score }\end{array}$} & \multirow{2}{*}{$\begin{array}{l}\text { Bias } \\
\text { Correction }\end{array}$} & \multirow{2}{*}{$\begin{array}{c}\text { Coefficien } \\
\quad \text { log } \\
\text { (Intercept) }\end{array}$} & \multirow{2}{*}{$\begin{array}{c}\text { Coefficien } \\
\text { t log } \\
\text { (Capacity) }\end{array}$} & \multirow{2}{*}{$\begin{array}{c}\text { Coefficient } \\
\text { log } \\
\text { (Head) }\end{array}$} & \multicolumn{3}{|c|}{$\mathrm{t}$ - statistic value } & \multicolumn{3}{|c|}{$p$-value } \\
\hline & & & & & & & & & $\begin{array}{c}\text { Log } \\
\text { (Constant) }\end{array}$ & $\log (P)$ & $\log (\mathrm{H})$ & $\begin{array}{c}\text { Log } \\
\text { (Constant) }\end{array}$ & $\log (P)$ & $\log (\mathrm{H})$ \\
\hline \multicolumn{15}{|c|}{ Modeling Results by Project Development Stage } \\
\hline All data (PEC) & $11,893,180 \mathrm{P}^{0.92} \mathrm{H}^{-0.15}$ & 0.87 & 84 & 10.19 & 1.20 & 16.11 & 0.92 & -0.15 & 67.47 & 22.3 & -3.1 & $5.93 E-73$ & $2.4 \mathrm{E}-36$ & $2.8 \mathrm{E}-03$ \\
\hline $\begin{array}{c}\text { Eng. \& } \\
\text { Construction }\end{array}$ & $5,749,624 \mathrm{P}^{1.02} \mathrm{H}^{-0.07}$ & 0.92 & 35 & 11.97 & 1.15 & 15.43 & 1.02 & -0.07 & 52.89 & 18.5 & -1.2 & $1.01 \mathrm{E}-32$ & $1.2 \mathrm{E}-18$ & $2.5 \mathrm{E}-01$ \\
\hline Construction & $8,717,830 \mathrm{P}^{0.98} \mathrm{H}^{-0.12}$ & 0.96 & 17 & 12.65 & 1.03 & 15.95 & 0.98 & -0.12 & 43.28 & 19.0 & -2.4 & $2.60 \mathrm{E}-16$ & $2.1 \mathrm{E}-11$ & $2.8 \mathrm{E}-02$ \\
\hline \multicolumn{15}{|c|}{ Modeling Results by Project Capacity (MW) } \\
\hline$<1 \mathrm{MW}$ & $22,492,292 \mathrm{P}^{0.22} \mathrm{H}^{-0.40}$ & 0.31 & 14 & & 1.26 & 16.70 & 0.22 & -0.40 & 21.43 & 0.4 & -2.0 & $2.54 \mathrm{E}-10$ & 7.0E-01 & $7.6 \mathrm{E}-02$ \\
\hline 1 to $<10 \mathrm{MW}$ & $6,253,472 \mathrm{P}^{1.10} \mathrm{H}^{-0.12}$ & 0.69 & 30 & & 1.12 & 15.54 & 1.10 & -0.12 & 48.18 & 7.7 & -2.1 & $1.01 \mathrm{E}-27$ & 2.6E-08 & $4.9 \mathrm{E}-02$ \\
\hline 10 to $<30 \mathrm{MW}$ & $1,944,037 \mathrm{P}^{1.59} \mathrm{H}^{-0.18}$ & 0.53 & 17 & & 1.14 & 14.35 & 1.59 & -0.18 & 9.39 & 3.6 & -1.5 & 2.03E-07 & $2.7 \mathrm{E}-03$ & $1.5 \mathrm{E}-01$ \\
\hline$\geq 30 \mathrm{MW}$ & $2,059,740 \mathrm{P}^{1.12} \mathrm{H}^{0.004}$ & 0.76 & 23 & & 1.15 & 14.40 & 1.12 & 0.004 & 16.08 & 7.9 & 0.0 & $6.64 \mathrm{E}-13$ & $1.4 \mathrm{E}-07$ & $9.6 \mathrm{E}-01$ \\
\hline \multicolumn{15}{|c|}{ Modeling Results by Head (ft) } \\
\hline$<67 \mathrm{ft}$ & $11,834,123 \mathrm{P}^{0.81} \mathrm{H}^{-0.06}$ & 0.8 & 23 & & 1.22 & 16.09 & 0.81 & -0.06 & 17.00 & 8.5 & -0.2 & 2.33E-13 & $4.5 \mathrm{E}-08$ & $8.5 \mathrm{E}-01$ \\
\hline $67 \mathrm{to}<200 \mathrm{ft}$ & $18,850,882 \mathrm{P}^{0.87} \mathrm{H}^{-0.27}$ & 0.9 & 14 & & 1.23 & 16.54 & 0.87 & -0.27 & 4.09 & 10.0 & -0.3 & $1.78 \mathrm{E}-03$ & $7.2 \mathrm{E}-07$ & 7.6E-01 \\
\hline$\geq 200 \mathrm{ft}$ & $1,247,190 \mathrm{P}^{1.05} \mathrm{H}^{0.12}$ & 0.9 & 47 & & 1.10 & 13.94 & 1.05 & 0.12 & 18.63 & 20.9 & 1.1 & $1.68 \mathrm{E}-22$ & $1.8 \mathrm{E}-24$ & $2.8 \mathrm{E}-01$ \\
\hline
\end{tabular}

Note: the model estimated cost includes bias correction. 

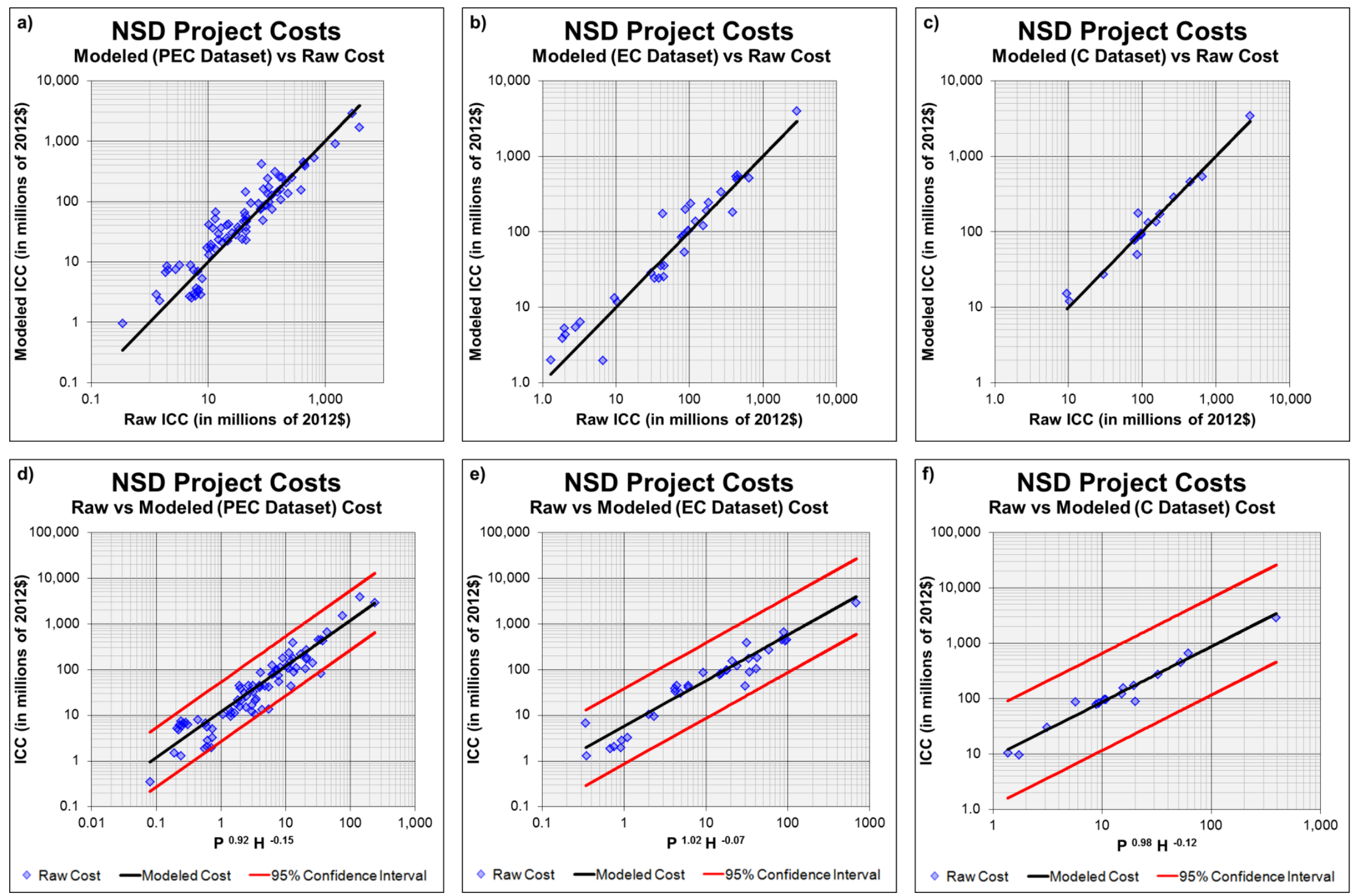

Figure 29. NSD in-sample model validation 

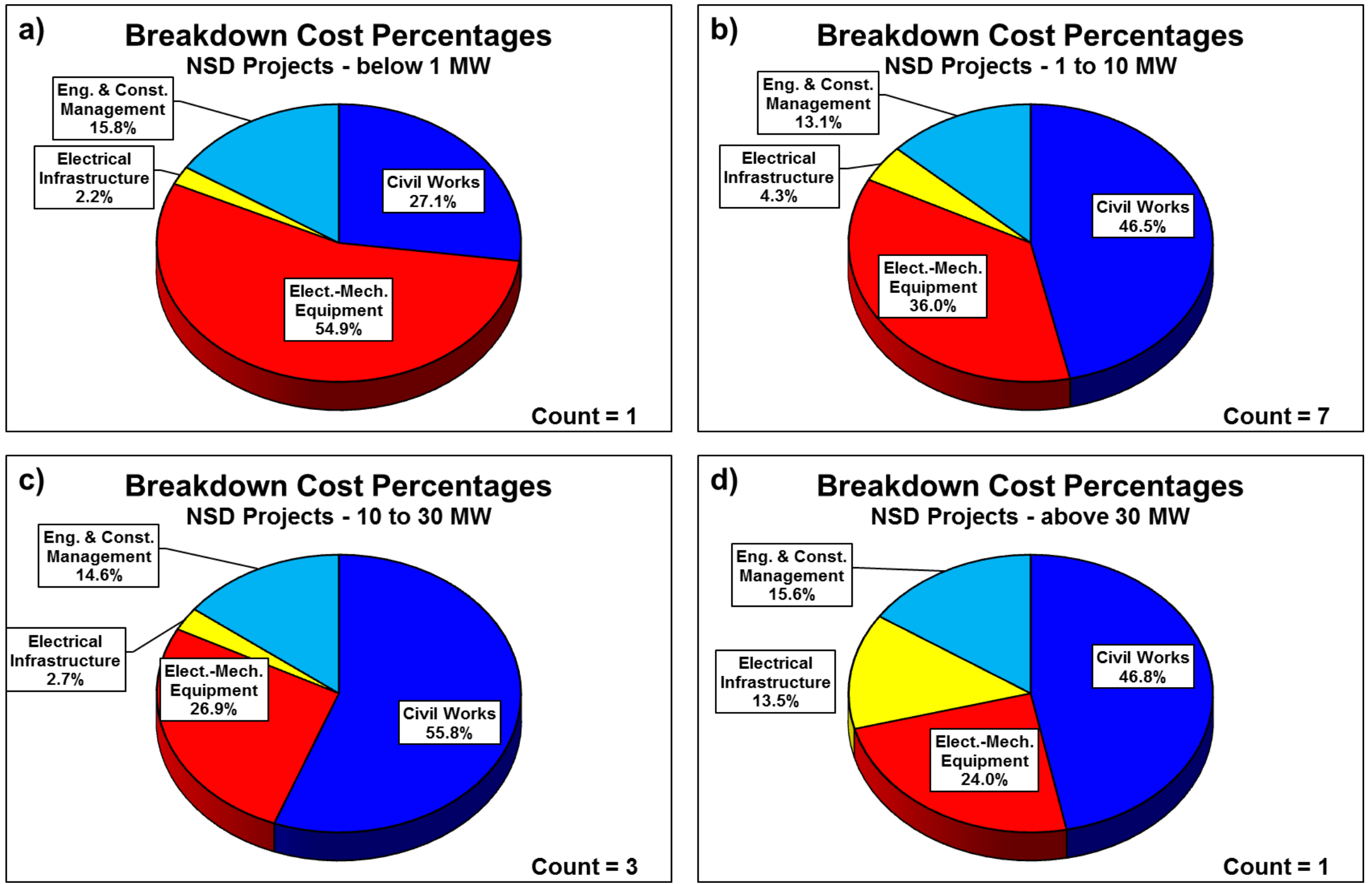

Figure 30. NSD breakdown cost distributions by Capacity range 


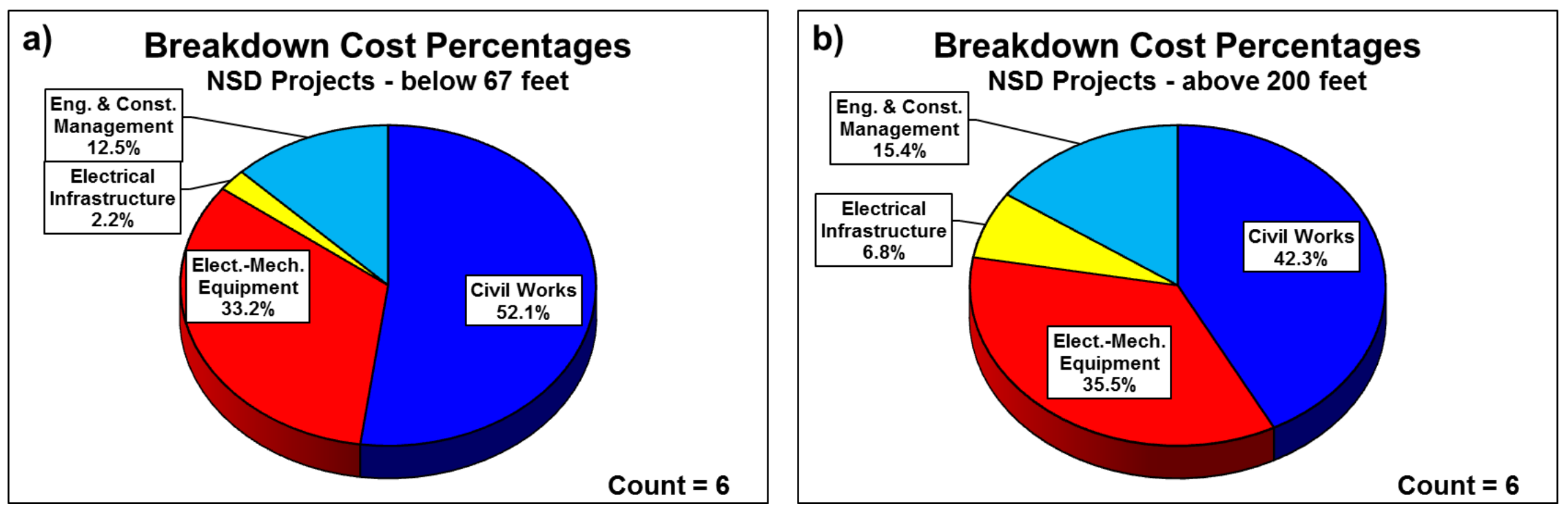

Figure 31. NSD breakdown cost distributions by Head range 


\section{Canal/Conduits}

The previous discussion on Canal/Conduit data illustrates the primary data sources but provides no details on the project locations included. As shown in the Figure 23 map, the United States was divided into six market regions: Southwest, Midwest, Rocky Mountains, Pacific, Southeast, and Northeast. Figure 32 shows regional distribution of cost data, providing the number of Canal/Conduit projects in each region, along with the average ICC, capacity, and hydraulic head. A total of 92 Canal/Conduit projects were used for the final analysis, all of which were located in the U.S. A minimum of 1 project was located in both the Midwest and Southwest regions, while a maximum of 61 projects were located in the Pacific region. No project data were available for the Southeast region. The cumulative regional project capacity ranges from $0.3 \mathrm{MW}$ in the Midwest to $91 \mathrm{MW}$ in the Pacific, while regionally- averaged hydraulic head ranges from $28 \mathrm{ft}$ in the Northeast to $382 \mathrm{ft}$ in the Rocky Mountains region. The ICC varies significantly among the regions, with a minimum of $3,309 \$ / \mathrm{kW}$ in the Northeast and a maximum of $6,779 \$ / \mathrm{kW}$ in the Pacific.

As described in Section 4 of this report, the recommended cost model for Canal/Conduit ICC estimation is the EC Dataset model, which used engineering and construction stage project data. However, numerous other models were evaluated as a part of the BCM development efforts. Table 23 provides various statistics for multiple models that were developed. Correlation and regression results are provided to help inform users of the relative benefits and limitations of using alternative Canal/Conduit models.

Figure 33 shows multiple in-sample validation plots that demonstrate the results for the PEC, EC, and C models for Canal/Conduits. The top plots (Figure 33a-C) show modeled vs. raw ICC for each model. The diagonal 1:1 line represents where the modeled and raw costs are equal and is the ideal case for estimating cost using a model. The bottom plots (Figure 33d-f) show raw and modeled cost data relative to the combined capacity and head power forms. The blue points represent raw cost, while the black diagonal line represents modeled ICC. The red diagonal lines represent the upper and lower 95\% confidence interval ICC. Ideally, all raw data would lie within the confidence interval, though sample size, correlation, and other factors influence the results.

Figure 34 shows Canal/Conduit breakdown cost distributions across a variety of different capacity ranges. These breakdown costs are categorized into 4 different groups according to the major sources of development cost. As seen in the plots, the major cost drivers for Canal/Conduits are civil works and equipment costs. For the smaller projects (below $10 \mathrm{MW}$ ), civil works costs are higher (41 to $46 \%$ on average); however, for larger projects (above 10 MW), equipment costs contribute more to overall ICC (nearly $47 \%$ on average). Since consideration should be given to the number of projects from which these plots were made, the project count is provided in the lower corner of each plot.

Similarly, Figure 35 shows breakdown cost distributions for Canal/Conduits across various head ranges. The civil works cost contribution remains higher for all three low, medium, and high head projects. 


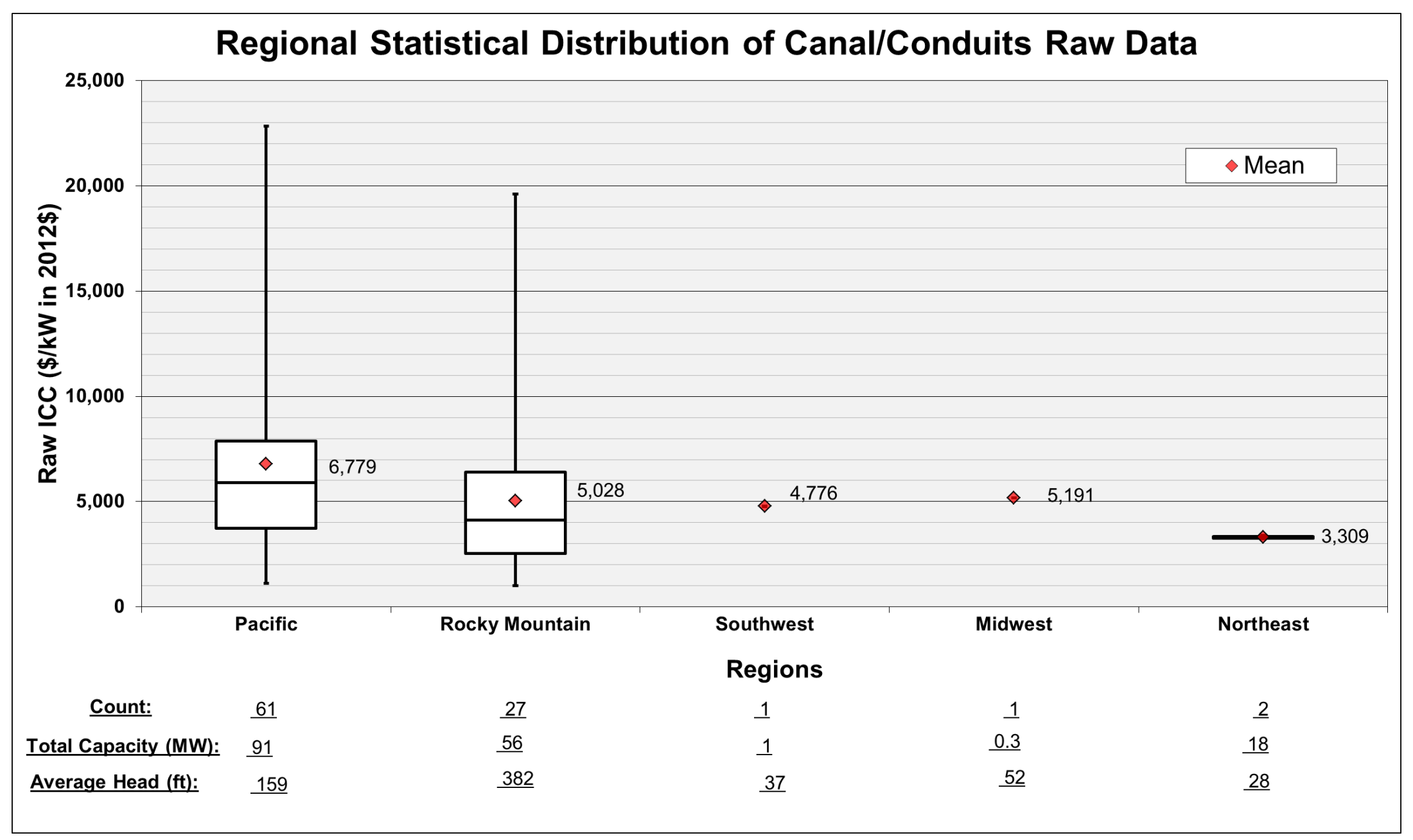

Figure 32. Regional distribution of Canal/Conduit cost data 
Table 23. Summary regression results for Canal/Conduit

\begin{tabular}{|c|c|c|c|c|c|c|c|c|c|c|c|c|c|c|}
\hline \multirow{2}{*}{ Category } & \multirow{2}{*}{$\begin{array}{l}\text { Model Estimated Cost } \\
\quad \text { (in 2012\$) }\end{array}$} & \multirow{2}{*}{$\mathbf{R}^{2}$} & \multirow{2}{*}{$\begin{array}{l}\text { Sample } \\
\text { Size }\end{array}$} & \multirow{2}{*}{$\begin{array}{c}\text { Confidence } \\
\text { Score }\end{array}$} & \multirow{2}{*}{$\begin{array}{c}\text { Bias } \\
\text { Correction }\end{array}$} & \multirow{2}{*}{$\begin{array}{c}\text { Coefficient } \\
\text { log } \\
\text { (Intercept) }\end{array}$} & \multirow{2}{*}{$\begin{array}{l}\text { Coefficient } \\
\text { log } \\
\text { (Capacity) }\end{array}$} & \multirow{2}{*}{$\begin{array}{c}\text { Coefficient } \\
\text { log } \\
\text { (Head) }\end{array}$} & \multicolumn{3}{|c|}{$\mathrm{t}$ - statistic value } & \multicolumn{3}{|c|}{$\mathrm{p}$ - value } \\
\hline & & & & & & & & & $\begin{array}{c}\text { Log } \\
\text { (Constant) }\end{array}$ & $\log (\mathrm{P})$ & $\log (\mathrm{H})$ & $\begin{array}{c}\text { Log } \\
\text { (Constant) }\end{array}$ & $\log (\mathrm{P})$ & $\log (\mathrm{H})$ \\
\hline \multicolumn{15}{|c|}{ Modeling Results by Project Development Stage } \\
\hline All data (PEC) & $8,244,256 \mathrm{P}^{0.82} \mathrm{H}^{-0.08}$ & 0.78 & 92 & 10.04 & 1.19 & 15.75 & 0.82 & -0.08 & 63.07 & 17.4 & -1.6 & $1.16 \mathrm{E}-75$ & $2.0 \mathrm{E}-30$ & $1.1 \mathrm{E}-01$ \\
\hline $\begin{array}{c}\text { Eng. \& } \\
\text { Construction }\end{array}$ & $11,277,566 \mathrm{P}^{0.82} \mathrm{H}^{-0.18}$ & 0.74 & 54 & 12.41 & 1.23 & 16.03 & 0.82 & -0.18 & 45.45 & 11.9 & -2.3 & $6.13 \mathrm{E}-43$ & $2.3 \mathrm{E}-16$ & $2.3 \mathrm{E}-02$ \\
\hline Construction & $8,339,054 \mathrm{P}^{0.74} \mathrm{H}^{-0.13}$ & 0.95 & 12 & 11.18 & 1.03 & 15.91 & 0.74 & -0.13 & 39.24 & 13.5 & -1.8 & $2.25 \mathrm{E}-11$ & $2.8 \mathrm{E}-07$ & $1.1 \mathrm{E}-01$ \\
\hline \multicolumn{15}{|c|}{ Modeling Results by Project Capacity (MW) } \\
\hline$<1 \mathrm{MW}$ & $11,060,981 \mathrm{P}^{0.83} \mathrm{H}^{-0.16}$ & 0.60 & 52 & & 1.17 & 16.06 & 0.83 & -0.16 & 48.32 & 8.2 & -2.3 & $5.31 \mathrm{E}-43$ & $1.1 \mathrm{E}-10$ & $2.3 \mathrm{E}-02$ \\
\hline$\geq 1 \mathrm{MW}$ & $6,796,820 \mathrm{P}^{0.56} \mathrm{H}^{0.02}$ & 0.37 & 40 & & 1.17 & 15.57 & 0.56 & 0.02 & 40.34 & 4.6 & 0.2 & $3.46 \mathrm{E}-32$ & $5.0 \mathrm{E}-05$ & $8.4 \mathrm{E}-01$ \\
\hline \multicolumn{15}{|c|}{ Modeling Results by Head (ft) } \\
\hline$<67 \mathrm{ft}$ & $18,748,503 \mathrm{P}^{0.77} \mathrm{H}^{-0.38}$ & 0.77 & 34 & & 1.10 & 16.66 & 0.77 & -0.38 & 29.24 & 10.0 & -2.3 & $3.46 \mathrm{E}-32$ & $3.2 \mathrm{E}-11$ & $2.8 \mathrm{E}-02$ \\
\hline 67 to $<200 \mathrm{ft}$ & $663,008,341 \mathrm{P}^{0.84} \mathrm{H}^{-1.04}$ & 0.81 & 31 & & 1.20 & 20.13 & 0.84 & -1.04 & 10.77 & 10.3 & -2.6 & $3.91 \mathrm{E}-24$ & $4.8 \mathrm{E}-11$ & $1.6 \mathrm{E}-02$ \\
\hline$\geq 200 \mathrm{ft}$ & $20,870,690 \mathrm{P}^{0.93} \mathrm{H}^{-0.22}$ & 0.81 & 27 & & 1.19 & 16.68 & 0.93 & -0.22 & 9.37 & 7.3 & -0.8 & 1.74E-09 & $1.5 \mathrm{E}-07$ & $4.5 \mathrm{E}-01$ \\
\hline
\end{tabular}

Note: the model estimated cost includes bias correction. 

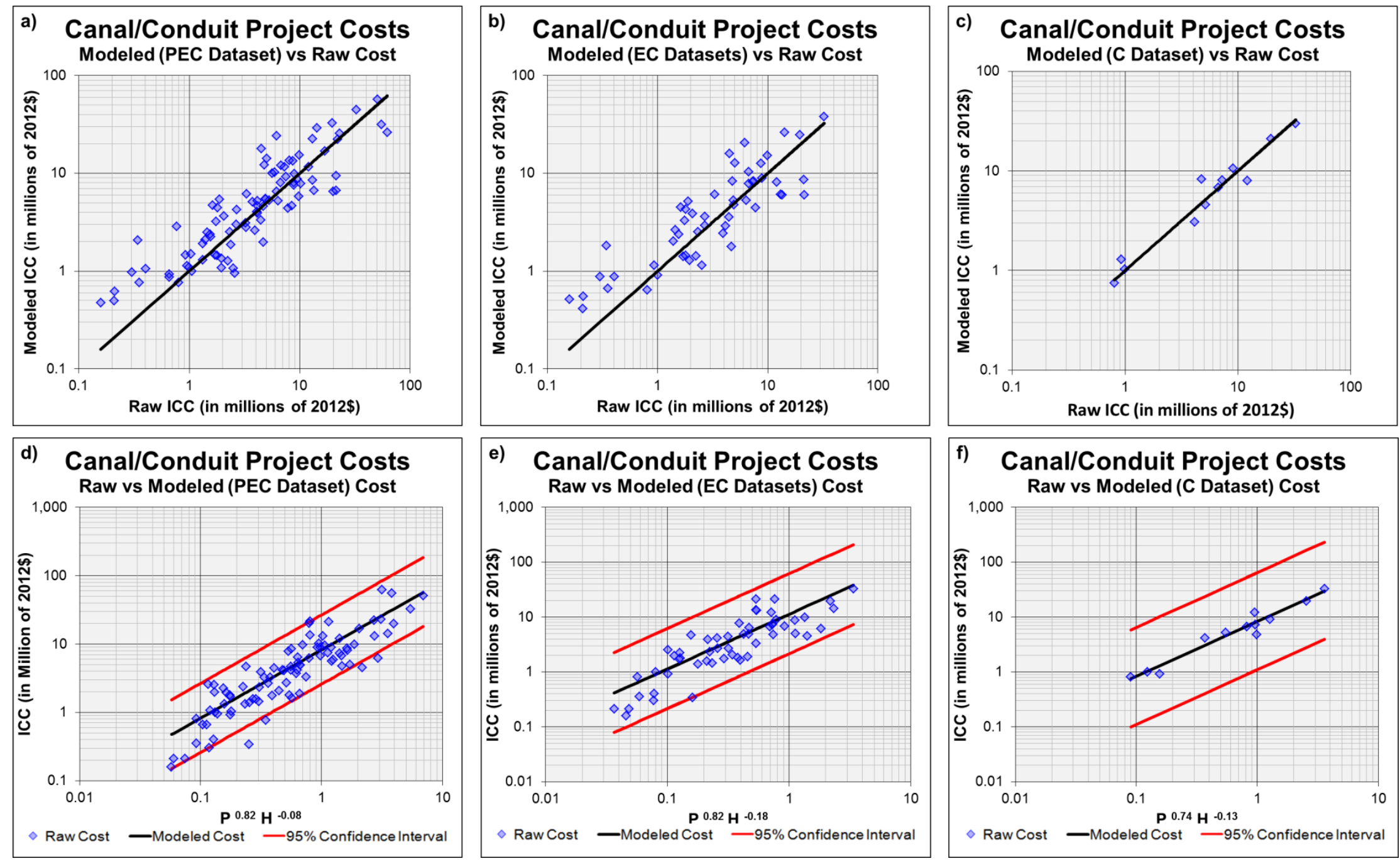

Figure 33. Canal/Conduit in-sample model validation 

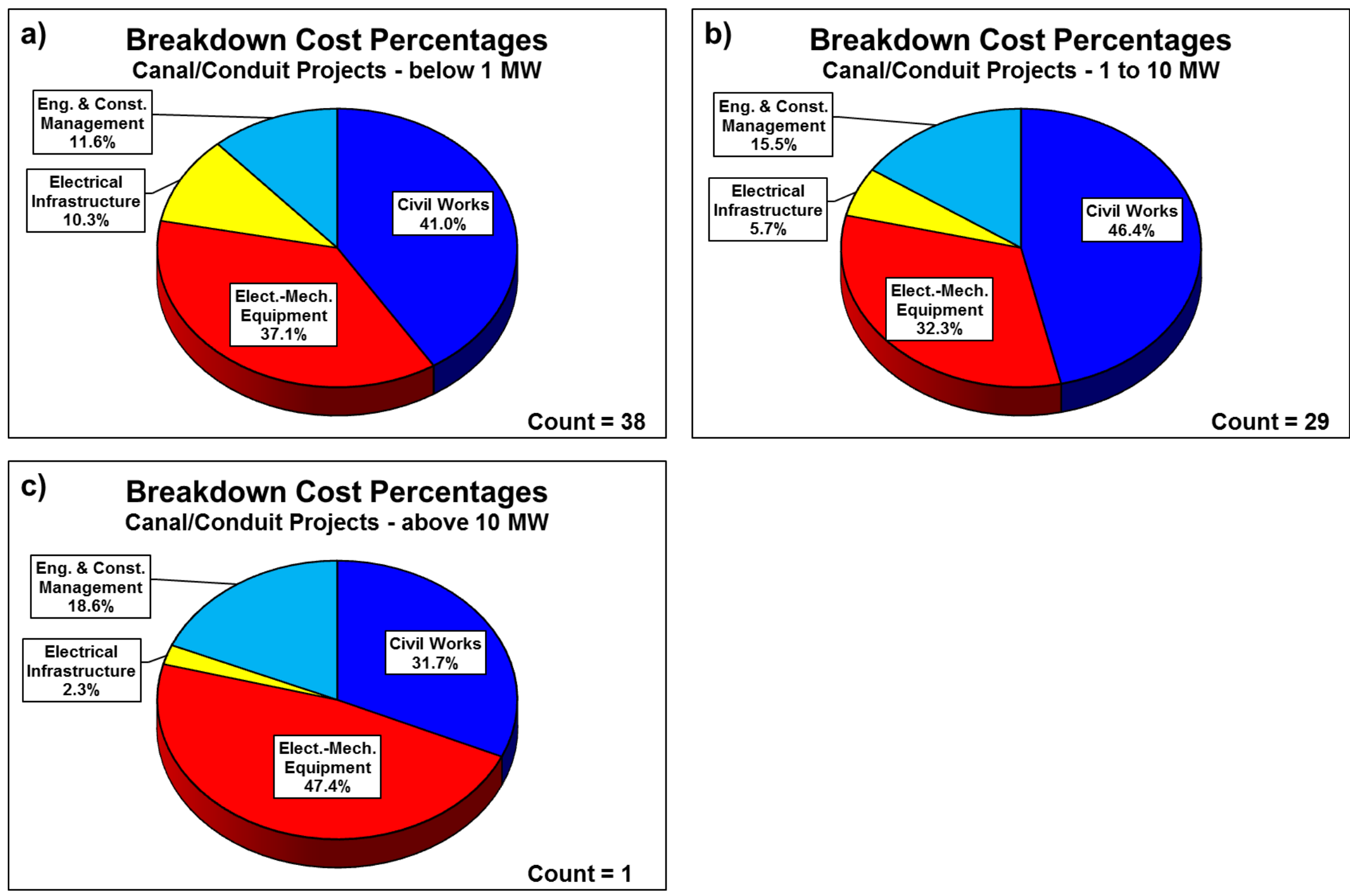

Figure 34. Canal/Conduit breakdown cost distributions by Capacity range 

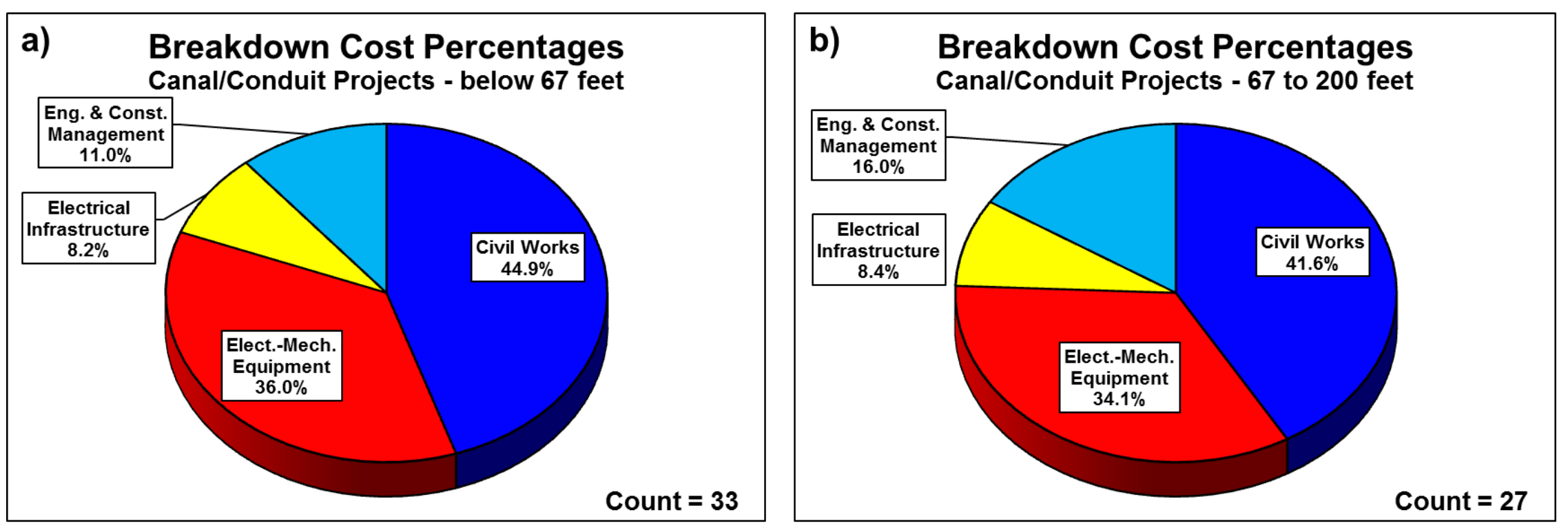

\section{c) Breakdown Cost Percentages \\ Canal/Conduit Projects - above 200 feet}

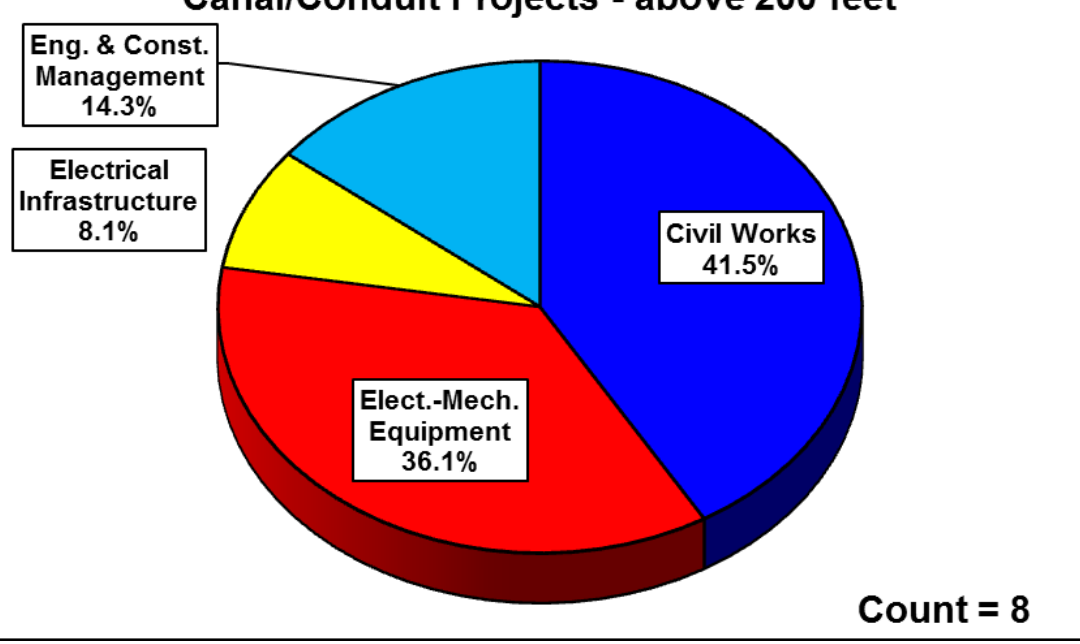

Figure 35. Canal/Conduit breakdown cost distributions by Head range 


\section{Pumped Storage Hydropower (PSH)}

The previous discussion on PSH data illustrates the primary data sources but provides no details on the project locations included. As shown in the Figure 23 map, the United States was divided into six market regions: Southwest, Midwest, Rocky Mountains, Pacific, Southeast, and Northeast. Figure 36 shows regional distribution of cost data, providing the number of PSH projects in each region, along with the average ICC, capacity, and hydraulic head. A total of 84 PSH projects were used for the final analysis, all of which were located in the U.S. A minimum of 4 projects were located in the Midwest region, while a maximum of 31 projects were located in the Pacific region. The cumulative regional project capacity ranges from 3,050 MW in the Midwest to 25,633 MW in the Pacific, while regionally-averaged hydraulic head ranges from $1,009 \mathrm{ft}$ in the Southeast to 1,432 ft in the Pacific region. The ICC varies significantly among the regions, with a minimum of $1,097 \$ / \mathrm{kW}$ in Southeast and a maximum of $1,756 \$ / \mathrm{kW}$ in the Northeast.

As described in Section 4 of this report, the recommended cost model for PSH ICC estimation is the PE Dataset model, which used planning and engineering stage project data only. However, numerous other models were evaluated as a part of the BCM development efforts. Table 24 provides various statistics for multiple models that were developed. Correlation and regression results are provided to help inform users of the relative benefits and limitations of using alternative PSH models.

Figure 37 shows multiple in-sample validation plots that demonstrate the results for the PE and $\mathrm{E}$ models for PSH. The top plots (Figure 37a-b) show modeled vs. raw ICC for each model. The diagonal 1:1 line represents where the modeled and raw costs are equal and is the ideal case for estimating cost using a model. The bottom plots (Figure 37c-d) show raw and modeled cost data relative to the capacity power form. The blue points represent raw cost, while the black diagonal line represents modeled ICC. The red diagonal lines represent the upper and lower 95\% confidence interval ICC. Ideally, all raw data would lie within the confidence interval, though sample size, correlation, and other factors influence the results.

Figure 38 shows PSH breakdown cost distributions across a variety of different capacity ranges. These breakdown costs are categorized into 4 different groups according to the major sources of development cost. As seen in the plots, the major cost drivers for PSH are civil works and equipment costs. Civil works cost contribution is nearly $70 \%$ for the project capacity ranges from 500 to $1000 \mathrm{MW}$. However, both civil works and equipment cost contributions are similar for larger project (above $1000 \mathrm{MW}$ ). Engineering and construction management costs are relatively minor, as the overall scope involved in such activities for large projects is not drastically different than for small projects. Since consideration should be given to the number of projects from which these plots were made, the project count is provided in the lower corner of each plot.

Similarly, Figure 39 shows breakdown cost distributions for PSH across various head ranges. Both the low head (below $1000 \mathrm{ft}$ ) and high head (above 1,500 ft) projects demonstrate high civil works cost contribution. 


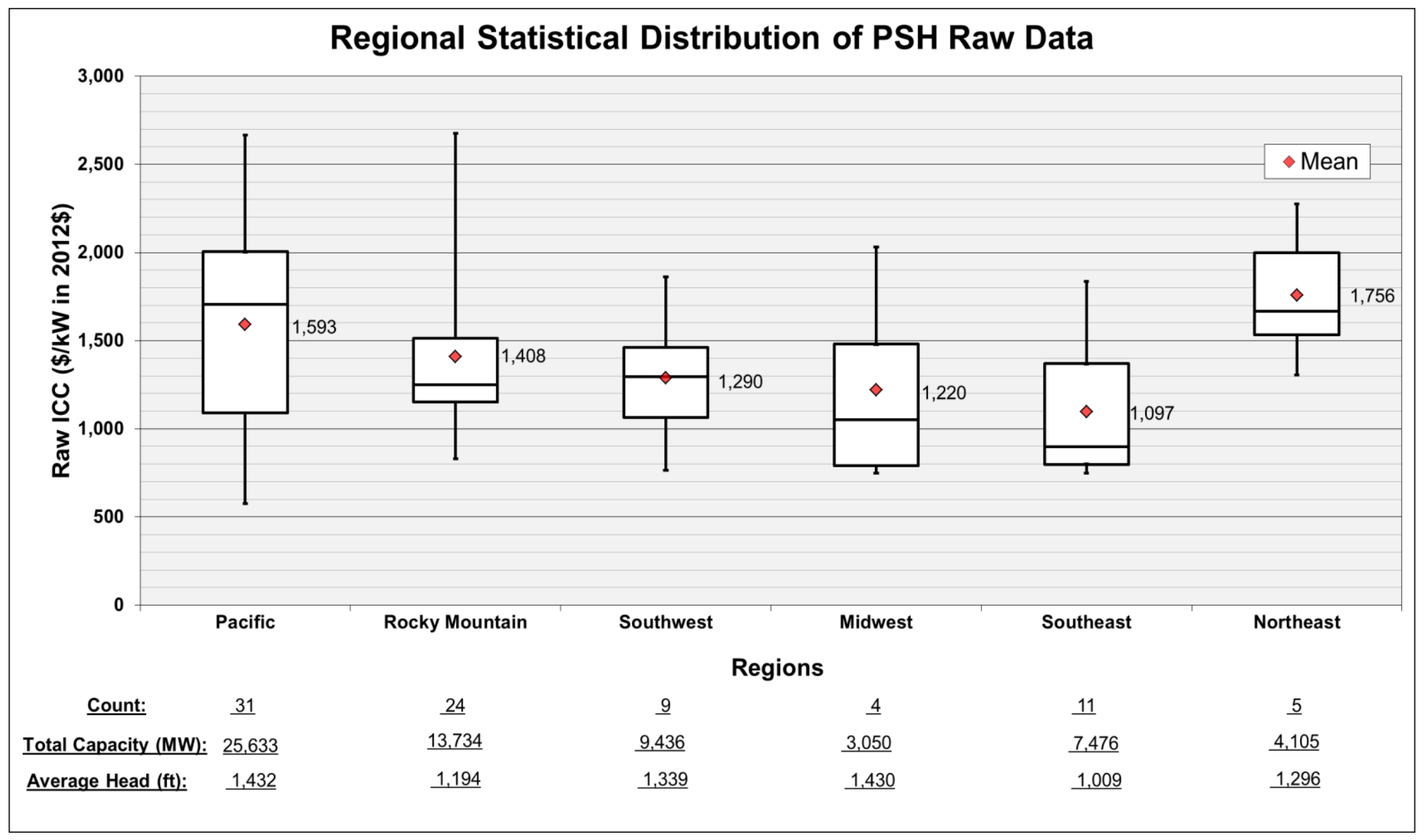

Figure 36. Regional distribution of PSH cost data 
Table 24. Summary regression results for PSH

\begin{tabular}{|c|c|c|c|c|c|c|c|c|c|c|c|}
\hline \multirow{2}{*}{ Category } & \multirow{2}{*}{$\begin{array}{l}\text { Model Estimated Cost } \\
\quad \text { (in 2012\$) }\end{array}$} & \multirow{2}{*}{$\mathbf{R}^{2}$} & \multirow{2}{*}{$\begin{array}{l}\text { Sample } \\
\text { Size }\end{array}$} & \multirow{2}{*}{$\begin{array}{c}\text { Confidence } \\
\text { Score }\end{array}$} & \multirow{2}{*}{$\begin{array}{c}\text { Bias } \\
\text { Correction }\end{array}$} & \multirow{2}{*}{$\begin{array}{c}\text { Coefficient log } \\
\text { (Intercept) }\end{array}$} & \multirow{2}{*}{$\begin{array}{l}\text { Coefficient log } \\
\text { (Capacity) }\end{array}$} & \multicolumn{2}{|c|}{$t$ - statistic value } & \multicolumn{2}{|c|}{$p$-value } \\
\hline & & & & & & & & $\log ($ Constant) & $\log (\mathbf{P})$ & $\log$ (Constant) & $\log (\mathrm{P})$ \\
\hline \multicolumn{12}{|c|}{ Modeling Results by Project Development Stage } \\
\hline All data (PE) & $2,043,064 \mathrm{P}^{0.94}$ & 0.86 & 84 & 9.77 & 1.07 & 14.46 & 0.94 & 52.90 & 22.3 & 3.81E-65 & $1.4 \mathrm{E}-36$ \\
\hline Engineering & $2,442,817 \mathrm{P}^{0.96}$ & 0.81 & 10 & 10.33 & 1.03 & 14.68 & 0.96 & 13.14 & 5.8 & $1.07 E-06$ & $4.0 \mathrm{E}-04$ \\
\hline \multicolumn{12}{|c|}{ Modeling Results by Project Capacity (MW) } \\
\hline$<500 \mathrm{MW}$ & $2,590,713 \mathrm{P}^{0.91}$ & 0.90 & 26 & & 1.07 & 14.70 & 0.91 & 42.36 & 14.8 & 4.53E-24 & $1.4 \mathrm{E}-13$ \\
\hline 500 to $<1000 \mathrm{MW}$ & $18,400 P^{1.65}$ & 0.59 & 27 & & 1.04 & 9.78 & 1.65 & 5.50 & 5.9 & $1.02 \mathrm{E}-05$ & 3.3E-06 \\
\hline$\geq 1000 \mathrm{MW}$ & $1,849,749 P^{0.97}$ & 0.23 & 31 & & 1.06 & 14.37 & 0.97 & 6.21 & 3.0 & 8.93E-07 & $5.8 \mathrm{E}-03$ \\
\hline \multicolumn{12}{|c|}{ Modeling Results by Head (ft) } \\
\hline$<1000 \mathrm{ft}$ & $2,406,015 \mathrm{P}^{0.91}$ & 0.91 & 26 & & 1.07 & 14.62 & 0.91 & 42.21 & 15.9 & 8.93E-07 & $2.9 \mathrm{E}-14$ \\
\hline 1000 to $<1500 \mathrm{ft}$ & $1,992,641 \mathrm{P}^{0.95}$ & 0.72 & 29 & & 1.06 & 14.44 & 0.95 & 18.81 & 8.3 & 4.94E-24 & $6.2 \mathrm{E}-09$ \\
\hline$\geq 1500 \mathrm{ft}$ & $1,180,258 P^{1.03}$ & 0.73 & 29 & & 1.06 & 13.92 & 1.03 & 17.65 & 8.5 & $2.37 \mathrm{E}-16$ & $3.8 \mathrm{E}-09$ \\
\hline
\end{tabular}

$\underline{\text { Note: }}$ the model estimated cost includes bias correction. 

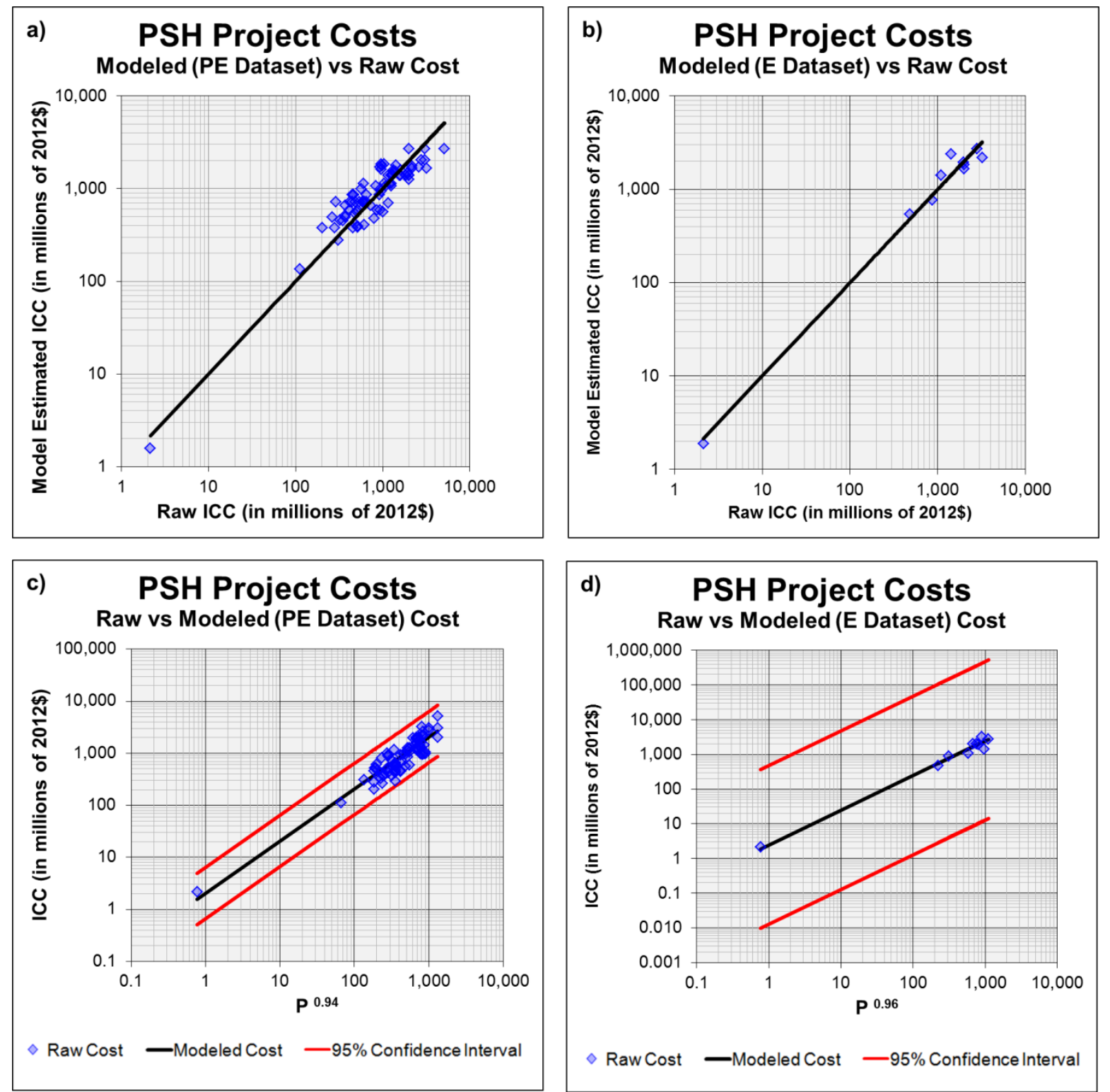

Figure 37. PSH in-sample model validation 

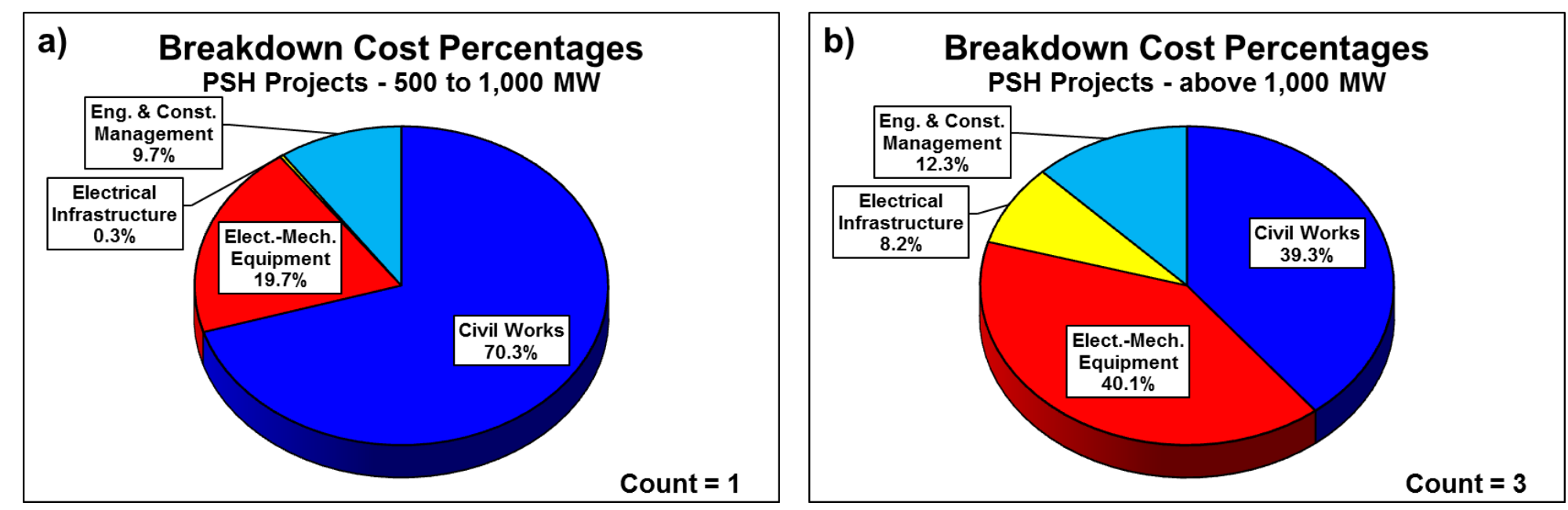

Figure 38. PSH breakdown cost distributions by Capacity range
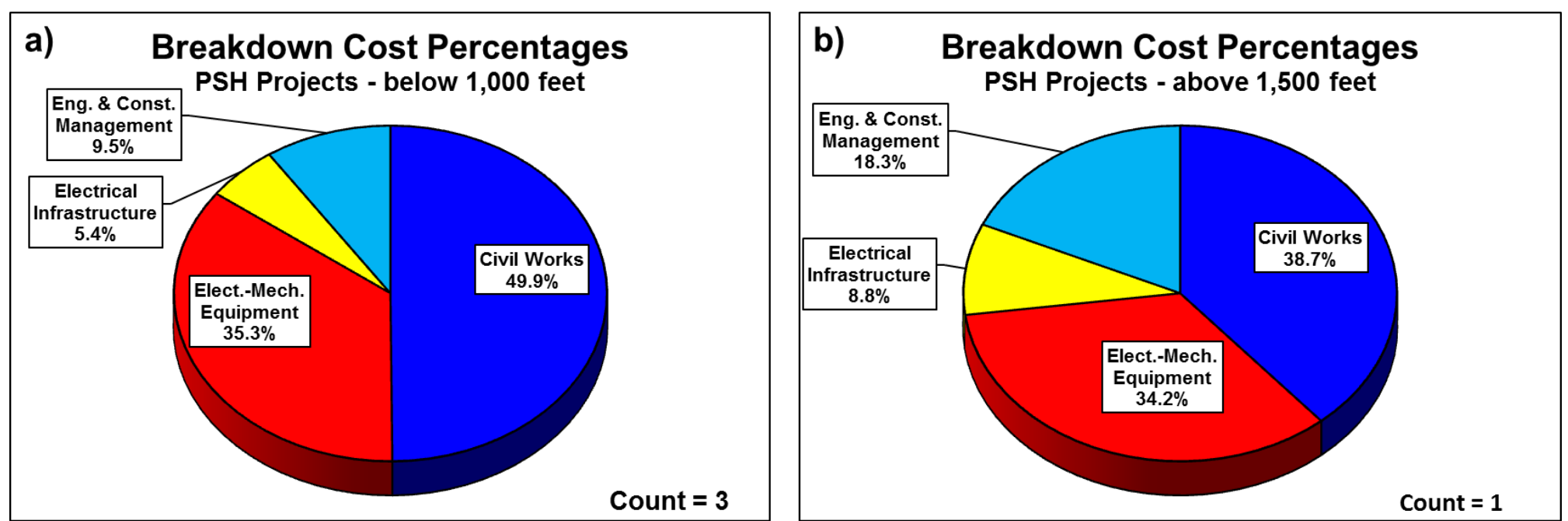

Figure 39. PSH breakdown cost distributions by Head range 


\section{Unit Addition and Generator Rewind}

The previous discussion on Unit Addition and Generator Rewind data illustrates the primary data sources but provides no details on the project locations included. As shown in the Figure 23 map, the United States was divided into six market regions: Southwest, Midwest, Rocky Mountains, Pacific, Southeast, and Northeast. Figure 40 and Figure 41 show regional distribution of cost data, providing the number of projects in each region, along with the average ICC and total capacity for Unit Addition and Generator Rewind respectively. No Unit Addition project data were available for the Southeast region. Also, no Generator Rewind data were available for the Midwest region. A total of 13 Unit Addition and 21 Generator Rewind projects were used for the final analysis.

Table 25 provides a summary of various statistics for each model that was developed for Unit Addition and Generator Rewind in Section 4. As the raw data were limited to a relatively small sample size, only the PEC Model was developed. Figure 42 shows in-sample validation plots that illustrate the model results. The modeled vs. raw ICC with the diagonal 1:1 line represents the points at which the modeled and raw costs are equal. Figure 43 shows raw and modeled cost data relative to the capacity power form. The blue points represent raw cost, while the black diagonal line represents modeled ICC. The red diagonal lines represent the upper and lower $95 \%$ confidence interval ICC. Ideally, all raw data would lie within the confidence interval, though sample size, correlation, and other factors influence the results. 


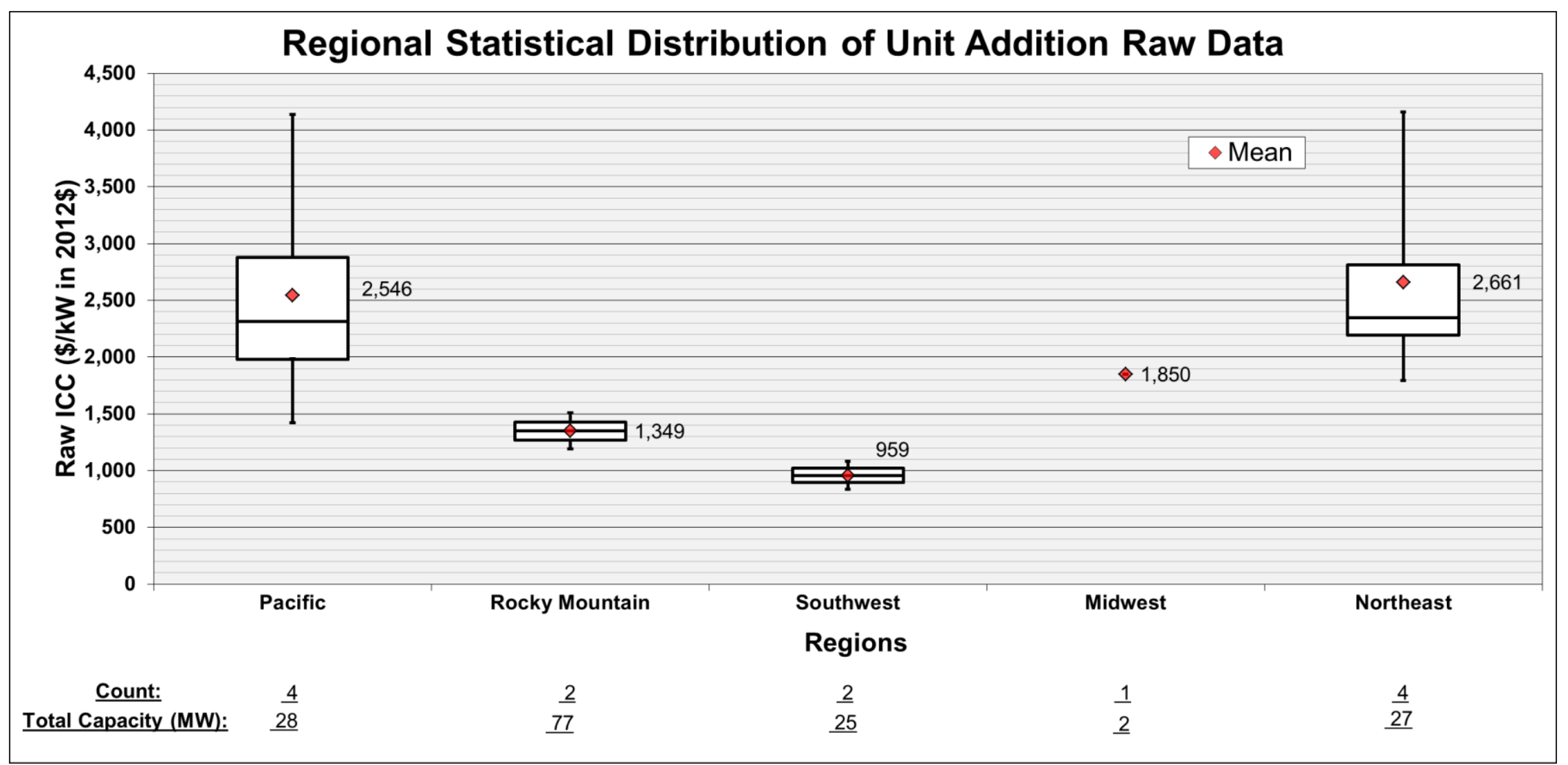

Figure 40. Regional distribution of Unit Addition cost data 


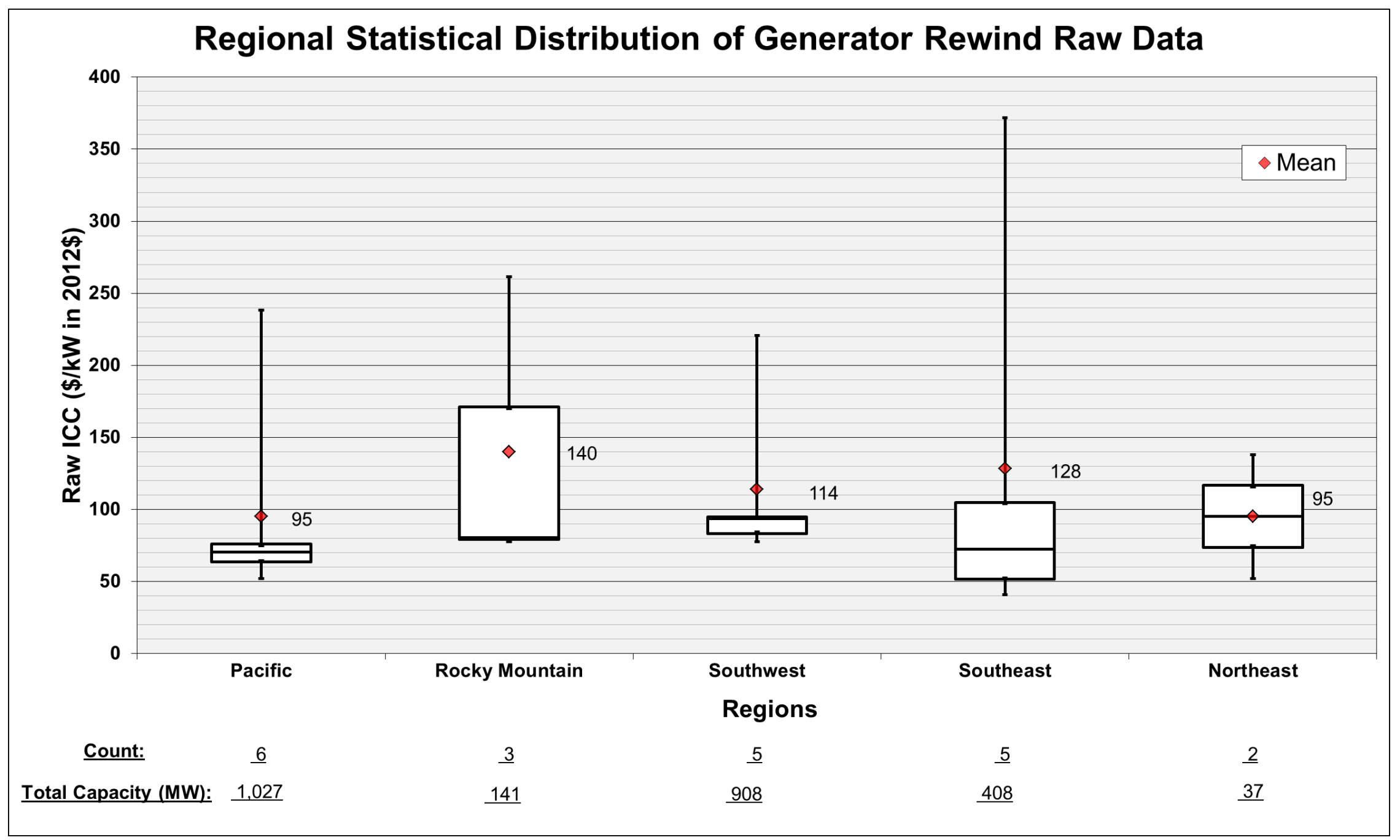

Figure 41. Regional distribution of Generator Rewind cost data 
Table 25. Summary regression results for Unit Addition ${ }^{16}$ and Generator Rewind

\begin{tabular}{|c|c|c|c|c|c|c|c|c|c|c|c|}
\hline \multirow{2}{*}{ Category } & \multirow{2}{*}{$\begin{array}{l}\text { Model Estimated } \\
\text { Cost (in 2012\$) }\end{array}$} & \multirow{2}{*}{$\mathbf{R}^{2}$} & \multirow{2}{*}{$\begin{array}{c}\text { Sample } \\
\text { Size }\end{array}$} & \multirow{2}{*}{$\begin{array}{l}\text { Confidence } \\
\text { Score }\end{array}$} & \multirow{2}{*}{$\begin{array}{c}\text { Bias } \\
\text { Correction }\end{array}$} & \multirow{2}{*}{$\begin{array}{c}\text { Coefficient } \\
\quad \text { log } \\
\text { (Intercept) }\end{array}$} & \multirow{2}{*}{$\begin{array}{l}\text { Coefficient } \\
\text { log } \\
\text { (Capacity) }\end{array}$} & \multicolumn{2}{|c|}{$\mathrm{t}$ - statistic value } & \multicolumn{2}{|c|}{$p$-value } \\
\hline & & & & & & & & $\begin{array}{c}\text { Log } \\
\text { (Constant) }\end{array}$ & $\log (P)$ & $\begin{array}{c}\text { Log } \\
\text { (Constant) }\end{array}$ & $\log (P)$ \\
\hline Unit Addition & $3,030,671 \mathrm{P}^{0.81}$ & 0.77 & 13 & 9.24 & 1.1 & 14.83 & 0.81 & 49.7 & 6.1 & $2.69 \mathrm{E}-14$ & $8.20 \mathrm{E}-05$ \\
\hline $\begin{array}{l}\text { Generator } \\
\text { Rewind }\end{array}$ & $299,461 P^{0.75}$ & 0.71 & 21 & 10.29 & 1.15 & 12.47 & 0.75 & 26.37 & 6.8 & $1.98 \mathrm{E}-16$ & $1.80 \mathrm{E}-06$ \\
\hline
\end{tabular}

Note: the model estimated cost includes bias correction.

\footnotetext{
${ }^{16}$ All Unit Addition models use incremental capacity (capacity added by any new units) as an independent variable
} 

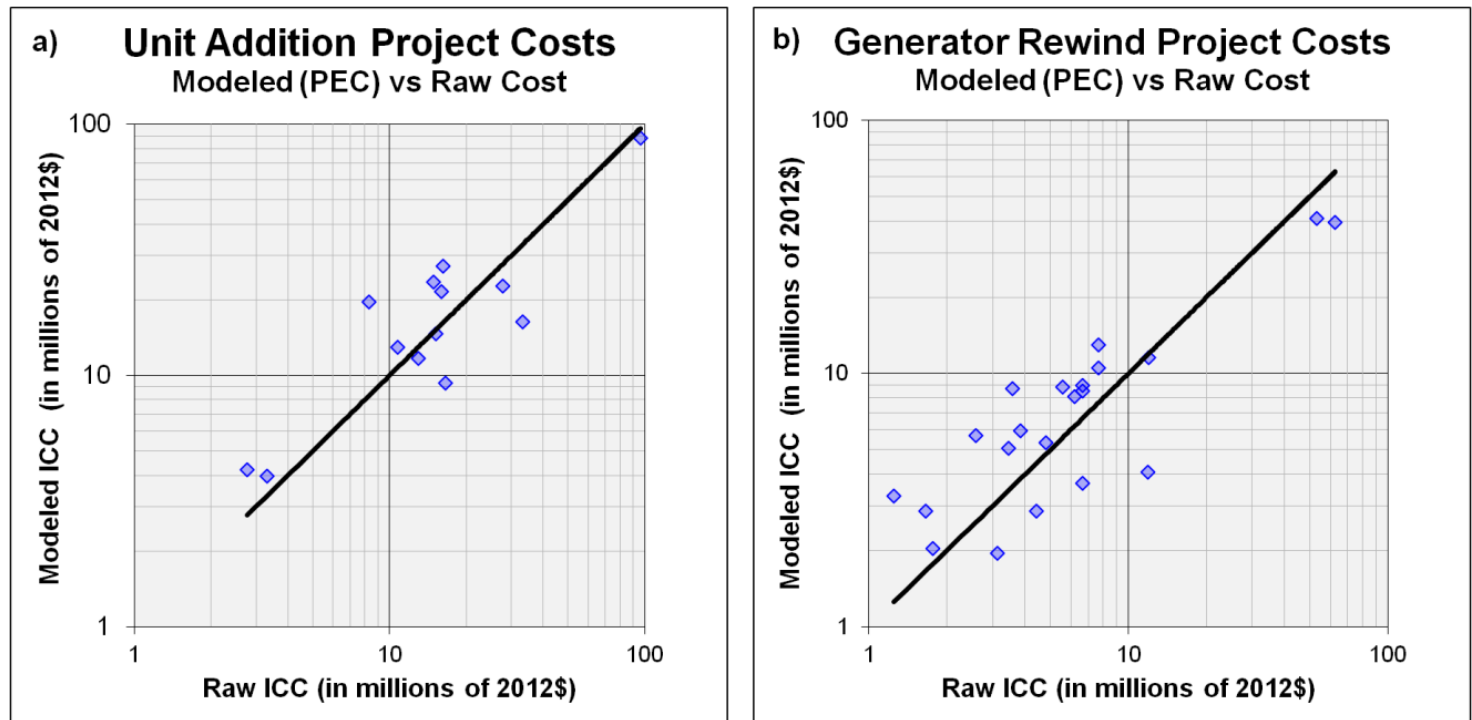

Figure 42. Unit Addition and Generator Rewind in-sample model validation
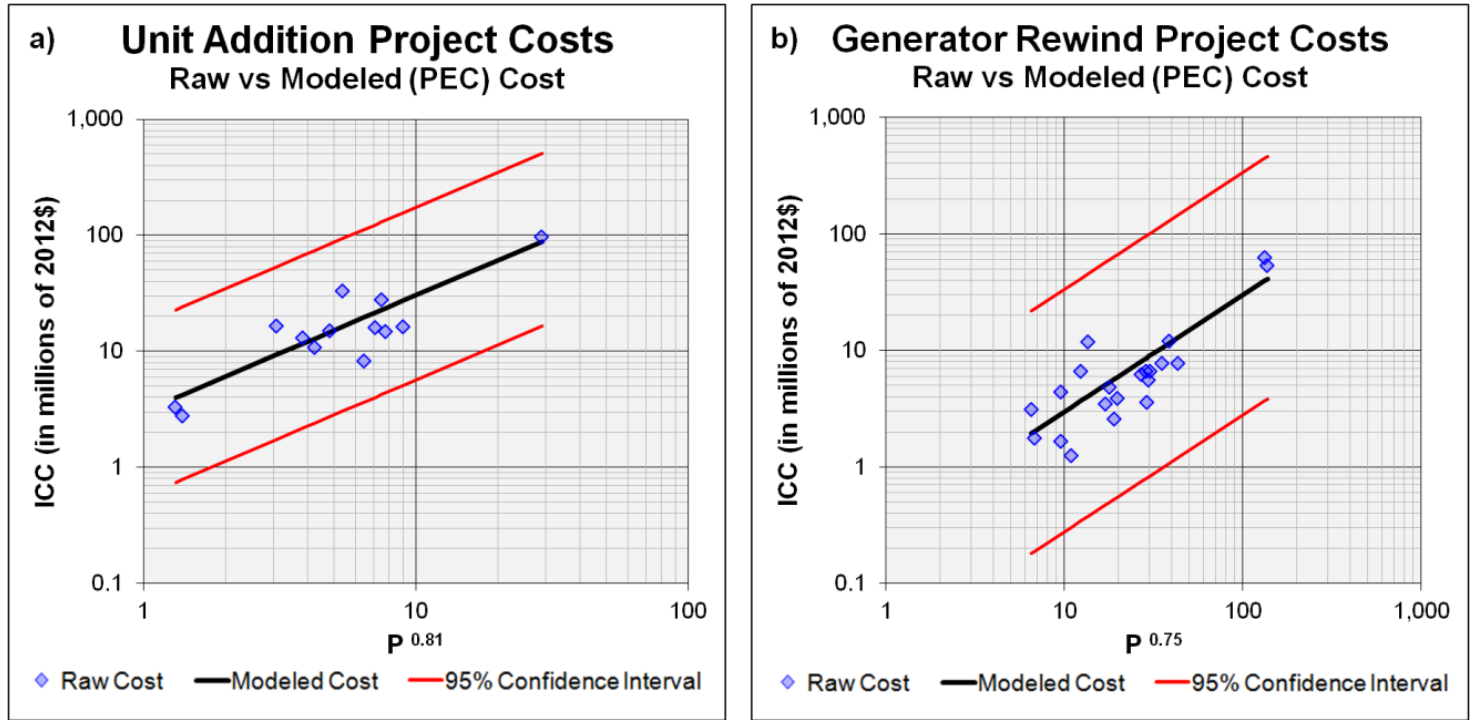

Figure 43. Unit Addition and Generator Rewind in-sample model validation 